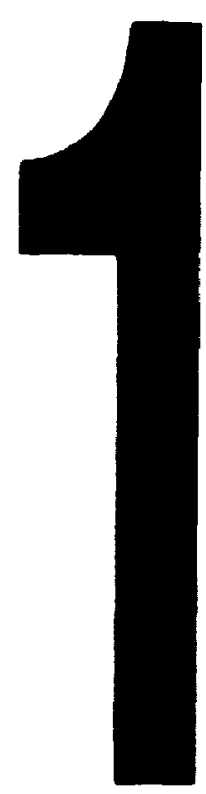

PM-1 31/2" 4 4" PHOTOGRAPHIC MICROCOPY TARGET NBS 1010a ANSI/ISO "2 EQUIVALENT

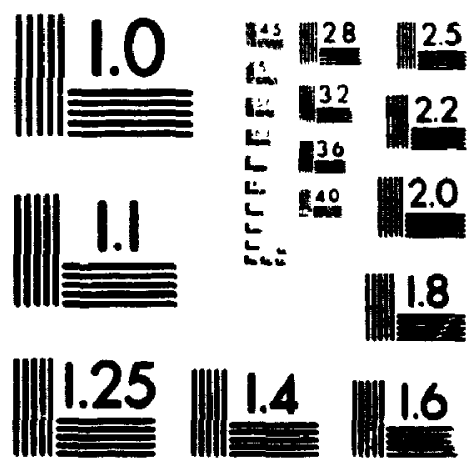

PRECISIONEM RESOLUTION TAF GETS 
National Library

of Canada

Acquisitions and

Bibliographic Services Branch

395 Wellungton Street

Otawa. Ontario

K1A onia
Bibliotheque nationale

du Canada

Direction des acquisitions et

des services bibliographiques

395, rue Wethnoton

Omawa (Ontario)

KIA ON4

NOTICE

AVIS

The quality of this microform is heavily dependent upor. the quality of the original thesis submitted for microfilming. Every effort has been made to ensure the highest quality of reproduction possible.

If pages are missing, contact the university which granted the degree.

Some pages may have indistinct print especially if the original pages were typed with a poor typewriter ribbon or if the university sent us an inferior photocopy.
La qualité de cette microforme dépend grandement de la qualité de la thèse soumise au microfilmage. Nous avons tout fait pour assurer une qualité supérieure de reproduction.

S'il manque des pages, veuillez communiquer avec l'université qui a conféré le grade.

La qualité d'impression de certaines pages peut laisser à désirer, surtout si les pages originales ont été dactylographiées à l'aide d'un ruban usé ou si l'université nous a fait parvenir une photocopie de qualité inférieure.

La reproduction, même partielle, de cette microforme est soumise à la Loi canadienne sur le droit d'auteur, SRC 1970, c. C-30, et ses amendements subséquents.
Reproduction in full or in part of this microform is governed by the Canadian Copyright Act, R.S.C. 1970, c. C-30, and subsequent amendments. 


\title{
Men, masculinities and feminist theory: Having a gender too
}

by

Simon Pinnegar B.A. (Mons)

\author{
A thesis submitted to \\ The Faculty of Graduate Studies and Research \\ in partial fulfilment of \\ the requirements for the degree of
}

Master of Arts

Department of Geography

\author{
Carleton University \\ Ottawa, Ontario \\ 7 April 1995 \\ (C) copyright \\ 1995. Simon Pinnegar
}


The author has granted an irrevocable non-exclusive licence allowing the Nationa! Library of Canada to reproduce, loan, distribute or sell copies of his/her thesis by any means and in any form or format, making this thesis available to interested persons.
L'auteur a accordé une licence irrévocable et non exclusive permettant à la Bibliotheqque nationale du Canada de reproduire, prêter, distribuer ou vendre des copies de sa thèse de quelque manière et sous quelque forme que ce soit pour mettre des exemplaires de cette thèse à la disposition des personnes intéressées.

L'auteur conserve la propriété du droit d'auteur qui protège sa thèse. Ni la thèse ni des extraits substantiels de celle-ci ne doivent être imprimés ou autrement reproduits sans son autorisation. 
Name

Dissentation Abstracts International is arranyed by broad, general subject categories. Please select the one subject which most nearly describes the content of your d-sertation Enter the corresponding four-digit code in the spaces provided.

\section{Subjoct Cokegories}

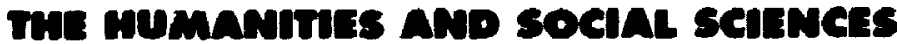

\section{Communcatrous and THE anTS}

Archilesture

Ant Hiskory

Uancerno

Chance

Intornotion '́rienre

kournolism

Librory Sconce

Mass C.ommunucations

Music

speech Commurix ation

Tweote:

\section{CBUCATION}

Menera!

Adult and Contınuing

Agricultised

Bilinguend and inulicultura

Business

Community College

Curriculum and instruction

Eurly Childhood

Elomentory

Finance

Guadunce and ciounseling

Houth

Higher

History of

Home fconomics

Industrial

Languoge and tiveroture

Mantemotics

Philosophy of

Physical

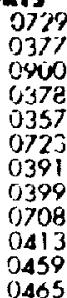

0465

$05 i 5$

0514

0516

0517

0273

$0<02$

0686

0275

0518

0524

0277

0519

0680

0745

0520

$027 \mathrm{~B}$
0521

0521

0280

0522

0998
Psychology

Pexding

Religious

Sciences

Social Sciences

Sociology of

Speciol

Teocher Trauning

Technology

Tests and Measurements

Vocoliona

LAMGUAG, ITERATUE ANO

Unculsics

Language

General

Ancrent

Modern

Literafure

General

Comporotive

Medieval

Modern

American

Asion

Conodion (English)

Canodian (french)

English

Germanic

Lolin Americon

Middle Eastern

Romance

Slavic and East Europeon
0525

0535

0527

0533

0534

0340

0529

0530

0710

0288
0747

\section{Americon Studes}

Anthropology

$$
\text { Archueology }
$$

Cutura

Business Admi ustrotion

General

Accounining

Bonking

Manoyernent

Morkeling

Economics

General

Agriculfural

Commerce Business

Finance

History

Labor

Folklore

Geogrophy

Gercniology

History

General

susuct coos

0422

0318

0321

0319

0322

0322

0323

0324

0326

0310

0272

0770

0454

0385

0501

0503

0505

0508

0509

OS11

0558

0358
0366

0351

0578
Ancient

Medieval

Moder

Africon $\quad 033$

Asio, Austraha and Oceonio 0332

Conodian

Europeon

Lotin Americon

Middle Easiern

Unived Siates

History of Science

Low

Polfical Science

Seneral

internotional low ond

Relatiuns

Public Administrotion

Recreotion

Sociol Work

Sociology

Criminology ond Penology

Demography

Ethnic and Rocial Studies

individual and Fomily

Studies

industrial and Labor

Relations

Public and Social Welfore

Social Structure and

Developenen!

Theory and Methods

Transportiotion

Utbon and Regional Planning

Women's Studies
0579

5581

28

0334

0336

0333
0337

0585

0398

0615

0616
0617

0814

0626

0627

0631

0628

0629

0630

0700

0344

0999

0453

\section{THE SCIFNCES AND ENGINEERING}

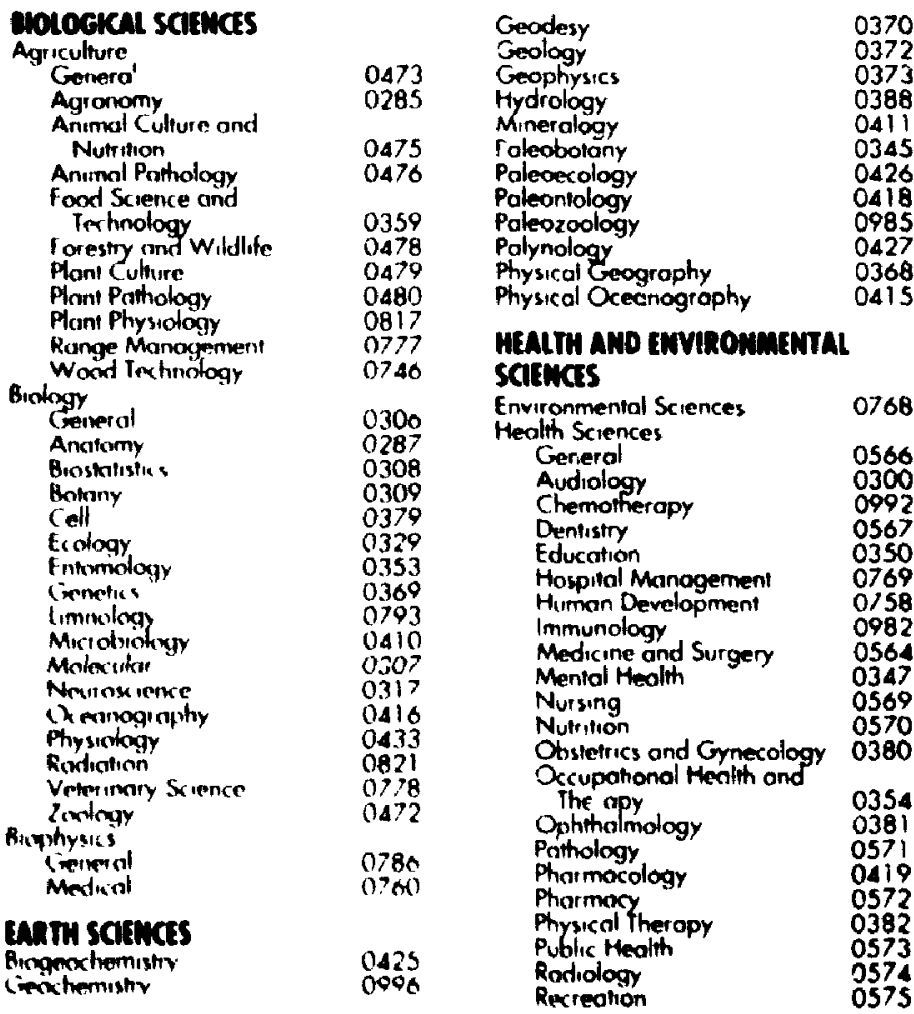

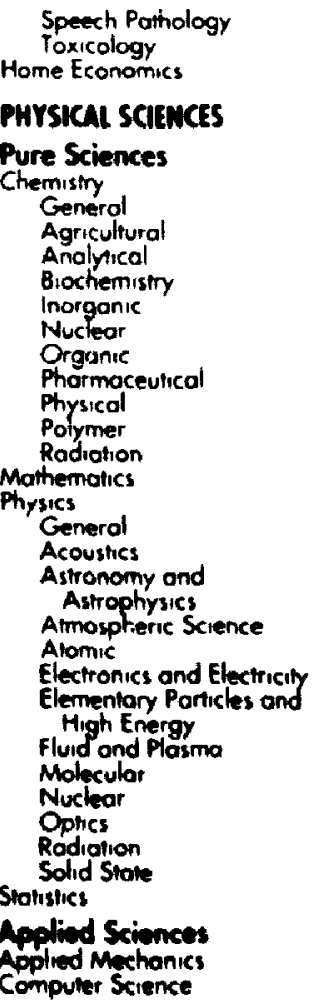

0460
0383
0386

0485
0749
0486
0487
0488
0738
0490
0491
049
0495
0754
0405
0605
0986
0606
0608
0748
0607
0798
0759
0609
0610
0752
0756
0611
0463
0340
098

Engineering

General

Agriculturol

Automolive

Biomedical

Chemicol

Civil

Electronics and Electricol

Heat and Thermodynomics

Hydraulic

Industric

Morine

Maneriols Science

Mechonical

Metallungy

Mining

Nuclear

Packoging

Petrobeum

Sonitory and Municipo

Srstem Science.

Geotechnologr

Operations Reseorch

Plastics Technology

Textile Technology

sronocor

General

Behovional

Developmentol

Exparimental

industriol

Personality

Psychobrolog

Purchometrics

Social 
The undersigned recommend to the Faculty of Graduate Studies and Research acceptance of the thesis

Men, masculinities and feminist theory: Having a gender too

submitted by Simon Pinnegar. B.A. (Hons). MS

in partial fulfilment of

the requirements for the degree of

Master of Arts

Department of Geography

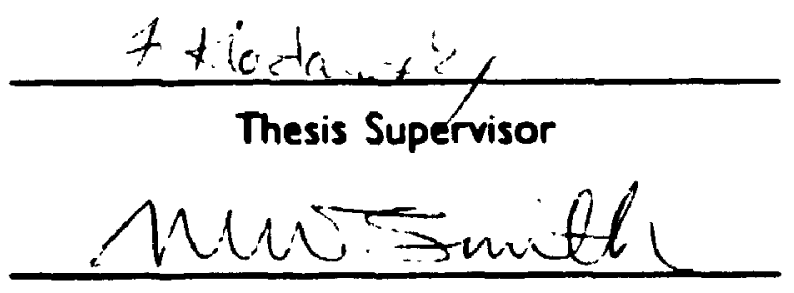

Chair. Department of Geography

Carleton University

April 1995 


\section{Abstract}

A number of male geographers, influenced by discourses of postmodernism. have increasingly recognised the importance of gender relations in their research and teaching practices. Associated with this trend, the lure of feminist insights has grown considerably. Men's engagement with feminism has initiated significant debate, and this has been reflected within the discipline with reaction from both feminist geographers and other male geographers. In this regard, interviews were held with male geographers concerning the issues raised by their engagement with feminist frameworks and the study of gender. A second aim of this research considers the potential for incorporating questions of men and masculinities into gender studies. It is apparent that many of the difficulties faced when considering men's involvement in gender studies may also prevent a critical but insightful discussion on men and masculinities within those studies. Limitations are recognised in the operations of language and power associated with existing discursive strategies. Concern is expressed regarding two interrelated issues: firstly, the need to problematise our understanding of power configurations; and secondly, the need to destabilise the tendency to conflate associations between, respectively, men-masculinity and women-femininity. A poststructuralist-informed feminist standpoint is advocated which enables such difficulties, characteristic of totalising frameworks, to be transcended. The constituted subject, which denies fixed and static attributes, is proposed as a means to challenge the essentialist/constructionist impasse of mainstream feminist frameworks. As such, subjects can be seen as representing fluid identities which congeal or become temporarily fixed through context-specific gender performances. Bodies act as sites of mapping and transaction, and spatial processes are of fundamental importance in this regard. The spatiality of gender - a proposed focus for a reconceptualised geography of gender - enables an understanding of how different gender relations are constituted through particular acts in different social spaces. 


\section{Acknowledgements}

I should like to thank all those who have provided help. support and direction during the research and preparation of this thesis: in particular, my Supervisor, Professor Fran Klodawsky, and my interview participants who made the research procedure both enjoyable and informative. As an international student, my two years in Ottawa have been enjoyable and I am delighted to have had the opportunity to study in Canada. 


\section{Table of Contents}

abstract
acknowledgements
able of contents
Introduction
objectives of research
framework for discussion
establishing a standpoint

Chapter two: deconstructing feminism $\quad 10$

introduction $\quad 10$

the challenge to masculinist discourse 13

identity politics $\quad 18$

$\begin{array}{ll}\text { poststructuralism and feminism } & 27\end{array}$

debating the merits of poststructuralism 27

the problematised subject 29

sex/gender $\quad 33$

queer theory for a queer nation 37

recovering the subject: rebuilding feminism 41

the constituted subject: fixity and political commitment 47

Chapter three: men \& feminism 51

introduction $\quad 51$

men \& feminist theory 53

'there are those and there are such as those'

drag queens, cross-dressers, and the pimps of postmodernism 57

mediation? $\quad 61$

men \& feminist practice $\quad 65$

$\begin{array}{ll}\text { differences of opinion } & 65\end{array}$

the historical tradition of 'male feminists' $\quad 68$

the rise of anti-sexist and profeminist men $\quad 72$

the canadian experience $\quad 75$

$\begin{array}{ll}\text { conclusions: a commitment to social justice } & 78\end{array}$

Chapter four: young turks and old turkeys? 81

introduction 81

the games of the trendiest boys

masculinist and masculine $\quad 82$ 
sharing a tradition with peter gould

berg vs. berry

sparke vs. olsson

90

'all mouth and no trousers?'

95

boys' talk

96

why open-ended interviews?

96

who was asked?

98

the interviewing process

100

transeribing

104

a general framework

105

why the interest?

106

problematising engagement

putting feminist insights into practice

implications for feminist-informed research

Chapter five: men, masculinities and spacing gender

Conclusion: transcending difference 


\section{Introduction}

objectives of reseorch

If ... geographers have orly recently awoken to the fact that women have been hidden from history, the experience of men as men has scarcely yet been addressed. (Jackson. 1991. p199)

Men's relation to feminism is an impossible one. This is not said sadly or angrily (though sadness and anger are both known and common reactions), but politically. (Heath, 1987, pl)

Feminist theories have provided geographical studies with some of its most powerful tools of critical social analysis in recent years. Feminist geographers have been successful in highlighting the 'malestream' nature of the discipline, both in terms of the exclusion of women as researchers and the researched (WGSG, 1984; McDowell 1988), and through the consideration of deeper epistemological assumptions and the implications of western Enlightenment thought (McDowell, 1991: Bondi \& Domosh 1992: Rose. 1993). The importance and centrality of gender relations in geographical research has become increasingly recognised and there would appear to be a wide degree of acknowledgement amongst male geographers working within critical frameworks of the need to understand and incorporate such ideas in both research and teaching. Despite this recognition, it is argued here that the relationship between men and feminism is one that has not been particularly well addressed within the discipline. Men interested in questions of gender, and wishing to develop feminist theory as a framework of analysis, will need to fully consider their relationship to the objectives. politics and ethics of feminist research. Whether men can be feminist or pro-feminist, or whether they should strive to be so, are questions which need to be addressed.

Difficulties of men's positioning clearly reflect the poststructuralist debate concerning deconstruction, difference and appropriation; questions which have challenged traditional methods of research and analysis in general. Whilst the need to acknowledge diversity between wornen in the creation of feminist agendas has become increasingly recognised, the interest and involvement of men in such agendas further complicates the issue of representation. 
This thesis has two primary aims: firstly, to examine the potential considerations and issues to be addressed by male geographers interested in engaging with feminist frameworks in their research; and secondly, to explore how questions concerning men and masculinities can be appropriately incorporated into gender studies. Although both issues have been increasingly addressed within geography in recent years, it is my contention that existing theoretical frameworks and discursive strategies need to be destabilised at a more fundamental level. It would appear that many of the issues at stake in debates concerning men's engagement with feminism also operate to problematise research focusing upon questions of men and masculinities. It is therefore necessary to carefully consider how existing frameworks structure and determine both the research conducted and the potential outcomes obtained. Whilst I recognise the centrality of feminist discourses in studying issues of gender. I would argue that male geographers need to be cognisant not to appropriate and misrepresent feminist insights, and also to engage in a framework which will enable constructive debate to take place. This does not inevitably necessitate an unquestioned acceptance of feminism; rather, men should engage in useful, challenging critiques which can contribute to the constantly shifting boundaries that feminist discourse represents.

fromework for discussion

Feminism as a framework represents a plethora of different standpoints, and debates as to how social change can potentially be brought about; the objectives of this change reflect such diversity. Recognising this heterogeneity is essential to prevent the objectification and homogenisation of feminist discourse: feminism should not simply be regarded as 'another' theory to be appropriated by men. Ramazanoglu (1989) suggests that at a most general level, feminism comprises various social theories which explain the relations between the sexes in society, and the differences in men's and women's experience. Questioning the construction and constitution of knowledge and dominant ideologies is also integral to feminist inquiries. A political commitment to fighting gender inequality is reflected in the relation between theory and practice, and further through active participation in movements and struggles for women's emancipation. The 
use of the terms 'dominant' or 'mainstream' when referring to feminist frameworks in this thesis acts to differentiate between those frameworks which tend towards totalising discourses and those which have incorporated poststrueturalist insights.

Chopter two - Deconstructing Feminism - considers the apparent tensions arising from the challenge of poststructuralist and postcolonial (often collectively recognised as postmode:n) insights to Enlightenment thought and feminist theory. At one level, the destabilisation of taken-for-granted notions regarding the construction of knowledge has clearly paralleled feminists' discussions of the malestream nature of theoretical frameworks and the limitations in how research has been traditionally conducted. Exposing how knowledge has been based upon binary (either/or) constructions such that gender, for example, is neatly dichotomised between male and female, feminists have uncovered the gendered power relations which operate through such constructions. However, at another level poststructural approaches have questioned whether 'knowable' subjects or collectivities, such as women, can be theorised; deconstruction has ensured that our understandings of social relations need to be reconceptualised. This challenge poses important questions to feminism: how can feminist strategies be articulated where the organising categories of 'men' and 'women' are disrupted? Furthermore, how can personal actions and behaviours be recognised when the multiple nature of identities should be acknowledged? Given these tensions, a consideration of potential resolutions between poststructuralism and feminist discol res is central to understanding the concerns surrounding men's engagement with feminist theory and practice.

The need to posit the existence of a category 'women' which represents a collectivity of all bodies sexed female distinct from a category 'men' reflects a long standing concern regarding the essentialist/constructionist dialectic in contrasting feminist frameworks. The danzers of either reducing explanation to essences, or the advocacy of social constructions which tend towards relativism where everyone and everything is different, have provided the focus for considerable discussion. Although the argument is often dismissed as tired, it is only more recently that the question of essentialism has been critically debated (Fuss, 1989; 1991; Butler, 1990; Kobayashi \& 
Peake. 1994). As a number of theorists have illustrated, even constructionist frameworks remain inextricably linked to an essential gendered dichotomy, where g?nder continues to mirror biological difference. Furthermore, definitions of biological or natural difference themselves represent discursively produced social constructions. The need to problematise the sex/gender distinction. recognised by Gatens (1983) is finally gaining increased acceptance within gender studies. Drawing upon the work of poststructural theorists, and insights afforded by Queer Theory, the fluidity and multiplicity of subjectivities can be recognised. It is suggested that this approach enables the limitations of both essentialist and constructionist frameworks to be transcended. Advocating a position which questions whether any single person or collectivity can be considered a static and fixed entity does not deny the existence of categories such as 'male' and 'female'. 'men' and 'women', but rather undermines pre-determined assumptions based upon those categories. This approach is developed in Chapter five when the incorporation of men and masculinities into gender studies is considered.

Much of the tension surrounding men's involvement with feminist discourse is reflective of the debates structuring feminisms' relations to the poststructural challenge. The complexities of men's engagement are discussed in Chopter three - Men \& Feminism - in the context of both theory and practice. Potential difficulties are widely recognised (Jardine \& Smith. 1987; Hearn, 1989; Porter, 1992) and concern has been voiced by a number of male geographers (Jackson. 1991; Gregory, 1994: Sparke, 1994). Inevitably. there is a notable degree of scepticism regarding men's ability and indeed motives for engaging in such research. Accusations of 'critical cross-dressing' (Showalter, 1987). 'gender tourism' (Chapman, 1988) being led by desire to 'get a bit of the other' (Moore. 1988) and new forms of imperialism (Spivak, 1988), illustrate fears that men will appropriate, objectify and misread feminism.

Similar concerns are expressed relating to men's practical and political support for feminism (Luxton, 1993). However, men's involvement, albeit minimal, is and has been influential and as such, should be acknowledged. In this regard, the suffragist movement at the turn of the century in Britain and the contemporary White Ribbon 
campaign in Canada are considered in detail. A tension which has been expressed historically in men's support for feminist causes arises between whether to protect the benefits of keeping the space of these causes for 'women only', or to accept the merits of men's integration and voicing of public support it has been typically felt appropriate by both men and women engaged in this debate either to postulate a position of 'male sympathisers to the feminist cause although not feminist' (Connell, 1987; Jackson; 1991) or to differentiate using a pre-fix, creating the 'profeminist' (Chapman, 1988; Stoltenberg, 1990). Positioning oneself politically, and making the link between men and feminist theory and practice, whether that be "in' (Jardine \& Smith, 1987) or "between" (Porter, 1992) is inevitably a highly contested and ambiguous issue.

Chapter four - Young Turks \& Old Turkeys? - considers how discussions of men's engagement with feminist discourse are reflected in the discipline of geography. As the centrality of gender issues in social research and the strengths of feminist theories as critical frameworks are recognised, a growing number of male geographers have incorporated these insights into their research. The reaction to this apparent increased 'gendered sensitivity' has been varied: on the one hand there is a certain satisfaction that after marginalisation within the discipline, the importance of feminism is being noted, whilst on the other, this increased interaction is viewed with a certain degree of understandable suspicion. There appear to be confused understandings and motives for such engagerr.e- and this is reflected in a rather hostile position from feminist geographers in published reactions. This largely unfavourable reaction has come not only from feminist geographers, but also from other male geographers, typically well established, who voice concerns regarding the future integrity of the discipline (Rose, 1993,1994; Berry, 1994; Gould, 1994a; Olsson, 1994).

In order to consider the men-feminism debate within the discipline, male geographers interested and involved in issues of gender and or feminist frameworks in their research and/or teaching were interviewed. It was not my aim to expose the continued level of gender blindness or lack of recognition given to feminist theories in much geographical research, since this has been clearly illustrated elsewhere (WGSG, 1984, McDowell, 1988). Rather, prospective interviewees were carefully selected to 
enable a focus upon those male geographers who have actively engoged with such frameworks. This selection was based upon published material, conference presentations and the suggestions of faculty. As a result, a certain level of understanding as well as tolerance towards such issues on the part of my study population could be expected.

The potential for developing new approaches in gender studies which enable a constructive consideration of men and masculinities is discussed in Chapter five - men, mosculinities ond spacing gender. Increasingly, research undertaken by male theorists has acknowledged the centrality of feminist theories to the consideration of men and masculinities (Connell, 1987, 1993b; Brittan, 1989; Hearn, 1994). The work of sociologist Bob Connell has been particularly influential in this regard. His theory of procticr attempts to weave together personal characteristics and social structures in order to transcend the limitations of the structure-agency debate. As a result. Connell's research exhibits close parallels with notions of the constituted subject, but also aims to translate these insights into developing a better understanding of gendered power configurations as exhibited by social structures. Despite the value of this framework, a certain degree of caution needs to be exercised. It is my contention that Connell's approach, drawing heavily upon feminist frameworks to focus his discussions of gender and power, needs to be further developed through a more rigorous understanding of the basic foundations structuring those power relations.

This argument reflects the need to more :ritically consider the mechanisms and limitations represented by existing discursive strategies employed in gender studies. There are two areas which I wish to address in this regard. Firstly, existing discursive strategies tend to naturalise a pre-determined difference between men and women. Instead of asking questions which assume a difference between men and women and then proceed to illustrate this, a more valuable line of inquiry would consider why and how that difference is defined and by whom, and how this operates to structure power configurations. Binary notions of gender, despite their recognition and problematisation through poststructural challenges, are represented by the continued reliance upon the conflation between 'men', 'male' and 'masculinity' on the one hand and 'women'. 
'female' and 'femininity' on the other. Following Ochs (1992) and McElhinny (1994), I suggest the need to distinguish between referential (undisputed, direct) and indexical (contingent, associated) markers of gender so that the tendency of conflation can be removed and a more challenging understanding of gender difference enabled. New discursive strategies provide the prospect of transcending pre-existing notions and accommodating more recent approaches which recognise the fluidity of the subject and the constant reconstitution and renegotiation of gender relations.

The need for a more comprehensive analysis of the configuration and operations of power and resistance represents a second, but clearly related, issue. The complexity of power relations and how these are constituted is lost to a certain extent within 'totalising' feminist theories whose discursive frameworks remain dependent upon recognising a general relation of male domination and female oppression. The terms in which such frameworks thiat describe configurations of power and oppression are established tend to reflect the very relations which need to be deconstructed. An alternative approach, where power and resistance are recognised as relational are advocated by poststructuralist theorists such as Foucault and Scott. Foucault argues that rather than being a totalising system, power is relational and irreducible to particular individuals or structures since it is diffused throughout the whole social order, from bodies to institutions of the State. The relation between Foucault's work and feminism has been an uneasy one, however it has been adopted by a number of feminists as a means to enable a more comprehensive reading of gendered power relations (Hartsock. 1990; Ramazanoglu, 1993: McDowell, 1995). Scott's (1990) interpretation of resistance provides a valuable counterbalance to Foucault's concentration upon power, and the development of this framework by Cornwall \& Lindisfarne (1994), offers a particularly useful approach whereby the importance of discursive struct.: es and strategies of both those 'with' power, and those subordinated, can be taken into consideration.

Adopting the insights afforded by these approaches enables a more flexible framework, which is less restricted by a priori determinations, to be proposed. By recognising the multiple nature of subjectivity, and therefore the fluidity of the subject, gender can be theorised as performonce, continually negotiated through a series of 
context specific acts (Butler, 1990; Lindisfarne. 1994). Through the stylised repetition of acts, gendered identities representative of a congealing or temporary fixing are produced. It shall be argued that the body acts as a site of mapping in which the multiplicity of the subject is made momentarily cohesive through the repression of internal contradiction and the displacement of difference onto other subjects (Strathern, 1988: Grosz 1990. Fiske, 1993; McDowell, 1995). Gendered identities are always in the process of constitution and redefinition and, as such, should never be regarded as static or fixed. However, the control and discipline of bodies can produce repetition and conformity through historically and spatially determined ideas of appropriate forms of behaviour. Any particular body is capable of enacting a plethora of gender performances, and these acts will vary according to the circumstances of different social spaces. The spotiality of gender therefore becomes apparent in a consideration of how gender performances are enacted and how particular subjectivities are mapped onto bodies. The spatial organisation of gender is well recognised; however, the relation between spatiality and subject formations enables the dialectical nature of this relation to be conceptualised.

estoblishing a standpoint

For male geographers interested in addressing gender issues, the need to incorporate feminist theories is central, and understanding the concerns, debates and possible limitations which may structure this relation should be a primary consideration in this engagement. Feminism cannot be regarded as simply another theoretical framework to be utilised by the male researcher. To separate the practical and political motivations of feminism from its theoretical positions is wholly inappropriate. As such, a certain degree of theoretical contradiction exhibited by feminist discourse can and is mediated by the need to recognise political commitment to social change (Ramazanoglu, 1989). In the case of feminism, this commitment is based upon the removal of gender inequalities, and at its most general level necessitates recognising a difference between men and women .

Men's acknowledgment of the importance of practice to feminist frameworks is important; however, this commitment does not completely eradicate the tensions 
apparent in men's engagement with such frameworks. It is my contention that theoretical understandings of gender relations and social change remain limited by existing discuisive strategies. This is not merely a critique of feminism, but of all frameworks which have a tendency towards totalising assumptions. Advocating the need to consider more comprehensively the fundamental structures of feminism is not to dermand a continual reinvention of the wheel, or indeed to reject that gender inequalities actually exist: however, 1 do not believe that feminism comprises a set of fixed and unchanging attributes and objectives closed to reformulation. Although the insights afforded by the poststructuralist chailenge have met with a degree of resistance, I believe them essential. These critiques need to be appropriately addressed in order to enable feminist frameworks to be more effective in theorising the continually shifting realities of societal relations. As such, a poststructuralist-informed feminist framework is favoured which, I believe, enables both a destabilisation of the assumptions structuring our understanding of gender relations, and a recognition that gendered differences and inequality are negotiated and reconstructed through discursive strategies which structure relations of power. 


\section{Chapter Two: Deconstructing feminism}

introduction

Debates surrounding men's engagement with feminist theory and practice are in many ways reflective of the wider challenges that postmodernism has posed to Enlightenment philosophy. This challenge has held a tenuous relation with feminist theory and practice. On the one hand. the exposure of the foundational principles of Western knowledge has complimented and enabled feminism's illustration of the 'masculinism' of scientific enquiry and the inadequacy of binary dualisms in structuring analysis. Yet at the same time, postmodernism has posed questions to a feminism as liable to deconstructing tendencies as the Enlightenment Philosophy which it seeks to destabilise. As a result, the relationship between postmodernism and feminism proves to be a difficult one, and the debates among feminist geographers are reflective of this WGSG, 1992, Bondi \& Domosh, 1992. McDowell, 1991a, Rose, 1993). Indeed, where notions of a knowable subject are challenged, and the restrictions associated with the use of categories recognised, then the grounds upon which feminist politics may be structured are called into question. If feminist politics is dependent upon the category 'women', in opposition to the 'men', what does it mean when the very definitions of man and women are shown to be constructions of the same discourse which an emancipatory politics would wish to displace! The decentring of gender as a meaningful construct problematises a central foundation of feminism and undermines the debates which necessarily reflect upon the differences and inequalities experienced between 'men' and 'women'. It has been feared that the loss of such categories will lead to the reduction of feminism to a subfield of a more general critical theoretical framework where no dimension or axis of power is prioritised over the other.

Although the relationship between poststructuralism and feminist theories has created, as Fuss (1989) argues, rather an impasse in feminist debate, it is fair to say that through such seemingly irresolvable tensions, many crucial questions have been placed upon the agenda. Through a consideration of the debates surrounding the potential dangers of advocating an identity based politics, the inadequacies of an essentialist/ 
constructionist dualism have been exposed. Associated with this recognition, the reevaluation of the sex/gender division has enabled feminists to rigorously challenge and determine that which was previously assumed. The destabilisation afforded by poststructuralism is also paralleled in Queer Theory, emerging from lesbian and gay studies, and shall be considered in this context.

Postrnodern insights are therefore employed to call into question the very foundations of feminist theory and practice; however, this does not necessarily lead to a rejection of fundamental principles. Challenging the notion that one may discover pregiven bases upon which feminist standpoints can be articulated is essential, and should not, I argue, be regarded as a threat leading to the inevitable dismantling of feminism itself. Through continually cali..ig into question the most fundamental assumptions. those terms which are central to a better interpretation of gender relations are appropriately considered. Therefore, instead of assuming and relying upon the integrity of the categories 'men' and 'women', the meanings and discursive formations of such categories are challenged and reconfigured. Following the work of feminist theorists such as Butler, Young and Mouffe. I recognise the importance of advocating a position which is anti-essentialist, yet accepts the inextricable link between essentialism and constructionism in the constitution of the subject. As a result, the categories 'men' and 'women' as pre-given entities are problematised and destabilised, whilst the potential value of recognising 'men' and 'women' as constituted, partially fixed entities is maintained.

A number of terms used in this chapter necessitate preliminary definitions and discussion. Clarifying the different interpretations placed upon postmodernism and poststructuralism is inevitably a complicated task since there is a tendency for the terms to be regarded as relatively interchangeable with no definable delimitations to each.' It is my contention that postmodernism should not be taken as a coherent theoretical approach, although it may be characterised by a recognised aim to destabilise the metaphysical assumptions behind traditional Western philosophy. ${ }^{2}$ Poststructuralism may be regarded as one of a number of means through which such an objective is achieved, and is associated with the analysis of language, textual strategies and history through 
deconstruction to illustrate the power of discourse in determining access to, and the definition of knowledge. Often, the influences of poststructuralism. postcolonialism. psychoanalysis and feminism are cited as the prime foci of contemporary critical theories where a common dimension would be an attempt to understand and reconstitute one or a combination of, for example, self, gender or race without falling back upon the linear, dualistic ways of thinking characteristic of Enlightenment thought An advocation of critical theory illustrates a commitment not only to understanding, but to also work towards beneficial change.

As Butler (1992) argues, poststructuralism is not strictly a theoretical position. but rather a critical interrogation of the formative and exclusionary operations of power through which positions are established. Notable poststructuralist theorists whose works have been interpreted and utilised in social theory include Derrida (the deconstruction of grammar). Lacan (the incorporation of psychoanalytic practices) and Foucault (discourse analysis and the construction of the subject). ${ }^{3}$ Alcoff (1988) recognises a common theme amongst these poststructural writers in illustrating that the authentic subject, which liberal humanism conceives as ultimately knowable below the social, historical and cultural overlay, is in reality a construct of that very humanist discourse. In this regard, the influence of psychoanalysis can be recognised for its importance in questioning the notion of the subject and illustrating how personality is structured at a number of levels, both conscious and unconscious.4

The concept of discourse, primarily developed through the work of Foucault. represents a historically and institutionally specific structure of statements, terminologies, beliefs and ideologies. Language is not co-terminous with discourse; rather it should be seen as representing a constitutive system through which "meaning is constructed and cultural practices organised and by which people represent and understand their world including who they are and how they relate to others" (Scoth, 1990. p135) Through analysing competing discourses, the operation of conflict and power can be investigated. By deconstructing such discourses, the inadequacies of knowledge based upon rational subjectivity, categorisation and difference can be illustrated. Deconstruction therefore provides a critique of normal modes of 
expression used to disseminate knowledge through analysing the operation of difference. As Spivak (1989, p214) comments, "deconstruction is not an exposure of error. Deconstruction notices how we produce truths." The assumptions of Western philosophy based upon the construction of difference are exposed, illustrating how fixed oppositions conceal the extent to which entities, such as self and other, presented as oppositional are in fact interdependent. The differences constructed by dominant discourses between entities are shown to be based upon the repression and refusal of differences within entities (Scott, 1992).

the challenge to masculinist discourse

The questioning of Western philosophy centres upon the deconstruction of its fundamental principles. Challenging the notions of a universal reason and Truth has enabled feminists to illustrate the gendered assumptions and expose the power structures implicit in Enlightenment thought. The recognition of the masculinism of scientific enquiry is a necessary observation in considering the issues surrounding men's engagement with feminism. Although I agree with the need to uncover th. - gendered assumptions characteristic of Western philosophy, it is essential not to conflate such labelling with the assumption that Enlightenment thought already represents a gendered male viewpoint. Whilst the association between the pursuit of universal knowledge and that regarded as masculine would appear defendable, the discourses which define what is and what is not masculine need to be destabilised and not simply assumed.

The basis of traditional knowledge construction appeals to reason as a universal Truth enabling the questions concerning the relationship between power and knowledge to be subsumed in the aim of searching for understanding which is both neutral and socially beneficial to all. As Flax (1992) discusses, a central premise establishes a homogeneous form of reason existing within all human beings which is unaffected by desire or historical experience. Three of Aristotle's basic laws of logical thought are important in this regard: the Principle of Identity ('if anything is $A_{1}$ it is $A^{\prime}$ ), the Principle of Contradiction ('nothing can be both $A$ and Not $A$ '), and the Principle of the Excluded Middle ('anything, and everything must be A or Not-A') (Berg, 1994a). The 
construction of knowledge defines a set of binary dualisms, for example between reason and emotion, self and other, culture and nature, man and woman which are considered internally coherent and stable. Pile (1994, p255) suggests that dualisms enable a marking out and polieing of "supposedly fixed, natural divisions between the powerful and the disempowered" and Bondi \& Domosh (1992) argue that self-proclaimed legitimacy of such universalising forms of knowledge can not be justified other than in reasserting their own authority. The existence of dualisms therefore establishes structures to reflect hierarchies of power, so that one side of the binary is validated and the other relegated. Furthermore, privileged attributes may be brought together so that the defining characteristics of what defines knowledge may be recognised and all other forms of knowledge construction negated.

Feminist theorists, for example Harding (1986) and Haraway (1991), have been particularly successful in exposing the foundations upon which Western scientific knowledge has been constructed. The existence of the dualism man/woman has ensured $t$ : man and that which is regarded as masculine has been valorised and that associated with woman and the ferninine has been relegated to the position of the 'other'. Rose (1993) illustrates the gendered nature of binary oppositions through the gendered associations of valourised positions in each established dichotomy:

Knowledge, the social, the theoretical - all these are associated with the masculine and with the cultural and the scientific, the work of Man. The bodily, the specific, the private, the relational - these are feminine, and are associated more with the natural, separate from Man. (Rose, 1993.p74)

The first terms in a binary opposition depend upon and derive their meaning from the second to such an extent that the secondary terms can be seen as generative of the definition of the first. It can therefore be argued that the definition of 'woman' represents a reflection of what 'man' is not in order to allow knowledge to be constructed through the recognition of clearly defined differences. 'Woman' merely reflects that which man does not see in himself, femaleness is conseructed as a lack of maleness (Massey, 1992; Rose. 1993). From the early Greek foundations of Western philosophy, for example the Pythagoreans (sixth century BC) and Plato (427.347 BC). 
maleness became associated with reason, and through their association with the fertility of nature, femaleness became associated with everything reason left behind and the dangerous qualities of human nature (Massey, 1991: Berg. 1994a). Maleness came to be associated with superior qualities which enabled men to transcend the intimacy with nature to which women were considered to be tied.

Similarly, postcolonial critics, for example Said (1985) and Spivak (1988, 1989), have illustrated how those subjected to colonial and imperialist oppression have been constructed as the 'other' through the discourse of the coloniser. Again, hierachical dichotomies are established between the coloniser and the colonised; characteristics which are regarded superior are attributed to the coloniser, whilst the colonised are constructed in a frame which symbolises that which the coloniser is not. Said (1985) illustrates how academics have written about and 'inscribed' the worlds of 'others' not least as a result of the latter not having the power to do so themselves. A number of feminist postcolonial theorists engaged in 'subaltern studies' have further illustrated the gendered nature of the dualisms set up between the coloniser and the colonised and the latter's association with that which is dark, unknown and feminine. Lesbian and gay theorists have also illustrated the heterosexist assumptions which structure knowledge production based upon a binary opposition where the samelother dualism is an essential foundation. The existence of the samelother dualism normalises and dichotomises difference and negates similarity. As such, the attraction of same and same (man/man) as opposed to same and other (man/woman) is established as a deviant form of a determined norm. The creation of an 'other' in order to establish a stable, reasoned definition of the self in Enlightenment metanarratives is problematic in its suppression of voices of difference and in subsuming the experiences of those who are not male, white, nor indeed heterosexual.

Within geography, concepts essential to all forms of Enlightment metanarrative, for example reason, self, power, gender and ethnocentrism have been destabilised and problematised through an engagment with postmodern critiques. Pile (1994) reflects that the discourse of academic geography is determined by particular defined rationalities which creates a geography which is 'good and correct' where it possesses 
the appropriate attributes of reasoning. The dualism reason/emotion enables (male) geographers to ground their experience in relation to universal reason, whilst at the same time negating the experiences and knowledge base of (female) others. The questioning of hierarchical dualisms and the recognition that certain attributes of knowledge construction are aligned with that which is masculine and others with those feminine, leads to the labelling of traditional geographic (indeed all scientific) discourse as 'masculinist'. Feminist geographers have illustrated the effects and implications of this masculinism in the creation of geographical knowledge and the position of women within the discipline on a variety of levels. A stated objective of Gillian Rose's influential text Feminism and Geography (1993) is to uncover the inherent masculinism within the discipline by illustrating the connection between masculine subjectivity and powerful claims to know. Within the discipline, it is argued, this is all too apparent:

Masculinism can be seen at work not only in the choice of topics made by geographers. not only in their conceptual apparatus, not only in their epistemological claim to exhaustive knowledge. but also in seminars, in conferences, in common rooms, in job interviews. (Rose. 1993. p4)

Bondi \& Domosh, like Rose, draw upon psychoanalytic theories to formulate an association between knowledge and masculinity in arguing that the pursuit of a unitary knowledge and authority is a masculine obsession. Such knowledge is recognised as 'phallocentric' in that 'its operation is bound up with an opposition between 'man' and 'woman' in which the former is dominant and proclaims its own privileged singularity in opposition to the inferior plural otherness of the latter"(Bondi \& Domosh, 1992, p202). The recognition of geography as 'masculinist' and 'phallocentric' has also been acknowledged to a certain degree by a number of male geographers who have engaged with postmodern critiques, for example jackson (199/b), Berg (1994a), Pile (1994). Sparke (1994c) and Gregory (1994b). Although these terms may be regarded as confrontational (if not directly confrontational, they are certainly meant to challenge) towards male geographers, those aiming to illustrate the masculinism of the discipline attempt to clarify their understanding of the linkages between their male colleagues and the form of knowledge construction which continues to dominate academic geography. Through recognising the gendered nature of Enlightenment metanarratives, 'woman' and 
that which is regarded as 'feminine' become identified as the gender, whereas masculinity, and indeed specific masculinities, are 'free' to define universal knowledge and therefore normalise what is considered to be knowledge around what are determined as the experiences of masculinity, and as Pile (1994, p259) suggests, around the experience of "male, white, middle-class, heterosexual, able-bodied, articulate, clean, disciplined bodies."

Whilst it is important to recognise the 'masculinism' which structures the dominant discourses in geography, it is essential not to conflate such labelling with the assumption that traditional geography represents a male gendered geography since the universalism associated with masculine knowledge largely ensured that men's experiences as gendered subjects have also been largely subsumed. In this regard one must be careful in advocating Rose's assertion that "to create geographical knowledge acceptable to the discipline is to occupy a masculine subject position" (Rose, 1993, p4) since this relationship between masculinity and subjectivity is both problematic in terms of universal, objective claims to knowledge and also given the questions afforded by psychoanalysis which debate the notion of a knowable rational subject. Therefore while I accept that geography as a discipline has been traditionally dominated by men, writing for men and using a form of knowledge based upon truth and reason regarded as 'masculine', I resist the argument which suggests that a consideration of masculinities within geography would once again be justifying a tried and tested but oppressive form of knowledge construction. As shall be discussed in Chapter five, the dangers of conflation need to be carefully considered in order to suggest a discursive framework which enables this difference to be acknowledged. Much of the critique I have with a conflatio. I of the 'masculinism' of the discipline to the production of knowledge by male geographers arises from the influence of poststructuralism and psychoanalytic theory which problematises notions of the 'subject' and 'identities'. These issues shall be discussed in more detail below. 
identity politics

The recognition by marginalised and negated groups of the repression of their experiences and differences has led to the regrouping of political movements to reflect notions of identity. An identity politics is seen to provide a greater accountability by reflecting upon the position from which one interacts and by recognising the importance of questions concerning representation. It is my aim to illustrate the debate which has surrounded the irifluence of identity based politics within feminist theory and practice and to consider the criticism which has often been directed towards this. Although I recognise that many such critiques are based upon rather a narrow conceptualisation of identity politics, where politics is seen to be assumed by a pre-given essential identity, a number of the dangers associated with the term are important to recognise. It is important to reflect upon such inadequacies in order to advocate a position which aims to be both anti-essentialist and cognisant of the certain inevitability of essential formulations (Fuss, 1989).

Throughout the 1980s, a progressive tendency towards fragmentation of political movements reflected the recognition that the operation of power in creating structures of domination and oppression was not restricted to a simple. single axis. A person's identity was more than simply 'woman' or 'gay male'; identities were seen to be shaped by a number of compating and complex interrelated aspects. Lesbians and women of colour challenged some of the most basic foundations of the feminist movement and exposed the largely white, middle-classed positions of those feminists engaging with questions of theory and practice in academia. In that feminism had posited a foundation which defines a universalised 'other' in assuming similar experiences and goals for all women, McDowell reflects that:

For the (mainly white) women working in the academy who had defined themselves in opposition to the traditional structures of the production and diffusion of academic knowledge, it came as a shock to find themselves being regarded as part of the problem. (McDowell, 1993b, p307) 
Although women of colour recognise gender as a key axis of oppression, it is contended that it cannot be regarded as the only one. Disadvantage based upon one's race and ethnicity is not a measure which can be added to gender as a further dimension of disempowerment, since it constitutes a complex set of relations adding up to more than would be suggested by a simple sum of parts. A consideration of gender relations in African-Americar, society for example, necessitates a consideration of the disadvantage faced by black males as well as women (Segal, 1990; hooks, 1990). In many political struggles, the alliance of men and women against racial oppression may provide a more powerful framework for action than an alliance between women of different racial backgrounds.

The recognition of difference amongst women has, on the one hand, be.n clearly welcomed in feminist discourse, yet on the other, has necessitated considerable debate as to how such differences should be theorised. Similar fragmentation has been apparent within lesbian and gay politics over time. Seidman (1993) recognises a transition during the 1980s from earlier theory and practice based upon gay liberation to a more reactionary 'ethnic' model delimited upon the basis of marginalised social interests. In it: presuppositions of a polymorphous, androgynous nature, the basis of liberation theory and its advocation of equality mirrors in a number of ways the foundations of socialist feminism and the importance of social construction in analysis. Despite such aims, and again similar to dominant feminist discourses at that time, the gay liberation movement tended to marginalise individuals who deviated from an apparently normalised viewpoint. For example, Seidman points to the work of black gay male writers such as Joseph Beam and Essex Hemphill to iliustrate how the 'mainstream' gay community reproduces the invisibility of black gays in both the African-American community and in US society in general. He argues that groups that felt silenced in a liberation framework reinvigourated a more radical gay politics which reflected the politics of identity and difference. As a result, politically defined st:bcultures emerged, most notably illustrated by gay males and lesbian groups going their separate ways. For each subculture a focus upon personal identity and lifestyle was central, with emphasis placed upon questions of cultural difference and local, context-specific politics. 
Questioning who may speak for whom and articulating the standpoint that the personal is political' leads to a fragmentation of political interests based upon one's personal identity. Fuss (1989) suggests that in identity politics, the link between identity and politics is causally and teleologically defined; one's identity determines a particular kind of politics. As such, there is the need to discover a true authentic identity in order to elaborate upon personal politics. 'Situatedness', 'positionality' and 'reflexivity' may be regarded as crucial elements in this search for one's own identity and the pursuit of an identity politics. Positioning oneself as an academic reflects both those positions we seek to adopt and also the "multiple ways in which we are positioned" and this would therefore reflect the constraints and possibilities which constitute our lives and by implication, our politics (Jackson, $199 /$ a). In recognising the particular positions from which we interact (from which we both speak and listen), identity politics critiques the binary ordering of difference characteristic of Enlightenment knowledge formations and advocates the situatedness and partiality of one's understanding and knowledge construction (Harding 1986; Hartsock, 1989; Haraway, 1991). Through the concept of situated knowledges. Haraway discusses an alternative to the apparent dualism between theoretical relativism where 'anything goes' and the single and totalising visions of scientific thought, where we may recognise:

partial, locatable, critical knowledges sustaining the possiblity of webs of connection called solidarity ... explicit positioning ... then grounds our knowledge and requires one to take responsibility, to speak from somewhere, to be answerable for what we learn and how we see. (Haraway, 1991, p 191)

Reflective of difference and providing greater acknowledgement of complex identity formations, the value of partial, situated knowledges has been recognised by a large number of theorists. Feminist geographers have illustrated the importance of the 'location' from which one speaks in the construction of this knowledge (Hanson, 1993: Pratt \& Hanson 1994). One's 'situatedness' reflects an autobiographical genre through which the intersection of a plethora of power and social relations provide a particular social relation from which we speak. It effectively provides a means of self-examination 
and encourages personal responsibility within one's research (Pratt \& Hanson, 1994). The practice of 'reflexivity' recognises the questions of represe'teation which are introduced into one's research. It is understood that knowledge cannot be wholly objective and will be influenced in a variety of ways according to the researcher's position. Reflexivity advocates the need to determine the limitations of one's research position as part of the research process.

Recognising the partiality and localised nature of knowledge construction necessitates the creation of a discursive space from which hitherto marginalised groups can speak for themselves and participate in defining the terms of interaction (Hartsock. 1987). In discussing one's position as a researcher, groups marginalised from dominant (masculinist, ethnocentric) discourses have illustrated the extent to which their political positions are located at the margins of such knowledge production (hooks, 1990). The margin is regarded as a dangerous but exciting position from which the marginalised can radically challenge hegemonic structures of power. However, as Soja \& Hooper (1993) observe, an important distinction needs to be made between marginality imposed upon particular groups by oppressive structures and those who choose marginality as a site of resistance and location of radical politics. Hartsock recognises that although the abandonment of the centre by a number of white. Western, male theorists for the margins is to be welcomed, the subordinated have occupied and start from quite different positions and therefore their direction should be different from such theorists. Minh-ha (1989) recognises a strategy of displacement where the validation of the margins as a site of action by marginalised groups is apprcved by those occupying the centre. If exclusive territory is clearly demarcated at the margins, then the division between the two positions (powerful/marginalised) remains intact in terms of their power relations.

Identity politics and its associated concepts of 'situatedness' and 'positionality' and 'reflexivity' have met with considerable opposition. For example, in evaluating the fragmentation of progressive politics based upon notions of 'social justice'. Harvey (1993) argues that situated knowledges are a "vulgar conception" in that they causally relate one's interpretation and understanding of the world to personalised life histories. 
He contends that situated positions reduce all political struggles to the personal so that the value of political discourse becomes devalued and is once again returned to the private arena away from the public sphere. Such a politics becomes one of closure and exclusion, promoting a large degree of misunderstanding between different identity groups and preventing active communication. Harvey further comments upon how situated knowledges may be employed to enhance authenticity of particular groups in providing some form of moral authority over those those voices they wish to call into question.

Marcus provides a powerful commentary upon the process of reflexivity in contemporary identity politics. suggesting that the procedure represents "a rather puritanical, competitive assessment among scholars of the relative virtue of each other's practices of self-identification and self-presentation" (Marcus, 1992, p489). It is argued that reflexivity acts as a medium for an 'odious political correctness' which prevents scholars speaking or writing about 'others' withour leading to agonistic questions surrounding identity which arise as academics search for their appropriate positions. Sayer agrees with this impasse, suggesting that academics have moved from a paternalistic and imperialist presumption to speak for others to an extreme reluctance and deference to speak for them at all. "even where doing so might help" (Sayer, 1993. p337). Such positions are also reflected in Bourne's dismissal of identity politics as fostering amaterialist and subjectivist points of view through an inward looking and selfrighteous politics':

Identity Politics is all the rage. Exploitation is out (it is extrinsically determinist). Oppression is in (it is intrinsically personal). What is to be done has been replaced by who am I. Political culture has ceded to cultural politics. (Bourne, 1987, pl-2)

The question has shifted from what is to be done to a consideration of who am I, and as a result, one critic reflects, political discourse has been infected to such an extent with concern for the characteristics of the speaker, that the actual contents of the speech become secondary or irrelevant (Kimmel, 1993). In terms of implications for research, a recent article by England (1994) reflects upon a number of difficulties faced relating to 
her 'position' and her decision not to go forward with a piece of research involving Toronto's gay community largely over concerns regarding (mis)representation.

The responses of Bourne. Marcus and Harvey to the practice of identity politics are rather forceful critiques of a more general scepticism towards such theoretical positioning which have arisen through the significant influence of poststructural and pychoanalytical frameworks. The dangers associated with identity politics arise through notions of 'authentic identities' and the interpretation of a politics of identity as 'rediscovering' a pre-given, essential self which appears innate and stable. Bondi discusses how the development of a "label" Identity Politics seems reliant upon pre-given categories of, for example class, sexual orientation or race. This conceptualisation invokes identity as something to be unearthed and acknowledged rather than constructed. Such formulations, Bondi argues, have the effect of "replacing politics with therapy. Identity becomes compensation for, rather than a challenge to. relations of exploitation" (Bondi, 1993, p87). Furthermore, since politics invariably becomes defined through its act of closure, Keith \& Pile reflect upon identity-based movements' underlying assumption that if you are not part of the solution, then you must be part of the problem: to recognise one's own oppression. the oppressor needs to be categorically defined.

The 'us' vs. 'them' logic is worked out in many arenas of political struggle; feminism mobilized women against men; class politics, labour against capitalists, anti-imperialism, colonized against colonizer. Dichotomized social movements... internalized an imagery that was as much symbolic as it was real. (Keith \& Pile, 1993b, p222)

Identity politics . Soja \& Hooper (1993) argue, has tended to create a 'competitive exclusivity' which resists an interpretation of a society populated by multiple subjects representing multiple, and continually changing, subjectivities. In constructing positions of this nature, a politics based upon identity becomes particularly difficult to call into question and critique since one is calling into question that which is personal and that which may be seen as not fully knowable by those not sharing a similar identity. As Sayer (1993) comments, the rightful recognition and respect of the 
kncwledges of others should not imply a privilige which grants those knowledges immunity from external criticism. Sayer further remarks that a lack of discourse between differently situated. localised knowledges inevitably leads to both conceptual arguments becoming stable and unchanging and marginalised discourses becoming once again silenced and ghettoized.

In problematising identity, questions of sameness and difference in Aristotelian logic are necessarily called into question (Fuss. 1989). Identity in such logic is closely allied with sameness, unity and oneness and, as such, has been conflated with 'essence'. Under such interpretations, identity politics appears unable to offer suitable grounds for an emancipatory politics which rejects the binary dualisms of Western philosophical thought since the concept of identity itself seems to be grounded in a universalised rational discourse. One is of a particular identity or one is not, there is no middle or mixed-ground: one is either a man or a woman, heterosexual or homosexual. No deviation is allowed, and internal consistency, predictability and stability are assumed to be found within established categories.

Given the inadequacy of such formulations, the need to abandon dualistic epistemologies has been recognised through calls to accommodate the multiplicity and heterogeneity of identities in new theoretical and practical frameworks. As discussed by Soja \& Hooper:

the aim is neither simply to assert dominance of the subaltern over the hegemon in a rigidly maintained bipolar order, nor even to foster some specified combination of opposing traits and traditions. It is to breakdown and disorder the binary itself, to reflect the simple structure of closed dualisms through a deconstruction and reconstruction that allows for radical openness, flexibility and multiplicity.

(Soja \& Hooper, 1993, p 198)

Advocating the creation of new spaces aims to move away from a simplistic recognition that identities are multiple and fragmented. Parmar (1990) suggests that 'authentic subjective experience' is no longer an appropriate foundation upon which to base a radical politics and a space needs to be created to acknowledge diverse identites of different races, classes, sexualities and genders. Seidman regards postmodernism as 
speaking of "multiple, local, intersecting struggles whose aim is less human liberation than the creation of social spaces that encourage the proliferation of pleasures, deisres. voices, interests, modes of individuation and democratisation" (Seidman, 1993, p106). Further 'spatial metaphors' (Smith \& Katz, 1993) are invoked in calling for a 'Third Space' (Pile, 1994) and an identification with 'in-betweenness' or the spaces between identities (Fuss, 1989; Katz. 1992: Staeheli \& Lawson, 1994; Bhabha, 1994). Bhabha contends that it is both theoretically innovative and politically crucial to focus uf. 7 the spaces in which processes articulating difference unfold. These "'in-between' spaces provide terrain for elaborating strategies of self-hood - singular or communal - that initiate new signs of identity" (Bhabha, 1994. pl). hooks (1990) envisions a move beyond binary oppositions towards a revised spatiality that creates new sites of struggle in which new "communities of resistance" can assemble and Minh-ha (1991) offers the concept of 'inappropriate/(d) others' to refer to the positioning of people who refuse to adopt the binary identity of either 'self or 'other'.

A key characteristic of poststructural influences on critical social theory has been an emphasis placed upon textual strategies in representational discourses. Associated with creating new spaces from which to speak is the recognition of the plurality of the voices which should be allowed to speak in new configurations of academic authority. Doel (1993) suggests that geographers have been unable to write the 'movement of difference' and that the solid and stable grounds upon which writing rests should be 'hollowed'. Another geographer, Crang (1992), suggests that a 'politics of polyphony' calls for writing to move away from unilinear, monovocal forms to more polyvocal forms of expression where the voices of those represented as well as the author are heard. Such strategies uncover that there is a politics of who can write, who can practice textual politics and who can represent. Drawing upon the work of ethnographer james Clifford and theorist/novelist Milan Kundera, Crang argues that polyphony "combines simultaneously many equally weighted lines or voices each of which has an independent merit but it does so in a 'coherent texture' where the voices are independent" (Crang, 1992. p530). Although Crang accepts that polyphony is not necessarily a new concept, he contends that existing treatments of ambiguity, contradiction and multiplicity are not 
equivalent to treatments which may be regarded as truly polyphonic. McDowell (1994) follows up discussions concerning new textual strategies with a consideration of the politics involved in teaching and reading such texts. The question posed is how students, who need help to make sense of partialities, are to be guided in these more 'egalitarian' and 'democratic' texts which provide the new discursive arenas.

Fuss (1989) offers some scepticism as to whether a new spatiality, the pluralising and fragmenting of identities, and polyphonic/participatory practices avoid the dangers of identity politics rather than simply disperse the same problems and make them even harder to conceptualise and confront. Through displacing questions concerning difference to a space of 'in-betweenness' amongst identities, the structure and differences within identities continues to remain unexplored. Supportive of this view. Bondi (1993) argues that the notion of multiple identities, which can become associated with hyphenated -isms, may potentially lead further towards the need to discover, reclaim and celebrate some pre-existing knowable identity. The avenues open for political mobilisation become increasingly fragmented and reduced and devalued through an overdetermined importance of the 'personal'. Although the dangers of identity politics are clearly recognised and would appear difficult to escape, a numb'. - of writers (Alcoff, 1988: Young, 1994) have rightly stressed the need to recognise the empowerment offered to previously marginalised groups through advocating some form of identity politics, and that initially in the formative stages at least, a defined and closed categorical identity as 'subaltern' is essential (Soja \& Hooper, 1993). Furthermore, it is important to recognise that critiques of identity politics have been largely based upon a rather narrow conceptualisation which relates Identity with essence such that identity becomes a pre-defined, unchanging entity. This tension between theoretical assumptions which appear to fall back upon essentialism and the political importance of articulating identity has become a primary focus of feminist theory and practice. 


\section{poststructuralism and feminism}

Problematising identity introduces the question of sameness and difference: a contradiction which lies at the heart of feminist politics and theorising (Snitow, 1990). Alcoff (1988) argues that the identity crisis in feminist theory reflects the tensions apparant between feminism and poststructuralism. Scott suggests that both poststructuralism and contemporary feminism are late 20th century movements that "share a certain self-conscious critical relationship to established philosophical and political traditions" (Scott, 1990, p134). Indeed, feminist theorising has acted as one of the most important instigators of poststructural practices (Flax. 1989). Hutcheon contends that both postmodernism and feminism are "part of the same general crisis of cultural authority ... as well as part of a more specific challenge to the notion of representation" (Hutcheon, 1988, p142).

Undoubtedly, feminist interpretations on poststructuralism reflect the heterogeneous nature of feminism as a movement. It is my contention that concern surrounding the need to recognise 'women' as a knowable group and in understanding women as a collective stems from the seeming impasse in feminist discourses created by the dichotomisation of essentialist and constructionist viewpoints (Fuss, 1989). The inadequacy of either of these standpoints taken separately is exposed through a reformulation of sex/gender as in the influential work of Judith Butler. Insights afforded by Queer Theory have assisted in blurring the constructed difference between sex and gender and has enabled new conceptualisations based upon the constituted subject to be theorised.

deboting the merits of poststructuralism

The deconstruction of dualistic epistemologies and the exposure of the gendered nature of hierarchical dichotomies has provided a beneficial discourse for developing feminist theory (although many ferminists would argue that it was feminism that exposed such dualisms, not poststructuralism. for example see WGSG, 1992). A number have welcomed the 'challenge' introduced by poststructuralism to question the foundations 
upon which feminist theories have been traditionally based. For example fraser and Nicholson (1990), recognising both the dangers and advantages associated with each practice, suggest that drawing upon aspects of each will allow new theoretical insights and the fostering of associated political frameworks to be developed. Others, quite understandably, have been a little more cautious towards the implications of poststructuralism.

Significantly, notable concern has been voiced by feminist geographers, who recognise the dangers of a direct questioning and discarding of feminism's self-generated categories and analytical tools (WGSG, 1992). MeDowell questions the need to employ poststructuralise frameworks to expose binary dualisms, difference and multiplicity when "feminism was there first" (WGSG, 1992. p224). Reiterating this viewpoint. Penrose suggests that some feminists have lost sight of the fact that feminism is capable of meeting its own epistemological challenges and defining it's own political direction. The question of politics and a reflection that poststructuralist insights fail to adequately call into question inherent dimensions of power are important issues raised by feminist 8eographers. Bondi \& Domosh (1992) argue that the larger postmodern project has been conceived by those with power as a means of dealing with threats to their legitimacy. If the politics of modernity has been exposed as, and associated with that regarded as masculine. Marcia-Lees et al (1989, p29) suggest that within the postmodern project "all stories are really about one experience: the decentring and fragmentation that is the current experience of Western white males." McDowell is a little more suspicious regarding the postmodern turn within the discipline, stating that:

It is ironic that, just as signs of disciplinary acceptance - the publication of increasing numbers of papers, conference sessions devoted to gender issues, references to feminist discourses by significant disciplinary figures are accumulating. 'the' feminist project seems to be crumbling. (McDowell, 1993a, p158)

She indicates that since the subject position of the dominant (male) group has been disputed, then the possiblity of there being any subject position is called into question: if 'we' are no longer able to speak with authority, then 'you' cannot either. Since feminists 
aim to challenge dominating groups from a different, subordinated, position. McDowell suggests that postmodernism and its leading tool, poststructuralism, are not appropriate starting points from which to achieve this aim.

the problemotised subject

The exposure of the inadequacies of knowledge constructed through binary dualisms and the problematisation of identity has focused attention upon our understanding of the subject as a rational transparent entity. Psychoanalytic theories have been particularly influential in this regard, which posit that there are no pre-given subject positions and that subjectivity itself is created in and through discourse. As a result, the foundations on which the subject has been regarded as knowable, or the basis for a collectivity of women in contrast to men, is destabilised and problematised. Calling into question the unity of the self, psychoanalysts have emphasised the existence and partial autonomy of an inner self pervaded by desire and fantasy. As Flax (1992) reflects, the unconscious of our inner world has effects upon other aspects of human subjectivity which, by definition we cannot know. Theorists concerned with the deconstruction of the subject have drawn extensively upon the work of Freud and Lacan, and inevitably also upon both post-freudian and post-lacanian critiques. The significance of such material in structuring our understanding of the constitution of the human subject has become increasingly recognised by geographers (Pile, 1993. 1994; Rose. 1993: Sparke. 1994).

Mouffe (1992) suggests that since the social agent (the subject) is conceived as constituted by a plethora of subject positions which cannot be fixed in a closed system of differences, identity becomes contingent, precarious and unstable. Necessarily, poststructuralists have abandoned efforts to defend or reconfigure identity and have advocated a shift of focus from the politics of personal identity to the politics of signification, to deconstruction of fixed categorisations which structure the social text of daily life (Seidman, 1993). Therefore. the deconstruction of binary dualisms, exposing the extent that identity always contains the spectre of non-identity, has as its logical extension the fragmentation of the subject. As Mouffe (1992) contends, if identity is 
permanently partial and unstable, how can the notions of 'men' and 'women' be retained?

Recognising difference and the multiplicity of subject formations leads to a crisis of representation at the very basis of feminist theory: the category 'woman'. Young (1994) discusses how recent debates have cast doubt upon a feminist project based upon advocating women as a definable group. She argues that the search for a common self. experience or a collective bond can not escape the dangers of a politics of closure. leading to normalisations and exclusions. As Soper contends:

feminism, like any other politics, has always implied a bonding together, a movement based on the solidarity and sisterhood of women, who are linked by perhaps very little else than their 'sameness' and 'common cause' as women. If this sameness itself is challenged on the ground that there is no 'presence' of womanhood. nothing that the term 'woman' immediately expresses, and nothing instantiated concretely except particular women in particular situations. then the idea of a political community built around women - the central aspiration of the early feminist movement collapses.

(Soper, quoted by Mouffe. 1992. p381)

The concept of woman is central for feminists since it is the necessary point of departure for any feminist theory and practice. predicated as these are on women's lived experience and the re-evaluation of social theory from a women's point of view (Alcoff, 1988). As Young (1994) suggests, ferninism has assumed that it can neither be political or theoretical without a subject: women's experience and the female gender identity delineate that subject. Feminist politics establishes an exclusive right to describe and evaluate women; it speaks in the name of the group women who are recognised by their gendered identity. Therefore a feminist polities requires that wumen themselves not only advocate feminist claims made on their behalf, but that together they will be able to conceptualise a common identity (Butler. 1989).

Snitow suggests that feminists live in a complex relationship to this primary divide: a common divide which inherently forms in both ferninist thought and action between "the need to build the identity 'woman' and give it political meaning and the need to tear down the very category 'woman' and dismantle its all-too-solid history" 
(Snitow, 1990, p9). The necessity to articulate a category 'woman' which is a knowable, recognisable entity has fundamentally structured the differences in theoretical positions which give rise to the existence of feminisms. Although disguised by a plethora of different labels, feminist standpoints in academic discussion broadly fall between those regarded as 'essentialist' or 'cultural' and those seen as 'anti-essentialist' or 'constructionist'. Based upon Aristotelian understanding, those advocating an essentialist position illustrate a belief in the existence of true essences which are irreducible and unchanging. Constructionists on the other hand argue that the meaning of the body is changeable and is produced by discourse shaping social relations.

Within feminist theory, essentialist discourse has been articulated in a number of ways and subtends a great number of related assumptions (Fuss, 1989). The division between the sexes is based upon the premise of an innate male and female essence. Essentialism has appealed to the discovery of a pure femininity which is identifiable outside the bounds of the social. Thus outside the space of cultural, historical and geographical influences, essentialist arguments assume 'man' and 'woman' to be stable, unchanging and predictable objects. A number of theoretical foundations of 'cultural' feminism (Alcoff, 1988) can be identified. Female oppression is regarded as universal. and the oppressor is universalised as male. $i c$ is also associated with a denigration of masculinity and in some cases male biology (Solonas, 1968: Alcoff, 1988). The distortion and devaluation of feminine characteristics in dualistic epistemologies is corrected through a reappraisal which typically reverses the dichotomy and valourises that which is feminine. A key aspect of this work is dependent upon recognising the specificity of women's anatomy as the primary source of identity and the source of female essence. The importance of childbirth, nurturing and association with the Earth are commonly recognised as helping to define this female essence. In reading 'the body', essentialists consider it to occupy a pure, pre-social, pre-discursive space which is real, accessible and transparent (Fuss, 1989).

Essentialism can also be seen to underwrite claims for the autonomy of a female voice and the recognition of a differentiated female language (Fuss, 1989: Tannen, 1990, 1994). Related to this, Feminist Standpoint Theory celebrates gender difference and 
attempts are made to reverse rather than abolish the traditional allocation of superiority to all that is masculine (McDowell, 1993b). Therefore not only is the gendered construction of knowledge accepted, but the hierachical dichotomy is reversed to signify feminine superiority. As Haraway states:

the gender specific and differentiated perspective of women is advocated as a 'preferable' grounding for inquiry - preferable because the experience and perspective of women as the excluded and exploited other is judged to be more inclusive and critically coherent than that of the masculine group. (Haraway, 1991, p74)

The particularity of 'women's experience', where the vision of the individual subject becomes the bedrock of evidence upon which explanation is built is therefore valorised (Scott, 1992). Flax (1989) argues that this standpoint rests on a numbur of problematic and unexplained assumptions. Firstly, it suggests an optimistic belief that individuals can rationally know themselves and that reality has a structure which reason can discover, both of which psychoanalycic insighes would call into questicn. Furthermore, it implies that those previously marginalised or oppressed are better positioned to reflect upon society than those in privileged positions, whilst assuming that the oppressed have not been damaged by their social position.

Feminist proponents of a definable female essence find unlikely bedfellows in the mythopoetic men's movement associated with the popular writings of Robert Bly. Sam Keen and Jungian psychologists 5 such as Robert Moore and Michael Meade (Kimmel, 1993). Robert Bly is commonly regarded as the founding 'Father' of the Men's Movernent which has emerged in the last ten years. Bly contends that men and masculinity are experiencing a crisis of identity, and that this identity needs to be rediscovered by exploring one's own deep inner psyche to find the 'Inner Warrior'. "The structure at the bottom of the male psyche is still as firm as it was twenty thousand years ago". Bly argues, and "every modern male has, lying at the bottom of his psyche, a large, primitive being covered with fur down to his feet" (Bly, 1990, p6). Much of Bly's discussion is based upon ancient stories and legends which provide images of a vigorous masculinity both protective and emotionally centred. The tale of "Iron John' is a translation of the Grimm Brothers 'Iron Hans' tale dating from the early 19th century 
which Bly analyses to explore its message of male initiation and the role of the wild old man as mentor.

By contrast, the 'anti-essentialist' or 'social constructionist' position asserts that the categories according to which people are identified as the same or different are social constructs that are not founded upon an innate nature or essence. Kimmel (1993) reflects the dominance of the constructionist standpoint in the Social Sciences and how this position has governed much of the recent research concerning issues of gender and sexuality. The importance of social construction as a theoretical standpoint is clearly reflected in recent feminist geography (and geography as a whole for that matter). particularly through the prominance of socialist feminism within the discipline throughout the 1980s, especially in Britain (WGSG. 1992). and also through the growing influence of cultural studies to this field. A number of geographers have illustrated the social construction of race and racism and the racialisation of crime and violence (Jackson, 1989, 1994: Keith \& Cross. 1993: Hesse. 1993). Keith \& Cross (1993) reflect upon the 'racialisation' of the inner-city riots in Britain during the early and mid 1980s which were represented as a black phenomenon whereas in reality a great variety of racial groups, including whites, were involved. The work of Foucault may also be considered in this regard, illustrating the social conseruction of 'deviant' groups, such as homosexuals, criminals and the mentally ill through discursive practices.

sex/gender

Anti-essentialist positions within feminism have focused upon the construction of gender roles and relations, and how such construetions reflect structures of power and domination. The distinction made between sex and gender has been central to the rejection of a foundational essence in social constructionist theories. In dominant feminist discourse, there has been a broad consensus that sex is a designation based upon a natural biology, whilst gender is socially, culturally and psychologically constructed. Characteristics of masculinity and femininity and resulting structures of gender relations reflect cultural variations which are hiscorically and geographically defined. Each person will have some qualities that a particular culture labels masculine 
and some it defines as feminine. This is true whether the person is male or female. Where biology and social construction 'co-operate'. men are masculine and women are feminine. However, since the sex/gender distinction suggests discontinuity between 'sexed' bodies and culturally 'constructed' genders (Butler, 1990), in other situeations men and women can be labelled more feminine or masculine respectively compared to 'most' of their gender as defined by hegemonic notions of masculinity and femininity. Cocks (1989) suggests that the bodily dispositions normally thought of as masculine or feminine refer to qualities that are, theoretically at least, available to individuals of either sex. Just as boys can be 'sissies'. girls who do not conform to dominant representations of femininity are seen as 'butch' or called 'tom-boys'. Woods (1994) contends that a person does nothing to acquire his or her sex: it is a classification based upon genetic givens. Gender, however, is regarded as neither stable or innate: it is acquired through interaction with the social world, and it changes over time. Given such a framework, the sex/gender distinction has enabled social constructionists to argue that there is no foundational, ontological essence onto which the structures of power and domination shaping society can be reduced.

However, associated with the seemingly irresolvable tensions between essentialist and anti-essentialist standpoints, feminists informed by poststructural and psychoanalytic frameworks have begun to question and break down the apparent binary construction of sex/gender insofar as it parallels the essence/construction dichotomy (Flax, 1989: Butler. 1990: Mouffe. 1992). Fuss argues that essentialism, when held most under suspicion by constructionists, is often effectively doing its work elsewhere and indeed that "essentialism is essential to social construction" (Fuss, 1989, pl). Whilst constructionists recognise that 'man' and 'woman' are constructed in an arena of a spectrum of discourses, the categories 'man' and 'woman' remain constant as do the descriptive attributes 'masculine' or 'feminine'. Since gender constructions still effectively reflect a binary dualism based upon sex. Fuss argues that it is difficult to visualise constructionism as constructionism without some fundamental recourse to an ontological essence. Alchough constructionists recognise heterogeneity and difference in such categorie: Fuss believes that this cannot defend against essentialism and rather 
than countering it, merely displaces it. The plural categories 'men' and 'women' still occupy a space which signifies unity and an embeddedness in the sex binary.

Constructionists therefore do not counteract essentialism, but often simply redeploy it through explanations calling upon historicity. Ultimately, the anti-foundationalist theorising of social construction remains a slave to essence, which through denial, leaves fundamental questions unaddressed. Conversely, the destabilisation of the essentialism/constructionism dualism has been illustrated in that constructionism is founded in defined essences which have been socially constructed. As Connell (1987. p76) contends, the "conception of what is natural and what natural differences consist of is itself a cultural construc:" and this is reflected by Butler (1990. p7) who argues that "gender ought not to be conceived merely as the cultural inscription of meaning on a pre-given sex: gender must also designate the very apparatus of production whereby the sexes themselves are established." Furthermore. as feminists influenced by Derridean deconstruction have recognised, the definition of what is regarded as natural remains tied to masculinist or phallocentric discourse. so that by advocating a sex/gender distinction more mainstream feminist discourse has maintained and concretised existing knowledge structures. In attempting to correct the arbitrary distinctions drawn in dualisitc epistemologies, feminists have inevitably ended up reproducing those differences.

Therefore it is my contention that terms and categories established to consider questions of gender and sexuality have constrained and normalised those very terms. The way in which gender relations have been conceptualised is necessarily called into question: what has been assumed is that which requires explanation. As Flax comments:

In order for gender relations to be useful as a category of social analysis we must be as self-critical as possible about the meanings usually attributed to those relations and the ways we think about them. Otherwise we run the risk of replicating the very social relations we are attempting to understand. (Flax, 1989, p49)

The need to articulate a category 'women' upon which to ground the political claims of feminism is clearly problematised, and the particularly influential work of judith Butler illustrates how the promotion of discourse centred upon binary gender 
constructs lends to a reification of the fluid and shifting processes in which people relate and struggle with one another over knowledge production and social practice. She contends that the paradox of essential foundationalism "presumes, fixes and constrains the very 'subjects' that it hopes to represent and liberate" (Butler. 1989, p148). Where the category 'woman' pre-supposes an internal coherence which provides differentiation from a category 'men', then the categories of gender remain unproblematised in feminist theory and practice. Butler further shows that a distinction drawn between sex and gender contributes and helps define the centrality of enforced heterosexuality in the social construction of gender. The heterosexualisation of desire (Butler, 1990) requires the production of asymmetrical oppositions between masculine and feminine and these attributes are regarded as expressive of males and females respectively. However great the differences that social constructionists indicate, the ultimate form of gender differentiation is typically binary, being either masculine or feminine, such that gender always mirrors sex in a mimetic relation. Butler argues that:

The institution of a compulsory and naturalised heterosexuality requires and regulates gender as a binary relation in which the masculine term is differentiated from a feminine term. and this differentiation is accompanied through the practices of heterosexual desire. (Butler, 1990, p22).

The mutual reinforcement of gender and sex remaining in fixed categories leads to the suppression of ambiguities and contradiction in practices of gender and sexuality so that measures of normality and deviancy are inevitable. Therefore politics dependent upon the preservation of the subject necessarily become exclusionary, concealed and naturalised. The coherence constructed in the heterosexualisation of desire, through the sex/gender binary, conceals the gender discontinuities in both heterosexual and homosexual contexts where gender does not necessarily follow from sex, and sexuality does not seem to follow from gender. The disruption of rigid constructions of gender reflect the inadequacy of both essentialist and constructionist frameworks; the fluidity and blurring of identities requires new terms of reference. The performativity of gender, Butler contends, reflects a gendered body that has no essence apart from the various acts which constitute its reality: gender becomes a performative and regulatory 
practice. If this reality is fabricated as an interior, natural essence, then that essence is clearly acting as a function of social discourse. Butler argues that acts, gestures and enacted desires create the illusion of an interior organising core which serve the discourse of sexual regulation and reproductive heterosexuality. Therefore:

If the inner truth of gender is a fabrication and if a true gender is a fantasy instituted and inscribed on the surface of bodies, then it seems that genders can be neither true nor false but are only produced as the truth effects of a discourse of primary and stable identity. (Butler, 1989, p337)

Gender parody reveals that the origin of identity upon which gender seeks to define itself is discursively produced and does not exist. Butler (1989) illustrates how the notions of an original gender identity are parodied in the practices of drag which consciously play upon the anatomy of the performer (for example, a man) and the gender which is to be portrayed in the performance (in this case, female).

queer theory for a queer notion

\author{
Gits who are boys \\ Who like boys to be gints \\ Who do boys like they're girts \\ Who do gits like they're boys \\ Alwoys should be someone you really love \\ "Girls and Boys", Parklift, blur6
}

Feminism is puritanism, separatism is anathema, political correctness is a straight jacket. This is Queer Culture. Will it be gone before you ever know it was here? Or will it take over the world, liberating men, women and others through the final withering away of gender? (Hayes, 1994, p14-15)

An important relation with Butler's work can be seen in the emergence of Queer Theory, often regarded as (one of) lesbian and gay studies' response(s) to the challenge of posestructuralism. A number of Queer theorists, for example Duggan (1992) and the collection edited byWarner (1993), have drawn upen Butler's exposure of the heterosexist assumptions built into the foundations of theories of gender to reconceptualise understandings of sexuality. Queer Theory's growing popularity reflects 
a viewpoint that traditional political strategies, whether based upon advocating an essentialist or social constructionist argument have only met with relatively limited success. Duggan (1992) reflects that for fifty years lesbian and gay organisations have worked actively to make lesbians and gays visible as a 'minority' group and to claim the liberal rights of privacy and equality on their behalf. As such, this political strategy has aimed to align lesbian and gay populations with other "identity" groups based upon racial, ethnic, religious and gendered lines for acceptance in society.

Through questioning the sex/gender construct, the theorisation of lesbian and gay identities has, paralle irrg feminist insights, been shown to contain desire and naturalise gender through the operations of their very definitions. Of key importance. Seidman (1993) reflects, has been the dominant assumption in discourse that gender preference defines sexual orientation. The heterosexualisation of desire in theories of gender as illustrated by Butler has also exposed the polarity that is constructed between heterosexual (normal) and homosexual (deviant) behaviour. The disruption and often acrimonious debates as to the inclusion of bisexuals in the political arena during the 1980s was considered by activists as a means by which this homosexual/ heterosexual dualism would be contested (Duggan, 1992). However, the creation of a 'third sex'. much like the third spaces (see above, p24) proposed to disrupt other identity based politics, has paradoxically reinstated rigidity through a third 'naturalised' item which reflects the rigid gendered identity of the other tv ' 0 , only 'doubled'. In that sexuality is defined primarily upon the basis of desire for a particular gender, bisexuality as a naturalised category merely doubles, but does not dismantle, gender based desire in that desire is directed towards both male and female, but only these entities. Seidman argues that some bisexuals have sought to legitimise the 'third sex' category in reflection of the political empowerment and community such an identity would afford. Others simply do not recognise gender desire as an important defining personal character's:ic and challenge this privileging of sexual object-choice. 
The term 'Queer' promises new ways of thinking and new forms of political activism. Definitions as to what constitutes 'Queer' greatly vary, from rather militant standpoints to a looser use of the term to widely reflect contemporary lesbian, gay and bisexual theory and practice. To those who visualise it as a newly defined political entity. it enables a crossing of boundaries and a construction of more fluid identities (Duggan. 1992). As Seidman contends, Queer Theory reflects the insights of poststructuralism as a resource upon which lesbian and gay theory can reimagine notions of identity and politics. Again reflecting feminist experiences, it is suggested that the introduction of such standpoints has acted in response to the impasse within gay politics between essentialist (radical separatism) and constructionist (assimilationism) arguments centring on the notion of identity. Furthermore, as with feminisms' relations to gender, it is advocated that not all social situations dictate that being gay will be the most important component of one's identity (Seidman, 1993). Hayes (1994) suggests that Queer theory posits a standpoint which is both anti-essentialist, in its rejection of notions of gender as specific, rigid and definable, and also anti-assimilative through aggressively challenging the concept of 'norms'. Seidman believes that the opportunities afforded by poststructuralist insights move beyond an anti-identity politics to a "politics against identity per se" wher e movement is celebrated: "Queers are not united by any unitary identity but only by their opposition to disciplining, normalising, social forces" (Seidman, 1993, p 133).This characteristic is also recognised by Duggan, who suggeses that the 'Queer Community' or 'Queer Nation' should be seen as "unified only by a shared dissent for the dominant organisation of sex and gender" (Duggan, 1992, p21).

Suggesting no fixed identities, Queer Culture reflects Butler's notions of gender as a performance, a stylised repetition of acts. Performance represents liberation; one can perform whatever gender one wishes to; Queer is effectively 'gender gymnastics' (Hayes, 1994). The fluidity and blurring effected in Queer Politics suggests that, at least theoretically, heterosexuals as well as gays can be Queer. Many of the debates which have focused Queer Theory parallel those articulated in contemporary feminist discourses. As such I would suggest that a number of the ideas afforded by Queer Politics may have some import in more general discussions of gender relations. If 
'straights' can be Queer, can men be involved in a queered feminism? Reporting on a conference held in San Francisco, Sloan reflects that the designation Queer constructed a community of:

men, women, transsexuals, gay males, lesbians, bisexuals, straighe men and women, African Americans, Chicanos. Asian Americans, Native Americans, people who can see and or walk and people who can not. welfare recipients, trust fund recipients, wage earners, Democrats. Republicans and anarchists - to name a few ... I often imagine it will be the 'queer community' - the oxymoronic community of difference that might be able to teach the world how to get along. (Sloan, 1991, p3)

Theoretically, Queer is meant to be confrontational; however, in terms of practice, the 'Queer Nation' or the 'Queer Community' has been characterised by a militant politics largely critcised by gay and lesbian communities. Indeed, Queer militants have participated in internecine thrashing, for example illustrated by the statement made by Queercore, a Toronto-based group, in the magazine BIMBOX: "you are entering a gay and lesbian-free zone ... Effective immediately, BIMBOX is at war against lesbians and gays. A war in which modern queer boys and queer girls are united against the prehistoric thinking and demented self-serving politics of the above mentioned scum" (quoted by Cooper, 1992, p31). The most reported tactic of Queer Nation has been the process of 'Outing', where famous and prominant members of the public are 'brought out of the closet' by poster campaigns and through running advertisements in newspapers and magazines. ${ }^{7}$ The motive is to increase the awareness of the general public to homosexuality's prevalence in public life, to show that it is acceptable to be so with the belief that such exposure will lead to greater public acknowledgement. The act of Outing was particularly prevalent in New York City in the late 1980s, stemming from the radical publication Qutweek, but also gained significant import into Britain at that time. In the British context, Hayes (1994) suggests that the popularity of Queer politics and Outing emerged in the context of the Conservative Government's Clause 28. reflective of the government's wider 'Back to Family Values' agenda, which banned the promotion of gay and lesbian lifestyles as an 'acceptable normal living relationship'. 
A number of geographers have begun to explore the potential insights offered by Queer Theory in studies of gender and sexuality (Valentine, 1993a. 1993b: Bell et al 1994, the Sexuality and Space Network, 1994). For example, the tactics of appropriating public space by direct action groups such as Queer Nation. Homocult and ACT UP (which has an AIDS awareness agenda) has been of interest. Public space, like shopping malls and leisure venues are taken over and heterosexual norms associated with such places challenged. Bell et al (1994) draw upon Queer Theory to expose the parodies of gender norms reflected by the existence of seemingly confused sexual stylisations in the form of gay skinheads (a hitherto strong masculine performance) and lipstick lesbians (likewise an extra-feminine performance). At this stage, such research is exploratory and the geographical implications remain preliminary: however new directions in the theorising of both gender and sexuality issues have clearly been raised.

\section{recovering the subject: rebuilding feminism}

we cannot afford to refuse to take a political stance 'which pins us to our sex' for the sake of abstract theoretical correctness ... There is the danger that (Foucault's) challenges to traditional categories if taken to a 'logical" conclusion ... could make the question of women's oppression obsolete. (Martin, quoted by Alcoff. 1988, p419)

Critics of poststructuralist theories have pointed to the inevitability of a movement towards relativism. where anything goes and everything becomes unique, which would result from the logical progression of deconstruction. The failure of fixed identity constructs and the promoting of fluidity would imply that deconstruction leads to the death of the subject, and specifically, the category 'women'. However, feminist responses to this challenge have been effective in uncovering the negation of questions of power and the sidelining of political processes that deconstructing abstract theory represents. Building upon the work of Butler, and as further illustrated by theorists such as Flax. Mouffe. Alcoff and Young. I shall argue that an anti-essentialist standpoint can be created, where the use of categories can never be pre-determined but can remain of value to feminist practice. 
In Flax's (1989, 1992) response to the poststructural challenge to feminism, the importance of politics and a recognition of the processes of power and dumination as positive attributes of feminist theory are firmly stated. She argues that deconstructing categories of gender have weakened understandings of power relations; femınısm's conceptualisations of gender categories provide a necessary counterpoint. Indeed, it may be contended that as well as feminism having a great deal to learn from poststructuralism, the same is true vice versa. Poststructuralism's primary foundations in textual strategies and deconstruction are criticised in that the text takes on a life of its own and in itself becomes the world (de Lauretis. 1986: Flax. 1989). At a distance from actual concrete social practices, poststructuralism's reflection upon issues of power and domination are therefore inevitably obscured. Following this. Flax (1992) reflects upon feminist understandings of 'masculine' and 'feminine' in terms of the effects of power and domination in social reality, not as positions in language which any subject may choose to assume. As such, Flax would seem to question the potential for a 'gender gymnastics' as posited by Queer theory: no subject can voluntarily switch sides in a regulatory gender system ${ }^{\theta}$. Whilst Flax questions the traditional assumptions and categorical exclusions of the binary gender construct, recognising as does Butler the implications this has for fixing and constraining feminist theorising. she discusses why. given the complexity and continual process of subject formation, it is that anatomical differences between males and females assume such significance. She argues that since reproduction is such an important part of human life and obviously, survival, then anatumical differences associated with the reproductive process will be far more salient than, for example, hair colour or handedness in structuring social practices.

As Butler (1990) argues, to deconstruct a consept is neither to negate or refuse it: deconstruction provides the necessary interrogation of fixed, pre-given gender constructs and frees up that concept to occupy and serve very different political aims. Drawing upon the work of Foucault, Butler (1992) argues that subjects who instizute actions are themselves instituted effects of prior actions. Our thoughts and actions are constitutive of our very capacity to act, and do not merely reflect an 'exterior field of operations'. The subject is therefore constituted through processes of differentiation, 
exclusion, affirmation and repression. Butler suggests that proposing the constituted subject is not to claim that it is determined; on the contrary. the constituted character of the subject is the pre-condition of its agency. In that the subject is constituted by structures of power, that power does not cease as soon as the subject is constitured since the process of constitution can never be complete. The subject should not therefore be regarded as a ground (essence) or a product (construction) but the site of a continual resignifying process. Gender performance is shaped and constrained through regulatory practices which are socially, institutionally and discursively produced to maintain the norms and coherence of our understanding of gender. As, a result gender may be seen as "the repeated stylisation of the body, a set of repeated acts within a highly rigid regulatory frame that congeal over time to produce the appearance of substance" (Butler, 1990, p33).

Butler's work provides an exposure of the irresolvability of essencel constructionist debates in questions of identity and illustrates a means by which identity may be reconceptualised as a site of permanent resignification. As such, identities do not become fixed (although regulatory practices promote a particular gender performance) and exhibit a continual openness to signifying processes. Theory and practice should not presume in advance the solidarity and coherency of the subject or category but instead designate "an undesignatable field of differences". Therefore, we may recognise categories of the constituted subjects 'man' and 'women', but the traditional ontological grounds upon which such terms were founded need to be destabilised. In terms of feminist theory. Butler argues that the desire to identify a pre-existing identity to assure the category 'woman' as a basis for feminist practice should therefore be questioned. and it is suggested that there need not necessarily be a pre-given "doer behind the deed" (Butler, 1990, p 142). For the subject to be a pre-given point of departure of politics simply defers the question of politics regulating the subject itself. Furthermore, Butler suggests that fears surrounding the loss of ale taken-for-granted subject should be put into context where political impasse would be inevitable if metanarratives designed to establish women's very subordination are legitimated by keeping them in place. In 
recovering the subject together with poststructural and psychoanalytical insights. Butler's work upon the performativity and parody of gender is central.

Like Butler. Alcoff (1988) aims to transcend the inevitable impasse of essentialist and constructionist standpoints and advocates an 'alternative theory of the subject' drawing upon Teresa de Lauretis' work on subjectivity. Alcoff illustrates how de Lauretis avoids assuming an essential characterisation of subjectivity in not employing pre-given biological or pyschological features, and also resists relativism by basing her conception upon real practices and events. A concentration upon concrete habits and practices counterposes the hegemonic importance of language implied in poststructuralist discourse. De Lauretis' suggests that what one perceives and understands as subjectivity is constructed through a process of continual renewal based upon interaction with the world. Therefore. Alcoff reflects that subjectivity is neither pre-given or produced by purely external causes, but is produced in one's engagement and relationship with the discursive practices that lend significance to events in the world.

Identity is regarded as constituted in a historical process of consciousness where personal interpretations, reconstructions, political commitment and struggle, related to dominant social discourse and practice, never become fixed (de Lauretis, 1986). De Lauretis' uses the term 'experience' to define this process of subjective formation: however, Alcoff recognises the dangers of articulating a knowable 'female' subjectivity clearly distinct from 'male' subjectivity and offers a new formulation which enables the concept of experience to be reconfigured. Experience becomes seen as a position constituted by "a complex of habits resulting from the semiotic interaction of the "outer world' and 'inner world', the continuous engagement of a self or subject in social reality" (Alcoff, 1988, p424) Advocating a 'positional' definition, such as man and woman, reflects both the fluidity and non-fixity which continually redefine their respective positions from which values are interpreted and constructed, and provides a political base which does not fall into essentialism. Such a conceptualisation enables the recognition of a specificity to feminist theory in being a "political, theoretical, self-analysing practice by which the 
relations of the subject in social reality can be rearticulated from the historical experience of women" (Alcoff, 1988. p424).

Young (1994) draws upon Jean Paul Sartre's conception of seriolity to enable the articulation of women as a social collective in answer to poststructural deconstruction of the subject. It is suggested that seriality designates a certain level of social existence and relation to others witere routine and habitual action are rule-bound and socially structured (compare here Butler's regulatory practices, see above). Individuals in a series pursue individual ends, but given their interaction with enabling and constraining structures of the material environment, represent an unorganised collective experience. As such, serial collectivity is not coterminous with membership in a group which is distinguished as recognising mutual identification focused upon a common project. Therefore, the series 'women' refers to a structural relation constituted historically in a continually changing material enivronment. Young suggests that the body as a site of constitution is significant, not as a physical entity but in its social meaning as inscribed by dominant discourse and as the product of past practices. The body is seen as a 'practicoinert object (that which both enables and constrains action) where both actions directed toward it and emanating from it reflect understood meanings and possibilities. For example, language and gestures and rituals of inclusion/exclusion of people in activities reproduce those divisions by atiracting or repelling people from those particular activities. Whilst such structures enable and constrain thought and action, it is important to note that they do not define it. In considering the sexual division of labour, Young suggests that individuals do pursue their own ends but the division of labour both affords possibilities to gain a form of living as well as constraining possibilities by placing restrictions on particular actions. As such, 'men' and 'women' can each be recognised as a serial collectivity. The distinction between defining groups and series is especially Important in providing a basis for feminist theory and practice. Feminists, Young argues. represent groups defined by their mutual identification and collective project, which reflect upon the serialised experience of gender: 
Feminist groups take something about women's condition as the explicit aim of their actions, and thus feminist groups at least implicitly refer to the series of women that lies beyond the group.

(Young, 1994, p737)

In proposing an anti-essentialist approach for a feminist politics, Mouffe (1992) discusses the potential for collectivity based upon recognising the double movement of identity. This double movement (based on Lacanian psychoanalytic theory) suggests that on the one hand deconstructive tendencies prevent the fixation of a set of positions around pre-defined categories or points, whilst on the other hand an opposite movement of partial and temporary fixations upon nodal points takes place limiting the fluidity of those positions. The social agent becomes seen as the articulation of an ensemble of subject positions corresponding to the multiplicity of social relations in which it is inscribed. This multiplicity is constructed through specific discourses which have no necessary and only contingent forms of articulation. As a result, there are no grounds upon which a specific subject position should be pertinent in all social relations. For example, being a woman does not dictate one's experience and interaction in every particular situation. As a result, no social identity can be regarded as permanently acquired, however, one can retain the notions 'men' and 'women' since they reflect partial fixacion or congealing of identities through the creation of nodal points.

Mouffe advocates a feminist politics that constructs a new conception of 'citizenship' which recognises both the specificity of womanhood and the cominon humanity of men and women:

citizenship is not a dominant identity that overrides all others, instead it is an articulating principle that affects the different subject positions of the social agent while allowing for a plurality of specific allegiances and for the respect of individual liberty. (Mouffe, 1992, p382)

The aim is to construct 'radical democratic citizenship' as a collective identity articulated through the process of 'equivalence'. Drawing upon her work with Laclau, Mouffe argues for the need to establish a 'chain of equivalence' among different democratic struggles (women, blacks, workers, gays) so as to provide an equivalent articulation between their more specific demands against hegemonic structures (Laclau \& Mouffe, 1985). Through this construction, the aim is to create the conditions required to establish new forms of 
social relations articulated through egalitarian practices and institutions. Feminist politics, therefore, should not be regarded as a separatist politics pursuant of the interests of women, but recognised in its pursuit of feminist goals and aims in the wider articulation of democratic citizenship. Feminist aims should be about "equality for women. not women as essence/identity but rather as a struggle against the multiple forms in which the category 'woman' is constructed in subordination"(Mouffe, 1992. p382).

the constituted subject: fixity and political commitment

even admitting the considerable age of the crisis, I still don't understand what the hell it means. If I cross the street on a red light, the cop blows his whistle and fines me (not someone else). How can this happen if the idea of the subject is in a state of crisis? (Eco, 1986, p 127)

The recognition of difference has initiated considerable debate within feminist theory and practice. Initially this recognition exposed the differences between men's and wornen's experiences and lead to a claim of separateness, the demand for voice and authenticity, and the encouraging of identity based politics. Yet, paradoxically, a feminist politics based upon identity and self-assertion has appropriated and developed theories that have undermined the very notion of a secure identity. This has been clearly illustrated by the more fragmentary layers of difference representing marginalised groups and the implications of poststructuralist deconstruction. Indeed, as Suzanne Moore (1988) contends, the explosion of difference leads to indifference and a utopian vision where oppositions and boundaries no longer exist. However, as illustrated by theoretical interactions between feminism and poststructuralism above, there is a potential way forward where a consideration of the subject and experience can offer some import. Although each writer dric vs upon a variety of schools of thought (some heavily influenced by psychoanalysis, others social-democratic frameworks), common themes are articulated. Most significantly the subject is neither simply an essence nor a social construction, but reflects the site of a continual process of constitution between what may be regarded as the subject's 'inner' and 'outer' worlds. For example, Butler's 
constituted subject represents the site of a contınual signifying process where over time gender practices may congeal to produce the appearance of substance

Whilst Ferguson (1993) argues that feminists must accept the contradiction and tension between articulating 'women's experience' and deconstructing this presumed commonality. Gibson-Graham (1994) suggests that the act of deconstructing is as much a political intervention in changing power relations as is identity-based political organisation. Feminist theory and other political standpoints establish the potential nodes around which the fluid identities of the deconstructed subject may coalesce and congeal. On this basis, there is no pre-given assumption to women's collectivity on the basis of gender, whether in Young's series, Alcoffs experience, or Mouffe's radical democratic citizenship. Rather, the subject becomes constituted in a historical process of consciousness related to dominant social discourses and practices. Significations and performances are continually questioned and identity reflects a site of contestation which can never be theoretically fixed (Butler. 1990). Yet regulatory practices and the operations of power within dominant discourse and practice enact a "congealing of stylisation where the effects of such processes may be experienced and re-experienced by the constituted subject. A subject's experience is not a pre-given formality inscribed according to a fixed identity, and politics based upon such a premise is inevitably problematic. However, one's subject position influences one's entrèe into social interactions and the ways one can speak, listen and be heard (Gibson-Graham, 1994). A political position should reflect a partial fixity based upon one's experience as a constituted subject and upon a commitment articulated by that experience. The notion of experience and its basis for theoretical practice needs to be continually called into question, and most crucially, as Seidman argues:

In framing identity as a social positioning we need to avoid assuming tha .ll individuals who share a social location by virtue of their gender or sexual orientation share a common or identical history or social experience. (Seidman, 1993, pl36)

I believe that the constituted subject offers a basis for social research away from a preoccupation with the politics of representation. Although agreeing with Kobayashi \& 
Peake (1994) that essentialism should be continually resisted even at the expense of never 'finding the answer', in advocating a social constructionist standpoint, I accept that the negative aspects of essentialism do not disappear. Therefore, as Fuss (1989) contends, the risk of essence needs to be taken such that one is always aware of its presence whether in essentialist or social constructionist frameworks. The dualism established between nature (essence) and culture (construction) is inadequate, and should be considered as a dialectical relation. Importantly, a position which advocates the constituted subject destabilises the sex/gender dualism which has fixed and normalised :hose very terms which need to be called into question. In resisting the a priori nature of women's (and men's) experience, feminist theorists have problematised the over-determined need to discover and define the 'feminine' as a basis for feminist practice. Although the fluidity of the subject and the problematic nature of categories have been illustrated, it is advocated, that the categories 'men' and 'women' can be redeployed providing that the assumptions upon which they are based are continually called into question. As such, the categories represent a partial and localised fixing which are continually being reconstituted. This standpoint should not and does not suppress the recognition of difference between different women and men. As Hayes concludes reflecting upon Queer Culture:

Gender jumping takes its toll. I want to believe that there are some fixed points, that I am a woman, regardless of what I do, because I was born that way and I don't wish to change. I become certain that most people need some certainty and that this is not a failing. I wane my gut feelings (fear?) to be true. (Hayes, 1994, p15)

\section{endnotes}

I In as much as they should be recognised as practises rather than grand theories. such blurring of interpretation is understandable. Where particular authors are cited, the terms that they identify shall be recognised and this will inevitably appear contradictory at times with other authors.

2 The 'postmodern' turn has attracted considerable interest in geography, notably Harvey's The Condicion of Postmodernity (1989). Soja's Postmodern Geognphies (1989). and more recently (and regarded by some as a response to Harvey and Sopa). Gregory's Geopraphical Imaginations (1994). Equally these exts have met with mixed reviews. which shall be discussed in Chapter three. Although I find postmodernism insightful, I can not help finding mysell in agreement with a recent advertisement for Octopus Books, here in Ottawa, which discribes postmodernism thus. "post-modern - usually associated with concepts that are obscurc, overtly somplex and pretentious. Often uttered at graduate student get-togethers. intellectual gitticrings and artsy cales". 
3 Along with Derrida, Lacan and Foucault, other influential french poststructural theonsts include Baudrillard, Deleuze. de Certeau and Barthes. Probyn (1993) sugsests that Quebecois theorists have an appropriate encompassing term for these men: 'les boys".

It is not my aim within the context of this thesis to explore in more deall the debates within psychoanalytic discourse: although I acknowledge that insights into problematisation of the subject have bargely emerged from psychoanalysis. I remain a little more sceptical concerning the explanations and reconstructions offered.

5 Jung is regarded as a dissendent from classical Freudianism. He argued that an unconscious personality develops as a negative of the socially acceptable one. For men. a strong authoritative masculine persona is based on the repression of vulnerability and dependency. The subsequent balancing act between these two facts of man's sexual identity, and their incapable demands, creates tensions and contradictions that threaten the appearance of masculinity's apparent seamless quality. There is a repression of emotion which can not be expressed in social practice, and this repression exists in a continual state of tension (adapted from Moore, S. in Male Order (1988)).

6 In 1994, the British group blur (appropriately named!) released their third album. Parklife, on which is found the very successful "Girfs and Boys". The song could be read as a statement on the contestation of gender identities and sexuality. The 'queering' represented by the lyrics is further compounded in a remixed version by another British group. The Pet Shop Boys. The music direction of blur has been the focus of interest in media circles, and particularly its transition from a bate 'Manchester' sound (associated with groups such as the Happy Mondays. New Order and the Stone Roses) on Leisure (1991) to a distmct intrepretation of everyday life and London culture through Modem Life is Rubbish (1993) to Parklife (1994). Also of interest is blur's attraction to both hetero-and homo- sexual consumers in terms of the images portrayed.

7 A number of famous celebraties have been outed. Both Cindy Crawlord and Richard Gere were targets, as were John Travolta and Jodie Foster. The poster campaign to 'out' Foster showed her picture and the inscription "Actress. Yaley, Dyke".

Bowever, the existence of 'transgendered' subjects who have undergone a sex-change furcher complicates this discussion. 


\section{Chapter three: Men \& Feminism}

\section{introduction}

Feminist terrorism is a mirror image of machismo. Unregeneratively separatist - men are the problem, so how could they possibly be part of the solution? - it offers the vicarious satisfactions of retaliation and reprisal in a war of the sexes for which the only acceptable end is unconditional surrender of all power to women. (Ruthven. 1990, p10)

Is male feminism a form of critical cross-dressing. a fashion risk of the 1980s that is both radical chic and power play. Or is it the result of a genuine shift in critical, cultural and sexual paradigms, a break out of the labyrinth of critical theory! (Showalter, 1987, p 120)

The engagement between men and feminism has initiated considerable debate which has often been characterised by a certain degree of understandable scepticism. The position of men would appear to be held in an irresolvable tension between, on the one hand, a criticisr of a lack of recognition and incorperation of feminist work in their studies and, on the other hand, where men do utilise feminist frameworks, a concern that such engagement is inevitably characterised by appropriation and misrepresentation. If one can meaningfully determine a category 'men' as distinct from the category 'women', and this distinction remains central in defining a feminist politics, then men's involvement is necessarily problematic. Since feminism can not be regarded as a single theoretical viewpoint, different positions within feminism ensure that women's relations to a feminist practice take on a variety of forms. When rien's interest is incorporated into this framework, increasingly complex political questions inevitably come to be asked. In this chapter I aim to illustrate the debates and tensions that surround questions as to whether men should, and how they may, engage with ferminist theory and practice. Although I share concerns of a number of feminists regarding the men-in-feminism debate, I argue that many of the difficulties observed reflect inappropriate readings and interpretations of feminism on the part of male practitioners which, once recognised, might be more resolvable than they would initially appear. 
In the study of men and masculinities, the centrality of feminist theory and practice to this task is widely recognised. As Brittan (1989) suggests, a consideration of masculinity as a topic was essentially non-existent until feminism illustrated the gendered assumptions of Western knowledge construction. Theoretical frameworks 'do not grow on trees' (Connell, 1987); it would be problematic not to acknowiedge the indebtedness of emerging studies in masculinities to questions made possible by feminist enquiry. Here, the issues of concern appear to have shifted: male theorists are not wishing to talk about and represent women as objects, but engage with feminist frameworks in gendered research. The result is sometimes to regard feminism as simply another theoretical framework to utilise in the name of critical research. Feminist theorists' fears of misrepresentation, universalisation and objectification are justifiable concerns in this regard. Clearly the necessity of engaging with feminism, yet the apparent inevitobility of appropriating the discursive space feminist practice affords women can not be easily resolved. Is it sufficient to acknowledge the contradiction through a prefixation such as 'pro-feminist', or 'male feminist' or do such terms simply accentuate tensions?

In focusing the primary issues raised in this chapter, it would be inappropriate to discuss tile influence of feminist theories upon the study of men and masculinities without recognising the wider political and practical implications of feminism and the women's movement upon men's lives. The link between theory and practice is an essential attribute of feminist frameworks reflecting that feminism can not simply be regarded as one of a number of disposable theoretical standpoints. Clearly, the ability of men to effectively critique themselves (the oppressor being destabilised by the oppressor himself) and display a political commitment to removing the social structures, relations and discourses which have favoured themselves, introduces further contention and debate. However, I argue that a recognition of the dialectical nature between theory and practice enables a framework for studying men and masculinities that is both beneficial and necessary in understanding gender relations. 


\section{men \& feminist theory}

"there ore those and there ore such os those"1

In discussing men's relation to feminism, Jardine (1987) identifies three groups of male critics that may be observed in academic circles. Although her reflections are based upon her experience in Literary Studies, comparisons with the Social Sciences in general are apparent. The first group she recognises is the silent majority; those who neither read nor have taken into account any of the insights afforded by feminist research in their work, despite some of these theorists being considered the most eminent and radical amongst contemporary thinkers. The second group is composed of those who move in and out of feminism without necessarily changing the overall structure of their research objectives or its outcomes. Jardine suggests that critics in this category may well be the most dangerous in terms of adopting inappropriate and damaging discursive strategies in their work. Already writing from positions of authority, these male theorists may compete to provide an authoritative voice on women. In their theoretical analyses, these critics who would appear sympathetic to feminist frameworks rationalise and hierarchically evaluate women's work through a process of 'divide and conquer' and from their authoritative standpoints judge the relative merits of feminist work. The third group recognised by jardine are those men who, she suggests, are "really trying. really reading and changing" (Jardine, 1987, p55). This recognition of the intellectual claims of feminism by male theorists is. Showalter argues, a phenomenon which women see as both gratifying and unsettling.

Smith (1987) believes that a question which needs to be asked by and of men interested in feminism is whether their involvement can be justified. Is it of any political use to feminism? Furthermore, is their engagement actually wanted or needed by the feminist project? Smith suggests that such questions, in any context, of who is allowed to say or do what, to whom and about whom, is ultimately a legal question. Such concerns can only be raised where a discourse, in this case feminism, is framing or has framed a mode of legislation through which an outside and inside come to be determined, and actual and potential transgressors can be named. It is important, Smith 
argues, that a labelled transgressor (a man in the case of feminist discourse!) needs to be aware not only of the form of punishment, but also the reason for the law's existence. Nelson (1987) reflects that as a discourse, feminism has no special need for male practitioners. Although at specific moments, feminism may benefit from the advocacy and alliance of men, this by no means necessitates men's political cooperation in the feminist movement.

Whilst Harding acknowledges the need to express caution, she argues that men can not be excluded from feminist theory and practice suggesting that "the designation 'feminist' can apply to men who satisfy whatever demands women must satisfy to earn the label" (Harding, 1986, p12). She recognises that men have made important contributions to the history of feminist thought and further illustrates how other movements have benefitted from the involvement and contributions by non-members of the oppressed group (for example, Marx and Engels in the proletarian struggle). Kremer (1990) argues that Harding's position is dependent upon the assumption that men have the ability to satisfy feminist standards and this viewpoint is something she would question. The position of men in a male-dominated culture generates numerous contradictions and tensions which make it impossible for men to meet such standards. Kremer further suggests that those men who were genuinely supportive, those 'men of conscience', would leave the discursive spaces of feminism to women; spaces which are both integral and necessary to feminist theory and practice. It is stated that:

In a global culture suffused with the ideological imperatives of women's male identification, passivity, acceptance, weakness and self-destruction, these new female spaces and meanings and their recognition are hard won. If men, man, male, become part of the meanings of feminist and feminism, these hard won alternatives and their vital spaces and meanings will be lost to women, the androgynisation of feminism will render it neuter. (Kremer, 1990, p467)

Kremer's forceful standpoint draws upon what she refers to as the 'realities of the sex order' to advocate the exclusion of men from feminist research. Since feminism has increasingly advocated the importance of women's self-definition and self-determination. Kremer believes that the involvement of men would be at odds with the production of such knowledge. Experience is elemental, both in every day life and through active 
participation in feminist projects such as helping staff rape-crisis centres or women's shelters, and is simply not available to men.

Although the majority of feminist responses to men's involvement have not expressed the irresolvability of the situation in Kremer's terms, concern is commonly expressed regarding the potential for men to understand the wider context of a feminist project beyond its theoretical insights. In wishing to understand the position of men visa-vis feminism, it is argued that feminist theory is objectified by male theorists and characterised as something 'up for grabs'. Probyn (1993) considers the way in which poststructuralism has encouraged a 'da-fort' or 'now you see it, now you don't' use of feminism, where male theorists take up certain aspects while leaving others ignored. Commenting upon much of the work by 'male feminists', jardine notes that "...these few men, our allies, have learned their lessons well. The actual content of their writing is rarely incorrect per se. It is almost as if they have learned a new vocabulary perfectly. but have not paid enough attention to syntax or intonation" (Jardine, 1987, p55). Braidotti's assessment adds to this concern: "blinded by what they have learned to recognise as theory, they bulldoze their way through feminisın ... They are walking all over us ... They are the best friends we[women]'ve got and they are not really what we had hoped for" (Braidotti, 1987. p234-235). Showalter (1987) reflects these anxieties where men borrow the language of feminist criticism without exploring the masculinist bias of their understanding so that a form of phallic feminism is inevitable. As such, she argues, many of the anxieties expressed by men concerning their relation to feminism represent the need to produce a feminism that competes with women instead of utilising such frameworks to dismantle patriarchal structures.

Jardine questions whether the appropriation of the feminist struggle is being experienced: do men, continually trying to justify and rationalise their own disputed positions, aim to instill order and provide a sophistication to produce a feminism which allows them to understand their own relations to such frameworks? Through debating how men can meet the criteria of feminism, and with men arguing among themselves who is the most feminist. Heath argues that men inevitably introduce 'stakes' into feminist discourses which are hierarchically ordered, simplified and objectified. He 
illustrates the problematic demands by men who need to understand their position in relation to feminism in order to rationalise and construct feminism as a usable approach. Heath suggests that men need to understand that feminism is not simply another discourse, "not another voice to be added, an approach to be remembered and catered for, but that it radically affects and shifts everything and that that radical shift is not negotiable" (Heath, 1987, pl).

There is a fear amongst men that despite offering credentials that they feel exhibit a high level of feminist commitment, they remain in an impossible relation which maintains their exclusion. As Heath (ibid.) comments: "no matter how 'sincere", 'sympathetic' or whatever, we are always also in a male position which brings with it all the implications of domination and appropriation, everything precisely that is being challenged, that has to be altered." Heath argues that the relation between theoryl discourse and practice is politically negotiable by women in that the reality of their positions reflects oppression, inequality and sexism. In contrast, men are caught in both a position and discourse which is a result of the domination of social maleness. It is therefore regarded as necessary to accept that men are not and can not be where women are in relation to feminism: the 'negotiation' which enables women to identify as feminist is blocked to men.

A question frequently articulated asks why are men now indicating an interest in feminist discourses? Numerous suggestions may be offered as possible motivations behind the apparent jumping of men onto the feminist bandwagon at a time when it is experiencing a certain degree of success in the academy. Showalter contends that this movement on the part of male theorists may be motivated by the recognition that feminist criticism offers a "mixture of theoretical sophistication and political engagement which they have been searching for in their own critical work" (Showalter. 1987. p 1 17). Nelson (1987) argues that if men take on feminist knowledge, they will do so not merely in intellectual admiration, but also because it is in their best interest. This may have several dimensions: acknowledging that feminist discourses represent some of the most intellectually challenging areas of the discipline in question; recognising that feminism offers the only practical route to one's own growth personally and 
academically, and, accepting that feminism offers the only effective historical discourse available to reflect upon the critique of men's enterprises. Heath observes that male theorists have exhibited an increasing pre-occupation with acting, speaking and writing 'feminist' as part of a wider political correctness. Through such correctness, authority continues to be redefined but nevertheless maintained. Also questioning the intentions of 'straight, white male intellectuals', Spivak (1982) reflects that unlike issues of race and class where academic people are unlikely to be directly challenged, the women's struggle provides a situation that men can support 'from the inside.?'

More critically, a number of feminist theorists suggest that men's engagement with poststructural discourses has led to a problematic intertwining between the 'feminine' and feminism which reffects men's misinterpretation of feminist theory and practice (Parmar, 1990; Probyn, 1993). Instead of engaging with feminist critiques, male theorises influenced by poststructuralism have invoked and appropriated the feminine subject in decentring themselves.

drog queens, cross-dressers and the pimps of postmodemism

these theoretical drag queens don the trappings of femininity for a night on the town without so much as a glance back at the women whose clothes they have stolen. (Moore. 1988, p185)

Heath (1987) suggests that men's relation to feminism is always potentially a pornographic effect, where the images of 'women' are constructed and represented in a particular way, as passive, feminine, the exact and separate other half, the opposite sex that constructions of masculinity require. Poststructural deconstruction, informed by psychoanalytic insights, has exposed the unity of the self in Enlightenment thought to be made possible only by the suppression of internal difference and the mapping of those contradictions on the 'other'. Therefore, 'woman' and 'feminine' are created as a representation of that which 'man' and 'masculinity' are not, or more accurately, the representation of characteristics suppressed in the creation of a hegemonic masculinity. Lacanian psychoanalytic theory emphasises the centrality of the phallus as the chief signifier of difference in cultures, and it is argued that humans develop a gender position 
tased upon presence or absence around this signifier. If the phallus is the key signifier then it follows that masculinity is set up as the norm and femininity can only exist as absence, as what masculinity is not. Since femininity represents a 'terrain of lack' or marginality, this space is seen to be open to men as well as women.

In response to the destablising of male authority, much poststructuralist discourse has invoked the desire to rediscover the feminine in its writing, as for example in Derrida's (1987) discussion concerning the desire to read and write as a woman, Barthes' (1979) valorisation of feminine pleasure and Deleuze \& Guattari's (1983) use of the metaphor 'becoming woman'. Recognising the emphasis placed upon the significance of the body upon one's referential position. Deleuze \& Guattari's metaphor suggests the necessity for theorists to enter a feminine subjectivity "in order to have access to the joissance of the maternal body" (quoted by Moore, 1988, p178). The 'becoming woman' of the male subject is an osmosis into the space of the 'other' defined as woman. As boundaries are permeated the identity of woman is lost. However, through the dissolution of all boundaries, the female subject formally identified as 'woman' is able to reterritorialise that which was once identified 'man'. Moore (1988) suggests that such a conceptualisation is comparable to a psychotic schizophrenia which, once again, expresses the experiences of the decentred male subject and the loss of authority. As Braidotti (1987, p237) remarks, one has to question "what is being exorcised by male thinkers in the act of their becoming "feminised'?" Heath argues that as men we may be able to learn to read and write as women, indeed to learn to read and write as feminists, yet this can not lead to an understanding of the motivations behind such work. Therefore although men can know feminism, they can not know that which fuels it (Probyn, 1993). As Jardine (1985) reflects: "it is the inseription of struggle, even of pain, that most distinctively marks feminist texts, and is most notably absent from texts that are not truely feminist."

The SCUM Manifesto contends that: "being an incomplete female, the male spends his life attempting to complete himself, become female" (Solonas, 1968, p6). Reflecting this, Moore (1988) argues that men's interest in feminism represents the perpetual desire to recover a vision of the feminine which men themselves have created. 
A form of 'gender tourism' holds the prospect of finding the perfect union whereby male theorists are able to vacation in the world of the other, in this case femininity, and bring home souvis.irs to remind them of their travels. The 'seduction of feminism', as Gallop (1987) appropriately remarks, would seem to be irresistible for male theorists.

Probyn (1993) argues that much of the problematic relationship between men and feminism is reflective of the intertwining of the 'feminine' and the 'feminist' apparent in their work. As a theoretical project, feminism comes to be depicted in the all too familiar attributes of the feminine. These particular constructions of the feminine, and a conflation with feminism, ensures that male theorists make their own positions problematic. Probyn considers the way in which feminism becomes turned into the feminine at the expense of ignoring feminist theorisations of experience. This occurs where men translate their desire to be feminist into the need to read and write as women, and therefore to search for the 'feminine'. The influence of poststructural discourses and their use of the imaginary and the feminine (and an association between the two) is clear in this regard. As Probyn states:

The figure of the feminine silences women as it gives men even more to say and a comfortable place from which to speak. Thus she stands as a fixed position against which a decentred self can be constructed, or she gives other male theorists the excuse to discourse at length on the difficulty of feminism. (Probyn, 1993, p51)

As discus,ed in Chopter two, the construction of fixed positions locks feminine and masculine ontological categories into a binary logic which does not challenge or undermine the grounds on which men have historically spoken. Like Freud's denouncement of the categories masculine and feminine yet his continual referral to them, male theorists' conflation of the feminine and the feminist ensures that feminism is lost to them because of how they have constructed it. By not recognising the phallocentric bias of their positions, the multiple and fluctuating experiences of being gendered - the dynamic role of experience central to feminism - is lost to men. The desire to search for the feminine imaginary leads to a misunderstanding of the central foundations of feminism, notably the experiences of 'real' women and the importance of political commitment to bring about social change. The theoretical distance of 
poststructuralist discourses from social reality makes its relation to feminism, and other social movements, understandably problematic.

A common reflection upon the insights afforded by postmodernism is that they have ignored, negated or repressed the influence of feminist discourses despite those voices being both present and insistent (Owens, 1987; Parmar, 1990; Probyn, 1993). Indeed, whilst contemporary feminism is repeatedly recognised as a central feature of postmodernism, the contribution of women to the debate continues to be largely overlooked. It is instead substituted by the invocation of the imaginary feminine. Therefore rather than an active engagement with feminism. "the isolated feminine becomes that which can allow for the masculine decentred and postmodern self" (Probyn, 1993, p46). It is my contention that it is this process - the repression of feminism, desire for the imaginary feminine, and a misrepresentative conflation of the two - which may help to explain partially the concerns expressed in feminist critiques of Harvey's and Soja's work on postmodernism within geography. ${ }^{3}$

The foundationalist explanations to the postmodern turn afforded by Harvey (1989) in The Condition of Postmodernity are exposed by both Deutsche (1991) and Massey (1991) as dependent upon the refusal and repression of feminist theories of representation. Through this process. Deutsche argues that Harvey necessarily homogenises quite diverse positions on feminism and postmodernism in order to reconcile them with his $\mathrm{c}$. n ohjectives in providing totalising explanations. An unacknowledged masculinist gaze is reflected in much of his discussion, for example of the film Blade Runner or the photographic worl: of Cindy Sherman, and is clearly exposed by his critics. In the case of Sherman's work, Harvey misunderstands the intentions of her self-portrait photographs as a result of parallel axes of thought in which he both refuses feminism and invokes his own 'imaginary feminine'. In these selfportraits, Sherman provides a plethora of different feminine images, all of herself yet never the same. As a result, the instability of social constructions of gender are revealed: something that is lost to Harvey who, Massey suggests, illustrates the specific masculine desire to fix the woman in a stable and stabilising identity. Sherman succeeds in disrupting the pleasures of the 'patriarchal visual field', and unsettles the masculinist gaze 
of her male critic, in this case. Harvey. As Deutsctie (1991, p29) contends: "What Harvey can not locate in Sherman's photographs and, more broadly, in postmodern culture what he takes them to task for concealing - is not the real woman but another fantasy - a preexisting and directly accessible social reality behind the image."

mediotion?

The cencerns expressed relating to men's engagement with feminism are clearly observable in many men's contributi uns to academic discourses in this context. In part, 1 believe that the problematic conflation between the feminist and the feminine has ensured that male theorists have cor "ructed their own boundaries and created their own impossible relations with feminism. However, this intertwining has not been a universal problem in the work of all male theorists. If such misrepresentation is recognised, then a workable relation is possible beyond the seeming impasse. It is particularly important to note that many of these theoretically-bosed exchanges have taken place in literary disciplines or in academic fields where the relation between theory and practice is inevitably less well developed than is (at least, should be) the case in the Social Sciences.

Much of the debate outlined above was initiated by Jardine \& Smith's (1987) text Men in Feminism, which commeritators have argued defines and simplifies the issue in such terms as to preclude any degree of resolution (Porter, 1992; Boone, 1992). Boone, for example, reflects that the structure of the text isturbingly reproduces a two-sided opposition, where men who try to stake some claim to feminism, articulated around uncomfortable apologies and contemplations of the impossibility of their positions, are responded to by feminists who reprimand them for their rather tired imitation of feminist theory and all too familiar arguments which ensure the irresolvability of the debate. As Boone suggests, the text effectively represents men as a unified body visually and temporarily set against women as a unified body such that "potential dialogue became confrontation between two sides aligned by gender - doomed to reinforce the stereotypes of both sexes" (Boone, 1992, p20). Another similar argument is presented by Ross who argues that sexual politics is once again created in a form which reduces 
the complexities of sexual difference to an antagonistic relation between two mutually exclusive groups of people: "the initiation of men and women into sexual politics is still so hegemonically informed by this mutually exclusive division between anatomical groups" (Ross, 1987, p88).

Although he argues that men can neither be regarded as 'within' or 'without'. Porter is confident that between these poles a space does exist. He advocates the need not to foreclose the impossibility of men's relation to feminism, arguing that being 'in' feminism should not be considered the only relationship. The conjunctive 'between' prevents confusion and mutual antagonism by establishing unarticulated buffer zones rather than boundaries. Porter (1992, p5) further suggests that 'between' connotes the "space of intimacy, of dialogue, of the potentially fruitful sharing of inspiration and example". Although, the barriers of exchange between women and men cannot be removed, acknowledging the existence of a space between men and feminism destabilises the otherwise static structure of the opposition itself. A sexual politics which insists upon the rigid dichotomies denies the constant flux which is inevitable as feminisms, and men's understanding and interaction with them, evolve. As Boone suggests, male theorists need to move beyond a penitential reflection and chart a potential direction whereby the antagonisms and points of contention do not automatically bar ac:ively reassessing the issue of men and feminism.

A further criticism raised by Boone questions the centrality of male desire in feminist critiques of male theorists' intentions shaping their involvement in feminism. Although the use of the feminine by male poststructuralists should be regarded as problematic, such work should not be considered as representative of all exchanges between men and feminism. Whilst Lacanian psychoanalysis may afford convincing explanations of men's desire - that their repressed selves may be recovered through the appropriation of feminism - such explanations are dependent upon the heterosexist assumptions of that desire. As the work of Butler and Queer Theorists discussed in Chspter two illustrates, the use vi such assumptions perpetuates a masculinist discourse which feminists aim to destabilise. Not least, these generalisations made about men's 
desire to become a part of feminism neglect the observation that at present many of the men in the academy who are feminism's most supportive allies are gay.

Jardine's categorisation of men involved in feminism can also be regarded as problematic in that the categories carry with them a prescribed and hierarchical structure of correctness which fails to explore adequately the multiplicity of men's responses to feminism. Ross contends that it is more plausible to expect that older males moy fall within Jardine's categories, not in any stable fashion but rather in different categories at different times or indeed in a number of categories at any one time. However, there are men who are young enough for feminism to have been a primary component in their intellectual formation. Boone suggests that the emergence of a whole generation of men whose education has been strongly influenced by feminism does not in itself necessarily remove the problem of misrepresentation or appropriation, but rather that the relation to feminism of these younger men may be quite different than those of older 'pre-feminist' men. Whilst the latter may chose to either ignore or appropriate feminism as a usable framework, Ross contends that this is less likely in young men whose experiences of feminist theory and practice are more deeply constituted.

I suggest that a pivotal argurient is introduced here: that the significance of feminism to an increasing number of male theorists moves beyond a theoretical appropriation or the desire to rationalise and objectify those discourses. Central to this relationship is a recognition by male researchers of the importance of the praxis between theory and practice. A committed objective to practice necessitates men to illustrate a political framework to their understandings and utilisation of feminist discourse. As such, the insights afforded by poststructuralism and psychoanalysis regarding the fragmented nature of identities and the fluidity of the subject need to be put into a particular context. Exposing the universal assumptions of Enlightenment thought has enabled men to more appropriately recognise themselves as gendered (instead of representing all of humankind) and to 'embody' their speaking positions. Notions of fluidity have destabilised essentialise foundations; however, they cannot provide an adequate political structure upon which social reality can be considered. 
Without providing some points of reference, for example 'men' and 'women' as constituted subjects (discussed in Chopter two). the only logical political base provided by poststructuralist discourse is the decentring of the sibject which manages to retain the significance of white, male voices.

If one acknowledges that there is no one, and never will be a, universal totalising theory, then as researchers the frameworks which we adopt will reflect a sense of 'travelling', indicating how each of our own individual knowledges are constructed from information and experiences gathered from a plethora of contexts (Said, 1985: Clifford. 1992; Gregory, 1994). Such notions would appear to trz.. siend the dangers of essentially-bound and parochial identity politics. However, while this viewpoint may appear liberating, as a number of feminist and postcolonial writers have pointed out, a vision of travelling and freedom of movement is very much situated within the advantages of be.ng a white, middle classed male academic (hooks. 1991: Haraway. 1991). Certain passports hold greater privileges in the political map of the 1990s: if you wish to travel abroad it is better to be a Canadian rather than a Libyan. It may be argued that this is equally true in the academic world. Whilst travelling reflects a certain theoretical fluidity, any final piece of research inevitably exhibits a fixing of tensions, even if those tensions remain readily apparent in the end product.

Fixing represents in some ways a compromise: it is boch inevitable and reflective of our understanding of social structures and life, but fixing also establishes a political commitment on the part of the researcher. If indeed it is easier for white, male academics to travel between theoretical frameworks, their research must equally represent a degree of commitment to particular standpoints in order to not simply reenact the processes of imperialism, exploitation and domination. As a male researcher interested in questions of gender and particularly issues relating to men and masculinities, I understand the necessity of fixing my poststructural insights by recognising my commitment to dismantling gender inequalities, if I am not to produce a rather narcissistic reflection upon the lives of men. It does not mean that I shall agree with all standpoi..io of all feminisms; however this is true of any feminist. 
It is my contention that men's growing interest in questions of gender and feminism is understandable given the changes that have affected men's lives in recent decades. As gender is a relational structure, changes in women's lives will undoubtedly be reflected in the changing lives of men and vice versa. In the study of men and masculinities, dependence upon feminist frameworks has been readily recognised. Brittan (1989) contends that feminism and women's studies introduced the questions, provided the context and structured the frameworks of analysis which characterise the contemporary research on masculinities. Morgan further emphasises this influence:

it is feminism ... that has put the critical study of men and masculinities on to the agenda. Any attempt, therefore, on the part of men to engage in such studies must be working within, and sometimes against, this context established by women and feminism. (Morgan, 1992, p2)

Obviously, feminism does not simply provide the analytical tools for an intellectual reflection upon changing masculinities; the influence of the feminist movement has significant social and political consequences upon the way in which men live their lives. I would therefore argue that the commitment to social and political change advocated by these researchers moves beyond simply the appropriation of feminism as a theoretical framework. However it is important to recognise that the significance of the relation between theory and practice cannot transcend all difficulties associated with men's engagement with feminism. As shall be discussed in Chopter five, many of these tensions remain apparent because of the limitations imposed by existing discursive frameworks. Binary notions of gender are particularly difficult to reconceptualise whiere such frameworks and the dichotomies they define remain in place.

men \& feminist proctice

differences of opinion

One may therefore argue that the largely abstract nature of critiques of men's engagement with feminism fails to adequately recognise the commitment to political change exhibited by many men, both in academia and outside it. However, despite this observation the concerns expressed in theoretical discussions are often reproduced 
where men wish to get involved in anti-sexist activities and events. Luxton posits the question:

How can men who are committed to doing anti-sexist political work most effectively address feminist concerns and lay the groundwork necessary for solidarity and strong collaborative political organising with feminist groups? (Luxton, 1993, p349)

In debating the appropriateness of men's support, tensions arise between the merits of keeping such activities as spaces for women only and the benefits of encouraging men's attendance and statements of support at public events. Such tensions have been historically apparent At the turn of this century, men such as Richard Pankhurst and Thomas Higginson can be seen as influential in campaigning for women's rights, calling upon both women and men to support the suffrage movement in Britain and North America. The more recent growth of men's involvement in anti-sexist movements since the 1970s is considered to be partially reflective both of the 'challenges' instigated by the women's movement and the increasing voices of gay men and associated cultural politics (Seidler, 1991).

As with the difficulties of men's theoretical engagement with feminism, the response of feminists to men's invol. nent in social and political activities reflect a heterogeneity of standpoints and experiences. Different theoretical positions on ferninism have associated with them different levels of confidence that sexism is something that can be eroded and eradicated. Therefore, how one regards the fundamental reasons behind sexism may well affect the position taken regarding men's involvement in feminist action. Where women consider the structures of sexism capable of change through a recognition of its damaging nature to both men and women. then the role of men in helping its demise may be seen as beneficial. However, from ferninist standpoints where the centrality of difference between men and women is prioritised, then the position of men obviously becomes considerably more problematic. As Segal comments:

A feminism which emphasizes only the dangers to women from men, which insists on the essential differences between women's and men's inner being, between women's and men's natural urges and experience 
of the world, leaves little or no scope for transforming the relation between men and women. (Segal, 1987, p37)

This variery of viewpoints towards male involvement reflects the contentions surrounding the use of the categories 'men' and 'women' as discussed in Chapter two. Advocating that "woman' is a simultaneous foundation of and an irritant to feminism" (Riley, 1988. p 17), Luxton argues that the concept of 'men' acts in a similar way. She suggests that although such categories are employed, feminists consistently struggle to develop a politics which challenges the systems of male oppression and exposes women's oppression, while both recognising the differences among men (they can not be regarded as a universalised, privileged group) and acknowledging differences in the concerns and interests of various women. Although it is important to challenge the essential nature and construction of the categories 'men' and 'women', it is equally necessary to maintain and insist upon a politics 'as if they did exist' recognising the fa..t that society behaves as if they do (Riley, 1988; Segal, 1990; Luxton, 1993).

Feminist responses to the involvement of sympathetic men recognises that individual women bring to feminist politics their own personal experiences of men, both good and bad. Although many experience positive, loving relationships with men, these same women also live their daily lives exposed to sexism and the threat of sexual abuse by men. Luxton (1993) suggests that women bring these feelings into the Women's Movement, sometimes consciously, often unconsciously, and such feelings enter the dynamics of feminist pclitics. Furthermore, with feminist activists frequently being challenged by male resistance and hostility, it is understandable the feminists react with mistrust and scepticism towards men who wish to become involved and commit to ferminist politics. Luxton contends that there have been too many situations where feminists have worked with committed men only to repeatedly come up against systematic sexism that even these men are a part of. Within mixed groups, feminists have experienced how anti-sexist and well-intentioned men tend to take over leadership tasks and do so without necessarily being aware of their actions. Can a link be drawn here with the concerns expressed by feminist theorists about the rationalisation and authorisation associated with the 'feminist' work of male researchers? 
the historical tradition of 'mole feminists'

Why don't you force us to give you the vote? Why don't you scratch our eyes out? (Richard Pankhurst, quoted by Strauss, 1982, p201)4

Contemporary discussions concerning the involvement of men in women's and feminist causes should be placed in the context of a historical tradition of support from men which, albeit on a small scale, has been quite significant in improving the lives of women. Typically, accounts of male support for women's causes read as a chronicle of the biographies of its leading figures. It is important both to recognise that it was the actions of a few prominent men rather than a mass following and not to inflate the status of such figures within the feminist movement (as Morgan (1992) warns "Do not turn these men into heroes!"). The rise of "male feminism' in 19th and carly 20th century Britain shall be considered here; however, it is acknowledged that similar movements were emerging across the world, predominantly in North America and Australasia. and indeed that there were links between the struggles fought within these different countries.

In Britain, men's involvement around the turn of the century centred upon the struggle for women's suffrage, although many of its supporters had also taken part in earlier campaigns such as the Contagious Diseases Acts during the 1860s. Men's support in the Contagious Diseases campaign is considered particularly significant because it called into question a prevalent double standard of sexual morality, one which not only differentiated between men and women but also between 'respectable' and nonrespectable' women. Involvement in such campaigns advocating equality between men and women as citizens reflected the wider phenomenon of a search for a 'new humanism', influenced by the growing movements of Chartism, Socialism and Pacifism during the latter half of the 19th century (Strauss, 1982). The political medium through which men's support became articulated was the emerging Labour Party, and particularly through a number of its early leaders and influential members who were committed to women's suffrage. 
Richard Pankhurse (1838-1898). strongly influenced by the Socialist and Chartist ideals characteristic of his Manchester origins. worked initially as a lawyer and used his position to represent households headed by women trying to expos loopholes in Voting Acts which would allow women to vote. During the 1868 General Election, five thousand women registered to vote in Manchester after Pankhurst urged women householders that they did indeed have the right to vote (only, of course. to be told in court that they did not). Advocating that gender must be eliminated as a criterion upon which voting rights depended, he became appalled at the conservatism prevailing at the women's National Suffrage Society where members were willing to exclude married women from their demands. In response to this. the Women's Franchise League was formed in 1889. The strength of the mutual support between him and his wife Emily drove a passion for feminism which became their lifelong struggle. As founding members of the Labour Party, the Pankhursts made women's rights an integral component of the party platform. Their friendship with Keir Hardie, the first leader of the Labour Party, assured that the Party's campaign for women's suffrage would continue after Richard Pankhurst's death.

Feminist Labour Party leaders illustrated determination in their support for the 'Votes for Women Now !' campaign and introduced increasingly aggressive tactics in these aims. Although not a major party in the House of Commons at the turn of century, Hardie and other influential Labour leaders used the tactics of protest and direct confrontation against successive parties in power. They refused to support either opposition party (Conservative or Liberal) until their demands for women's suffrage were met; indeed more radical members demanded that the Labour Party refuse to support the Government on any issue until those demands were met. Hardie encouraged Emily Pankhurst to continue in the campaigns she and her husband had initiated, leading to the establishment of the Women's Social and Political Union (WSPU) in 1903. Although affiliated to the Labour Movement. Pankhurst sought a wider audience and appesled to the middle and upper classes in Britain for support. Frederick Lawrence and his lifelong partner Emmeline Pethick (upon marriage and hereafter known as the Pcthick-Lawrences) shared a commitment to a pursuit of the social causes 
in which they believed, and with the Lawrence family fortune, became key figures in the feminist movement. The Pethick-Lawrences' personal wealth secured bail for the release of suffragettes and financed the publication of a weekly publication Yotes for Women.

Whilst prominent members used aggressive tactics inside the House of Commons, outside Parliament male suffragists heckled and disrupted public meetings. As these men's actions became more militant, they joined women suffragettes being sent to prison and went on hunger strikes to continue their protest. The Men's League for Women's Suffrage (MLWS) was created in 1907 advocating educational rather than militant support to the feminist cause. Demonstrations were held in prominent public spaces in London where information leaflets were distributed explaining how men could help in the suffrage movement. Titles included: 'How you can help distribute handbills', 'Exhibit posters at [your] homes', and 'Assist in chalking pavements' (Strauss, 1982). The MLWS also solicited endorsements from prominent members of society in an broad range of fields, from literary and artistic, through scientific and educational to legal. religious and military. Many hundreds, including E.M. Forster, H.G. Wells and George Bernard Shaw illustrated their support through such campaigns. Another group, the Men's Political Union (MPU) was established in 1909 as the male counterpart to Emily Pankhurst's Women's Social and Political Union. The MPU clearly paralleled the goals and methods of the WSPU and this close relation is illustrated by the fact that the weekly report of the MPU was published in Votes for Women. As well as fielding members in elections to stand against candidates opposed to women's suffrage, the MPU also employed militant tactics to cause disruption at public meetings and were frequently imprisoned for doing so.

The year 1912 saw an increasing level of militancy which at times led to rioting and 'public violence'. As feminist leaders' calls for greater action were heeded, the Pethick-Lawrences and Pankhurst were imprisoned with other suffragists for inciting violence. George Lansbury (1859-1940), a strong believer in the use of these militant tactics, used his position in Parliament to demand the release of men and women held in prison. Prime Minister Asquith's response, that they were free to go 'the moment they 
abandon their militancy', was met with a heated confrontation and Lansbury's dramatic resignation. Frederick Pethick-Lawrence used his trial as a platform to express support for the suffrage movement and called upon the common cause that should exist between men and women, quoted at length here:

I am a man, and I canrot take part in this women's agitation myself, because I am a man: but $l$ intend ... to stand by the women who are fighting in this agitation ... I think in the first place it is not merely a woman's battle, it is not merely a battle for women - 1 think it is a battle for the good of the people of this country, a battle waged by one half of the community whose deeds are valuable to the other part of the country. And when I see other men standing out against this agitation, then I am more determined to stand in with it; and I feel this further, that but for some of those men who have stood in with this agitation there might be a danger of this agitation becoming a sex war. I think a battle of women against men is an ugly thing - a thing to be deplored, and I say it is because of the men who have shared in the battle that a sex war has been prevented. (quoted by Strauss, 1982, p217-218)

The activities of the suffragettes and their male supporters were disrupted by the First World War, but continued until women's suffrage was partially achieved in 1918 and full suffrage installed in 1928. Whilst reflecting upon the importance of men such as Pankhurst and Pethick-Lawrence to the suffrage movement, Morgan makes the obvious point that in contemporary terms there are limitations to the standpoints and visions of these persons, most notable being the well defined and clear understanding advocated at all times concerning sexual difference: there were strict beliefs in what it 'meant' to be a woman or a man. However, a number of concerns resonate more current debates. Firstly, prominent male feminists often accept acknowledgement for the authorship of texts which in fact primarily represent the thoughts and ideas of women. Secondly, although expressing support for the feminist cause may have induced financial and political hardship, this has to be put into context given the sacrifices made by women to the cause. Thirdly, men speaking on such issues agitated and discomforted people which made them more willing to listen, whilst women's voices continued to be regarded as unimportant (after all, they did not vote). Finally, one may question whether the support for and influence of feminism extended from the public to the personal lives of these 
men. There is much evidence to suggest that it did to a large extent; however, it is fair to expect that the relations between public and private were variable.

the rise of anti-sexist and profeminist men

The historical involvement of men in feminist struggles provides a context in which to consider more recent support and discussion. Connell (1993) suggests that gay men and an increasing number of heterosexual men provided support for feminism and the women's movernent during the late 1960s and early 1970s. The development of consciousness raising groups, describing themselves as 'anti-sexist' and 'profeminist', recognised and endorsed the aims of feminist movements and explored the arguments and concerns about their place as men in feminist struggles. Clatterburgh (1990) notes that the profeminist movement reflected the diversity of the Women's movement it supported, and that a blurred division could be drawn between those supportive of radical ferminism, for whom the term 'antisexist' was reserved, and those more accepting of liberal forms of struggle, referred to as 'liberationists'. It is commonly argued that feminism had a profound impact on the lives of these men, often reflecting the direct influence of women with whom they were intimate (Connell, 1993a; Rutherford, 1992; seidler, 1991; Clatterburgh, 1990).

Two paths to men's gender awareness are suggested by Hearn (1992), the penitential and the petitional; however, I would argue that in many instances, these modes are intertwined in shaping men's positions towards feminist politics. Penitential means include the recognition of the wrongs men have done to women and the desire to make amends through the participation in profeminist men's groups designed to challenge men's practices in a patriarchal society. Many radical profeminists have questioned the role of men and denigrated masculinity in order to exhibit their feminist credentials and suggest some degree of separation from the oppressor group. Stoltenburg, author of texts such as Refusing to be a Man (1990) and The End of Manhood (1994) provides a rather disturbing exampl. "I had always felt irremediably different - even when no one else noticed, I knew; I knew I wasn't really one of them [men]. Radical feminism helped me imagine a gender-just future" (Stoltenburg, 1990, 
p188). Clatterburgh reflects that participants in consciousness-raising groups often questioned their own motives and became suspicious that groups comprised exclusively of men mighe become "small patriarchal structures in which men would support one another in their misogyny" (Clatterburgh, 1990. p46) instead of providing contexts by which male power and privilege could be unlearned.

The second path to male gender awareness, the petitional method, relates to men's realisation of the damage done to themselves as well as to women in society: that the pressures of patriarchy disadvantage men as well as women. Initially at least. Connell (1987) suggests, this may be as some kind of backlash or response to a perceived threat from an increasing feminist voice. The recognition that not all men are beneficiaries of a patriarchal structure is a valid one: however there is a danger here of drawing a false parallel between the suffering of men and the oppression of women. Such a standpoint leads to a potential displacement of the significance of power and domination in the consideration of gender relations and argues that men are suffering too. This is often reflected by the self-help, therapeutic structure integral to many profeminist men's groups.5

Reflecting upon the formation of the Achilles' Heel Collective during the 1970s in Britain. Seidler (1991) suggests that it was the emergence of the Women's Movement and the challenges it presented which encouraged a group of left-wing men from different backgrounds to $g$ :t together in consciousness-raising groups. Achilles' Heel produced a number of publications between 1978 and 1984 as part of a project to make public the shared experiences of these groufs The importance of men's emotional explorations were recognised in the collective and at least initially such therapeutic activities absorbed the group's energies and took them away from more obviously political concerns. Politically, the collective aimed to identify the structures of patriarchal power so that men could ally with women in an anti-sexist struggle, and at the same time consider the way men related with each other and with women in everyday relationships. 
It was recognised that many men were responding to ferninism in a way that left them feeling guilty and as if the only option was to denounce masculinity itself. Achilles Heel aimed to provide a balance between anti-sexist actions and a questioning but not disowning of masculinity. As such, it was argued that anti-sexist men did have an appropriate role to play in femirisi struggles and that to isolate them, as if they were to be despised or pitied for not being 'real men', was unhelpful. Furthermore, although they engaged seriously with the issues raised by feminist theory and practice, the collective was prepared to challenge some of the generalisations that various strands of feminism made about men and masculinity. Seidler argues that this enters understandably difficult ground, but contends that in part it meant "contesting some of the images of men and masculinity as well as the assumptions that subordination and oppression mean that women are always morally virtuous and men are always wrong and bad".

Segal (1990) suggests that 20-30 anti-sexist men's groups had bean set up in Britain by the mid 1970s, the most well recognised being the Achilles Heel Collective. At the peak of interest in the early 1980s, every sizable urban area and many rural districts had a profeminist men's group; more recently, in Britain at least, the number of groups appears to have declined despite the continued interest by academics in topics related to men and masculinities. A number of researchers have been particularly influential in this regard and have initiated exciting work at a number of key institutions: Lynne Segal at Middlesex, Jeff Hearn at Bradford and David Morgan at Manchester. A number of general observations are offered by Segal (1990) regarding the composition of men's groups such as Achilles Heel Collective in both Britain and North America. Broadly, she characterises anti-sexist men as those whose personal and often public lives existed within a radical middle class culture, which permitted, if not necessarily promoted, alternative lifestyles from the defined traditional norms. The men were predominantly heterosexual and in relationships with women who recognised themselves as feminists. Through the greater opportunities offered in such circumstances, these men wei a afforded the possibility to live more collectively, to be more involved in childrearing and generally were provided with an environment more 
open to behaviour traditionally regarded as feminine As a result, there were enhanced opportunities for these men to accommodate and be more sensitive to the needs of wome.1. Although it would be problematic to characterise all profeminist men iri such terms, the predominaritly white middle-class, heterosexual composition of these early profeminist groups remaıns a defining feature of contemporary men's groups.

the conadion experience

The profeminist men's movement in Canada has iliustrated a more continued support base since the formation of a large number of local and issue based groups in the late 1970s and early 1380s. Unlike the United States, where the success of books such as Robert Bly's Iron John: A Book for Men reflects the increasing dominance of the mythopoetic and men's rights movement in men's gender-based politics, the profeminist groups in Canada have continued to be recognised as a significant voice for anti-sexist men. Many of the groups and individuals involved came together to form the Men's Network for Change (MNC) in the Spring of 1989, although links and associations have been encouraged since 1984 through annual meetings and retreats at Kingston and Grindstone Island, both in Eastern Ontario. The Network has become a coast-to-coast organisation; ho'vever its members are primarily based in the larger cities of Southern Ontario (Toronto. London, Kingston, Ottawa) and Montreal in Quebrc. The MNC aims to provide an environment which coordinates men's social activities and acts as a basis for political support around issues such as violence against women, homophobia, reproductive choice, and treatment programs for assaultive men. The men's groups here in the National Capital Region, collectively referred to as the Ottawa-Hull Men's Forum, have been particularly successful in terms or their membership and support of activities and this support base has been particularly effective in lobbying the Federal Government. For example. the Forum has made repeated demands for the equality of men and women in C.anadian society; has advoci:rej the establishment of a Men's Advisory Committee; and have illustrated their full support for governinent sponsored Women's piograms. 
Luxton (1993) suggests that 1989 was a pivotal year in Canadian gender politics. particularly for men sympathetic to feminism. The massacre of fourteen female students at the Ecole Polytechnic in Montreal, followed shortly by a number of well publicised attacks by men on women in other Canadian cities, focused the nation's attention on the devastating effects of men's violence on women. It was later disclosed that the man responsible for the Montreal shootings had made it abundantly clear in the process that a hatred for ferninists was the motivation behind his actions. Men's violence against women became an issue men could readily organise around, and the recently formed Men's Network for Change created an environment which enabled men to take a public stand against the problems of violence. At the MNC's first National Conference in October 1991, a statement was produced for circulation calling for men to display a white ribbon during the week preceding the anniversary remembrance of the Montreal massacre (31 Novemuer-5 December). The White Ribbon Campaign became the first national campaign in the world that invited men to symbolise opposition to men's violence towards women. As Ken Fisher (1994, p5) reflects: "no other week in the year raises more questions about what it means to be a man." The movement saw men campaigning alongside feminists gaining large-scale support from the public and having considerable impact on mass media and conventional politics.

Widespread support from the public enabled the White Ribbon Campaign to reach tens of thousands of men, mainly through the direct mailing of ribbons to over a quarter of a million households across the country. The campaign was particular:y successful in soliciting grants and sponsorship from corporations and local muncipalities in order to carry out its work. As visibility and success increased, so did voices of concern and criticism. At public meetings, women continually asked how the White Ribbon Campaign would be occountable to feminism, and expressed concern that funding for the campaion was deflecting available money away from women's projects, and indeed overshadewing the women's campaign itself. Furthermore, Luxton (1993) notes that a traditional concern of ferninists about men's involvement could be observed: where men take up feminist causes or activities, the chances are strong that they will be acknowledged and praised, while women who have been doing the same 
things for years have largely met with criticism, and at best have been ignored. Each year during December, similar questions concerning men's involvement recur, such as the presence of men at certain memorial services and events and their exclusion at others. Once again, the tension between providing a space dedicated to women, and the need to recognise the public support of men against violence, is apparent. Misunderstanding between men and women has also fuelled controversy regarding a memorial in Vancouver commissioned to remember the fourteen victims of the Montreal massacre. Objections have been raised to the part of the inscription that reads 'murdered by men'. This has led to a number of commentators coming to the view that the whole monument acts as a calculated insult towards men. Worse, it has been also contended that the women behind the project are exploiting the deaths of the fourteen women as a means of promoting hatred against men. Respondents to such accusations have supported the use of the questioned phrase, illustrating that once the 'male' is removed from 'male violence', a misplaced sense of impartiality results which renders violence as a causeless phenomenon (Gale, 1994).

Also reflective of the growing public recognition of the problems of men's violence against women. Men Marching Against Men's Violence Against Women (MMAMVAW) was formed in 1992. In the spring of 1992, men walked for six weeks from Windsor to Toronto, and in the following autumn marched up to Ottawa. In each community they passed, the men spoke to schools, church groups and community centres concerning the issues of male violence. Leaflets were distributed explaining the goals of the march, and although a relatively small number of men actually took part in the duration of the walk, a great number of people were reached through these town and village meetings. Organisers urged men to take time off work to join the march to illustrate support. In an effort to address feminist concerns, proposals were sent out to women's shelters along their proposed route and comments invited. Money was collected for these shelters along the way, and the organisers agreed that women should screen men in order to prevent known abusers taking part and turning the march into a charade. As a result, the march was successful in gaining endorsements and support from feminist groups. 
The White Ribbon Campaign continues to be a focal point of activity for men's profeminist groups in Canada: however many other examples of support throughout the year should also be recognised. In larger cities such as Toronto, members of local men's groups have been going into high schools to talk to young men about issues of violence. Campaigns have also been waged against backlash, and the pervasiveness of men's violence continues to be documented as the growing list of women who have died at the hands of men. For example, the Montreal chapter of MNC produced a list of 291 women and children who were murdered by men in the previous five years in Quebec. Support continues to be offered to feminist activities, for example in providing childcare at conferences and 'Take Back the Night' marches, and by confronting misogyny and homophobia in the workplace.

\section{conclusion: a commitment to social justice}

It is apparent that men interested in feminism inevitably face a double-edged sword, with scepticism articulated both from other men a 1 from feminists. This is true both theoretically and practically, and I would argue that many of the concerns expressed are as relevant to one as they are to the other. For example, whilst the inclusion of men theoretically potentially dilutes the political importance of the categories 'men' and 'women', mer's exclusion suggests an essentially dichotomised framework that also shapes sexual politics. In practice, this dilemma is reflected in the tensions arising from questions as to when, where and how men should express public support for feminist concerns. Another related issue is male appropriation and rationalisation of feminist discourse in theoretical terms, and the authoritarian stance often taken by even profeminist men in mixed-group political settings.

It is also apparent that men's support for feminist struggles illustrates historical consistencies: both in terms of the form and degree of that supporz and the concerns expressed by feminists surroundir.g their involveınent. Compare for example the Men's League for Women's Suffrage (MLWS) distribution of leaflets at the turn of the cuntury explaining how men could help in the suffrage movement by exhibiting posters in homes and assisting in chalking pavements, to the display of white ribbons by profeminist men 
in the 1990s. Consider also the continued link between socialist principles and the advocacy and acceptance of alternative lifestyles. Furthermore, it remains the case that supportive men are essentially white and middle-class, for whom such lifest;les are more accessible.

Luxton (1993) concludes that feminist scepticism centres around the issue of men's accountability to feminism, which is clearly difficult to measure but is an issue requiring on-going scrutiny and critical debate. In this regard, the greatest challenge for men is to take responsibility for privilege - both in theoretical and practical contexts - as well as being prepared to face hostility and ridicule as women feminists have had to do. Related to this, a commitment to the public support of feminist concerns and activities should also be reflected in recognising the need to change personal lifestyles. As such. the 'personal is political' needs to be more than simply a rhetorical statement for men committed to feminism. To put the widesprez $J$ support of the first White Ribbon campaign in 1991 into context, the following year in Canada, 70000 women and children entered shelters for battered women and domextic violence was as prevalent as aver.

it is in this regard that the tensions between men and feminism need to be recognised and understood. Social reality ensures that theoretical abstractions engaged in by men (and sometimes women) which intertwine the 'feminine' and the 'feminist' and produce the imaginary feminine and imaginary woman are particularly problematic. This is reilective to a certain extent of the dangerous conflations typically drawn between men and masculinity, and women and femininity which structure much of our discursive frameworks, and which shall be explored in Chopter five. Although I recognise the seemingly irresolvability of such tensions, I argue that there is a place for men to support feminist concerns in both theory and practice. A common cause can be found, without either appropriating feminist struggle or falling into the me-too mould as the 'Men's Auxiliary to Feminism' (Connell, 1993). The energy spent debating the feminist credentials of male sympathisers needs to be redirected. As Jardine $(1987$, p60) states: "we don't want you to mimic us ... we want your work." Feminism is a space for women, and in defining men's relationship. as Porter suggests, the nature of this 
relationship must be kept clear "in order to avoid gestures of appropriation of feminist space, or the temptation of self-vindication with it" (Porter, 1992, p3).

endnotes

1 'there are those and there are such as those' is a traditional Scottish saying. used typically in the context of those who try to emulate the middle-classes. It is used in the context of men engaging with feminism by Andrew Ross (1987) in Men in Feminism, (eds) Alice Jardine \& Paul Smith.

2 whereas the representation of women has improved in academic environments. the academy remains essentially white and middle-class.

3 As Massey (1991) rightly emphasises, the work of Harvey and Soja is not seen as representative of eicher postmodernism or critiques of postmodemism. However, both books have been particular y influential in this context within the discipline.

1 Richard Pankhurst, to his wife Emily Pankhurst, in the light of increasing dismay over the suffirage cause. Quoted by S.Strauss (1982) Iritors to the masculine cause: The Men's Camparans for Women's Rights Westwood Conn.: Greenwood Press. Quote from p201.

5 increasingty under the popularity of the mythopoetic mens movement, associated with Robert Bly and Sam Keen. groups have focused around these issues. 


\section{Chapter Four : Young Turks \& Old Turkeys ?'}

introduction

A number of male geographers, influenced by the discourses of postmodernism, have increasingly exhibited an awareness of the significance of gender relations to their research and teaching practices. Associated with this trend, the lure of feminist theories as critical frameworks has grown considerably. Reactions by feminist geographers to this movement reflect the wider concerns and debates surrounding male-feminism interactions, discussed in Chopter three. On the one hand, there is a certain degree of satisfaction that after considerable marginalisation within the discipline, there is at last an apparent recognition of the insights offered by feminist discourse. On the other hand. this seemingly improved interaction is viewed with scepticism and suspicion since there appear to be confused understandings and motives behind the utilisation of feminism by these men. Criticism has not only been voiced by feminist geographers, but also by other male geographers, typically well established, who have questioned the objectives of those men wishing to engage in some way with feminism. The arguments that have arisen around this issue, both through journal articles and personal discussions, shall be considered and illustrated in this regard.

In order to focus the context of the men-feminism debate within the discipline, a central component of my research involved interviewing male geographers whose work indicates a certain degree of interest in this field. Selection of potential interviewees reflected both those male geographers for whom gender and gender relations form key aspects of their research, and also geographers who have considered and engaged with feminist discourses in their discussions. As a result, the interest and theoretical background or my study population illustrates considerable diversity. It is not one of the aims of this research to highlight the continuing lack of attention given to questions of gender and the recognition of ferminist theories in many areas of geographic research. Therefore although feminist critiques of this 'lack' in the work of many male geographers are instructive, my interest focuses upon those who have tried to engage activelywith these issues, and the associated concerns and responses those male geographers have had to such work. It shall be argued that the relation between male 
geographers and feminism is not a simple one, however; in its diversity the possibility for finding a workable position remains. I suggest that many of the arguments which have been transferred into geography from other disciplines may not wholly reflect the reasons and objectives behind men's engagement with such issues within geography.

\section{the gomes of the trendiest boys}

mosculinist \& masculine

sure, men and their theories. except that their theories now might

include a superficial (I insist - a superficial) feminism. (Rose. 1994, p507)

The destabilisation of Enlightenment thought and the exposure of geography's dominating masculinist discourse by feminist geographers has led in both a degree of resistance and rejection of such claims on the part of some of its male practitioners, as well as a certain amount of reflection and reassessment by others. Although the impact of postmodernist insights do not solicit the same response from all male geographers. Rose contends that this response, however articulated, will be influenced in part by the fact that these men's interests in geography more generally may both reflect and construct particular forms of masculinity:

Geography's practices are not only symptoms of geography's masculinism. they also constitute quite specific geographical masculinities. And since not all men become masculine in the same way, geography will not attract all men, and those it does attract will react in different ways to the discipline. (Rose, 1993, p10)

Whilst I agree with Rose that as constituted subjects we are all inevitably in the continual $f^{-x c e s s}$ of signification and re-signification. I feel that there is a danger here of conflating the masculinism of discourse exhibited by the discipline. and notions of masculinity directed toward its male practitioners. As with the misrepresentation which accompanies the intertwining of the feminist and the ferminine, such an association needs to be carefully questioned. Rose does indeed recognise that the relationship of individual men to the masculinism of geography may be highly problematic and unstable, yet proceeds to offer a closed assessment of such contradictory relations. It is suggested that two kinds of masculinity can be recognised within the discipline: the social scientific and aesthetic. Social-scientific masculinity, Rose argues, is exhibited through the 
assertion of authority by claiming access to a transparent and knowable geographica! world at the expense of the existence of the 'other'. In contrast, aesthetic masculinity expresses itself where practitioners first decentre themselves only to re-establish power through claiming a heightened sensitivity to human experience. Such a position admits the existence of the other in order to provide the legitimacy and profundity of that masculine voice. Therefore where either position is advocated (and Rose does not make it clear whether she believes any other positions to be possible) the voices of the 'other' remain controlled and repressed by a dominant masculinist discourse. As such, the position of men would appear to be irresolvably problematic.

It is understandable that the illustration of the problematic oppressive power structures which have ensured that tha geographical subject is effectively always white. middle-class and heterosexual has led to a number of male geographers questioning their roles in creating such a masculinist discourse. However, some feminist geographers have argued that this increased interest in issues of gender and feminist standpoints does not necessarily reflect a level of soul-searching on the part of these men, but rather a desire to engage with a radical, contemporary discourse as part of wider careerist moves. There is concern that postmodernism provides a freedom ticket to those who already hold positions of power to roam around theoretical discourses as a means of illustrating their new sensitivity and awareness: it is in effect, Rose suggests, "a gladiatorial arena in $v$..ch the combatants slug it out hoping for an imperial thumbsup at the end" (Rose. 1994. p508). In this process, male geographers will engage with feminism as they have with all theoretical frameworks: with the quest to rationalise, objectify and universalise, and to capture the Truth without getting their hands dirty. As Massey comments: "it's still possible to spot men doing pretty much the same manly theoretical thing in the discipline. What has changed is the range of theories they use to do it" (quoted by Rose, 1994, p508).

Similar concerns have been expressed by a number of other feminist geographers 2 and indeed by a number of men, for example jackson (1993b). Sparke (1994c) and Goula (1994a) although it should be noted that the diversity of opinions expressed reflects the existence of different standpoints within feminism. Pratt's 
progress report in Urban Geography (1993) provides an example of a potentially more positive interaction. Summarising the recent trends and debates in feminist informed urban geographical research. Pratt recognises and comments upon the work of a number of men who have provided feminist contributions to the field in question. Equally, the positions of those feminist geographers who have not written directly upon the issue of men's engagement should not simply be assumed. ${ }^{3}$ Nevertheless, published responses by feminist geographers have largely been unfavourable and confrontational.

Consider in this context a viewpoint offered by Rose:

fancy footwork is going on to maintain masculinist epistemologies while appearing not to, it seems to me. And much of this fancy footwork is being danced on the ground of feminist theory. It almost feels like citing feminist theory in order to iulster a vulnerable masculinity is the latest game among the trendiest boys. (Rose, 1994, p508)

Through quoting Gillian Rose at length it is not my aim to advocate her voice as the prevailing opinion amongst feminist geographers upon this issue, however 1 express concern as to how such comments may be received by male colleagues. My own initial response would probably include a certain degree of anger as well as disappointment in the articulation of her arguments. However, that such feelings were forthcoming is surely the primary objective behind this confrontational style: men sit up and take note. When sonsidering the reaction of male geographers more generally, a number of ot.servations may be postulated. Firstly, ieminist geographers may register their success if men actually read the piece in question, arguing that such articles do not usually attract a male audience. Secondly, geographers hestile to feminism would probably remain so. whilst those interested and wishing to engage in debates may feel offended because it is implied that to be so may symbolise a vulnerable masculinity. Finally, and derived from these first two observations, the possibilities for discussion not determined purely by sexual difference are damagingly curtailed. If Rose's objective is to achieve the discomfort of male geographers then I think she is successful. However, if she is inviting male geographers to recc gnise their relation to masculinist discourse, which I would contend she is, then her message is too subule and thus, too difficult to support. 
Despite the concerns I have regarding Rose's articulation of the debate, I support the importance of the issues raised by her discussions. Although geography represents a key discipline within the Social Sciences, and one which has been exposed to radical and critical discourse for many years, disturbing degrees of sexist, and indeed heterosexist, assumptions remain predominant in writing and research. Not only is the hostility towards feminist geography and its women practitioners recognised as a tension within the discipline, some of the more contentious illustrations of such divisions have taken place as rather acrimonious showdowns between male geographers, with 'patriarcha! elders' maintaining order by continuing to define what is considered to constitute correct and appropriate viewpoints.

The attention given to these debates may well reflect a concern expressed by feminists: when men discuss feminist issues, they are more likely to be given attention, initiate greater concern, and extract greater praise and or recognition compared to the women doing the same. Sparke reflects on the reaction following an exchange with Olsson, expressing his concern that it was enacted as rather a spectacle, and that wider issues at hand became subsumed. 4 Furthermore, if feminist geographers have been successfully exposing and criticising the masculinist principles of the discipline for many years, why is it that the support of male voices in this regard suddenly cause so much anxiety and debate amongst other male geographers? Where one may argue that feminist critiques have been ignored by a masculinist discourse as emotional and irrational, it has become apparent that similarly disturbing techniques have been employed to negate and silence the voices of other men. Since these men cannot be so easily dismissed as 'hysterical', as has been a favoured technique against women, has the old order simply feminised their victims in order to re-establish and execute their authority?

Fears and dismissal of men's support for including feminist insights into geographic discourse are reflective of wider concerns regarding the effect of Political Correctness (PC) upon the discipline. Reflecting a more general right-wing backlash, the objectives of 'Political Correctness' - to provide environments and mechanisms to enable a greater inclusion of underrepresented groups in society - have been rather 
problematically misconstrued.5 As such, the contentions which surround the PC debate have been used to dismiss the threat of challenges by marginalised groups. That the discipline remains particularly squeamish (McNee, 1984; Bell, 1992) about issues of gender and sexuality was reflected in the outery which followed Knopp's article on the geography of homosexuality in the Geographical Magazine in 1990. Not only does such work face hostility among the readership, but its practitioners may meet with resistance within the department, not only from other faculty, but also from secretarial and administrative staff. This latter problem is illustrated in Bell et al (1994). The article describes the difficulties they experienced in obtaining department secretarial assistance to produce a manuscript on homosexuality and Queer Theory. As shall be seen in the case of Sparke's critique of Olsson, such resistance can be found throughout all levels of the publication hierarchy. With the growing recognition of poststructural, postcolonial and feminist discourses in geographical research, the perception of a growing threat to the reputation of the discipline would appear to be significant.

shoring a tradition with peter gould

$\ldots$ in the process, it is not impossible that I may tweak a few noses. but it is not my fault if there are a few pinnochios around.

(Gould, 1994a. p194)

The Wiley Lecture given by Peter Gould at the 1993 Annual Meeting of the Canadian Association of Geographers caused a certain degree of contention both during the address and through its subsequent publication in The Canadian Geographer a year and a half later. 'Sharing a Tradition - Geographies from the Enlightenment' represents a reflection by Gould upon the challenges afforded by poststructuralist, postcolonialist and feminist insights to the discipline. Although he does not necessarily dismiss these theoretical frameworks, he urges 'students of all ages' not to be overly enthusiastic to dispose of geography's historical foundations in the blind uptake of these new insights. Gould expresses notable discomfort about what he regards as the unquestioned authority of radical standpoints within feminist geography which would appear to stand above critique. The disappointment he feels for the apparent hatred being voiced in such literature (here he is referring to comments made recently in an article by Gillian Rose) 
is matched by his concern for those male colleagues who would appear supportive of such material:

... under the exploding hegemonic power of strident feminist critique, we see increasingly male geographers scurrying around in print, flashing their gendered sensitivity. (ibid., p/96)

Gould did indeed tweak a few noses, being met by a number of geographers walking out of the theatre during the address as well as inviting critical commentaries in response to his paper. Two written responses were given by Momsen and Peake: Gregory provided his reflections in the form of an open letter. Both Momsen and Peake illustrated the inappropriate readings of feminist discourses that Gould had used to enable his argument. Peake was more successful in this regard even though her article did read rather as a pre-judgement of white male practitioners in privileged positions rather than a critique of the paper's content per se. This was also reflected in Peake's response to Guld's advice that "it is time we all grow up" in her scepticism about male geographers' engagement with feminism: "The problem is that the Young Turks, the (exclusively male) intellectual vanguard of academic geography to whom he makes reference several times, have a habit of growing up into Old Turkeys" (Peake, 1994. p205).

In responding to his inquisitors, Gould was largely dismissive of Momsen's and Peake's arguments and concerns, and chose to address in more detail the "thoughtful and concerned critique of Derek Gregory, a distinction [he is] quite sure will be misinterpreted" (Gould, 1994b, p209). Although many interesting observations were addressed by Gregory and replied to by Gould, my primary consideration relates to the question of men engaging with feminism. In this regard, Gregory's position would appear more hopeful than that advocated by Peake in asking whether Gould's reflection was "a fair characterisation of all those men who have tried tc think through the questions that feminist politics asks of them" (Gregory, 1994a, p208), adding "In most cases, isn't their effort made in good raith?" Gould remained unmoved by such an appeal and reaffirmed his questioning of the sincerity of men flashing their sensitivity: "You bet $I$ do! And ... so do many women, a number of whom have told me that they see nothing 
quite so ridiculous as men trying to be more feminist than the feminists" (Gould, 1994b. P212). The effective restriction that such a standpoint places upon men suggests to Gregory Gould's desire to 'feminise' feminist geography. It also reflects an assumed association of men's desire for the 'f - ninine' as opposed to the 'feminist' (and therefore an inaccurate reading in most cases). As a result, men's interest in questions of gender and gender justice is believed to remain tied to and structured by notions of male desire for the feminine: no other relation is possible. This is disappointing since 1 feel Gould raises a number of interesting issues, such as his discussion on the inappropriate use of sic, and his illustration of how there remains continued dependence on concepts such of rationality and Truth even for those standpoints which seek to deconstruct such concepts. These issues need to be more widely addressed: however any positive insights offered in the address will remain overshadowed by the controversy it initiated.

berg vs. berry

An interesting series of commentaries passed back and forth in Urban Geography during 1993 and 1994 between Lawrence Berg, a graduate student completing his doctoral studies in New Zealand, and Brian Berry, editor of the said journal, and by many accounts a most distinguisned and accomplished geographer. Berg initiated the exchange through a critique of an article dealing with issues of race which had recently appeared in the journal. It was suggested that the article in question was limited in its analysis of race because recent studies surrounding the notions of 'constructionism' and 'racialisation' had essentially been ignored. As a result, the ensuing discussion was limited by what were considered by Pierg to be rather outdated representations of race.

Exercising his position as editor. Berry replied to Berg in the form of an editorial entitled 'Should UG become PC?', where Berg's response was cast as an example of the wider tendency towards political correctness within the discipline. To ground hiargument, Berry offered his interpretation of what it means to be politically correct. suggesting that it represents a belief that identities are not qualities of individuals but rather pertain to groups derived on the basis of their class, gender and racial 


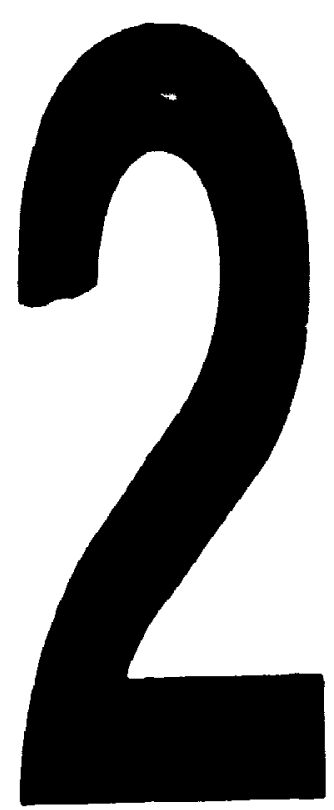

PM-1 31/2" $\times 4$ " PHOTOGRAPHIC MICROCOPY TARGET NBS 1010a ANSI/ISO \#2 EQUIVALENT

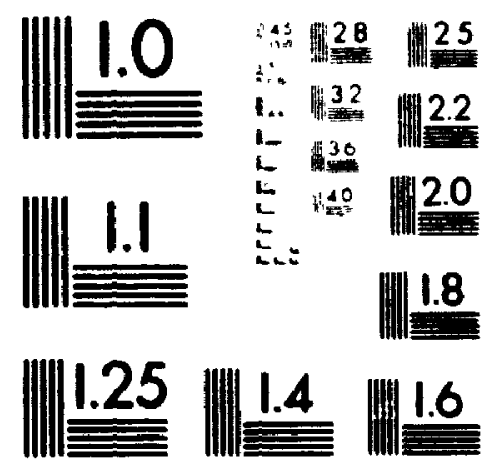

PRECISIONSM RESOLUTION TARGETS 
backgrounds. Such variations in background delineate and distinguish between different 'cultures'. and these cultures define alternative realities to which there corresponds alternative truths.

To be PC in academia, there is to combine the role of analyst-as-advocate. structuring 'research' to expose the assumed oppression, with that of political activist, working to empower new nations, women, blacks, browns and the economically disadvantaged. (Berry, 1993, p315)

Therefore to advocate political correctness. Berry contends, is to recognise that there can be no re:-lity other than a culture's representation of it and. as a result. there can be no rational grounds on which truth can be determined. By contrast, Berry points out that "a professional journal is, however, built on the presupposition that there exists both a commonly understood language and generally accepted categories that make researchers' work mutually intelligible" (ibid., p315). If such guidelines indicative of Berry's defined professionalism are not adhered to, then political correctness threatens to return geography to 'an academic Dark Ages' characterised by 'tribalism' and the 'thought police'.

Berg's reply to these assertions, appropriately titled 'Masculinism. Power and Discourses of Exclusion in Brian Berry's "Scientific" Geography' cleverly exposes the privileged position from which Berry speaks through subjecting his editorial to a comprehensive discourse analysis. The apparent omission in Berry's argument of important concepts brought to light in poststructural, postcolonial and ferninist theories - the intimate connections between power, knowledge and the production of truth - is called into question. Berg, drawing upon Haraway's 'partial and embodied' perspectives, illustrates how Berry's claims to a universal, abstract Truth are a product of discursive power reflective of his privileged position. Furthermore, it is shown how Berry employs a number of binary notions in order to normalise his 'rational' standpoint. As such, those viewpoints not concurrent with his are established through discursive strategies as 'otherness' offsetting notions of 'universal standards', 'a rational basis' and 'mutual intelligibility' against the 'assumed oppression', 'tribalism' and 'Dark Ages' of political correctness. 
The success of Berg's analysis is recognised in its solicitation of a further commentary by Berry, who it would appear has realised that his first attempt to silence Berg and the forces of political correctness has failed. On this occasion. Berry proves to be successful in undermining Berg's voice: whilst an appeal to universal Truth and reason did not achieve his desired aim, the simple tactic of condescension proved effective. As Berry comments: "My purpose was to stimulate discussion about philosophical differences and their consequences. I am pleased that he snapped at the bait and in so doing was so politically correct" (Berg. 1994b, p288). In this latter sentence, Berry reestablishes his privileged position and in his actions once again asserts the dominance of masculinist discourse.

sparke vs. olsson

how far can theorists manipulate and mock theory in politically harmful ways and yet still be given credence as 'progressive' scholastic freedom fighters? (Sparke. 1994a. p207)

The exchange between Sparke and Olsson reflects in many ways the reassertion of authority by Berry over Berg. but differs over the basis of contention. Although Olsson, like Berry, is a notable and well respected figure within the discipline and Sparke, like Berg is a doctoral student, the conflict was not simply one reflecting different standpoints concerning Enlightenment thought. In fact. Olsson has published a number of articles and texts which disrupt traditional textual strategies in order to produce new forms of language use and knowledge dissemination. As such, his arguments would appear to be of interese to critical theorists; in reality. it may be argued his writing style symbolises the very pretension which can have no aim other than to reassert authority by speaking in terms which only the well informed and favoured few will understand (Massey, 1991; Rose, 1994). The interaction between Sparke and Olsson developed from a critique offered by Sparke to Olsson's article "Chiasm of thought-and-action" which appeared in the journal Environment and Planning D: Society and Suace in 1994. The motivation for Sparke's response is clear: 
... since it [Olsson's paper] has been published, and since it therefore represents writing given sanction by an arm of geography's disciplinary apparatus, $I$ think it provides an appropriate object of critique. Moreover. because it condenses in so stark a fashion an array of patriarchal assumptions concerning gender ... the paper also serves to make explicit what are normally better hidden motifs in the writing of masculinist geography. (Sparke, 1994a, p208)

Hidden by the viscosity of its articulation. Sparke suggests that Olsson's argument, despite his own efforts to undermine traditional textual and linguistic strategies, continues to depend upon a 'patriarchal' mode of analysis. Drawing upon the work of Gillian Rose and her argument that masculinist knowledge remains in tension between voyeurism (the masculine gaze which 'objectifies' the feminine) and narcissism (admiration for and interest in oneself) Sparke deconstructs Olsson's article to illustrate the masculinist privilege upon which his viewpoints and contentions are based. The freefloating nature of Olsson's discussior, is. Sparke suggests, indicative of the freedom he has to roam unconstrained through epistemological debates. Such freedom has been assured and secured historically both in the practice and scholarship of geography. Much of Sparke's critique, as with Olsson's article, is based upon psychoanalytic frameworks and insights afforded by theorists such as Lacan and Irigaray, whom Sparke argues Olsson misrepresents in his textual strategies in a way that becomes both politically unacceptable and anti-feminist.

Olsson's subsequent response to Sparke, it may be argue $J$, reads as a reassertion of authority through carefully exposing the many traps which Sparke fell into in the process of his critique. As such, in his response Olsson is able to avoid many of the issues raised by Sparke, and concentrates upon exposing the inadequacies of his inquisitor's critique. With the inaceuracy and the apparent one-sidedness illustrated by Sparke, Olsson suggests that "ferninism has more to fear from its hired hatchet-men than from me"(Olsson, 1994, p221). In response to being accused of practising a masculinist discourse, Olsson cleverly (but as I have argued, incorrectly) intertwines notions of the 'masculine' with the 'masculinist' by rhetorically asking: "How could I, as a man, have the audacity of pretending that I could get anything but a superficial impression of what it really means to be a woman?" and adds. "But is this not exactly what the 
accuser claims he can !" (ibid., p221). Sparke, in his engagement with feminist insights, is 'fem., ised' in Olsson's response which is compounded where Olsson suggests that his "wet dreams are as dry as snuff!" (ibid., p225). In the patriarchal hierarchy. Olsson has denigrated Sparke's position to that of a female impersonator or inadequate male.

Sparke's response to Olsson reaffirms his argument that Olsson's position remains politically circumspect. This is not. Sparke contends. to draw upon political correctness as a critique of Olsson's standpoint, but rather to expose how the debates around PC have been seized upon by more conservative practitioners, such as Olsson as well as with Berry in the preceding example, to reassert their authority in the face of new challenges. Sparke questions Olsson's motivations for implying that he was both mad and out of touch with his 'proper' masculine identity. There would appear to be a large degree of antipathy in Olsson's criticisms to any attempt by men to contribute to ferninist critiques within the discipline. Although Sparke notes the potential dangers of men engaging with feminism, he clearly rejects the position of Olsson, reflecting that:

men who work to change their position within patriarchal relations are not mad. ... such work is not just a hatchet job on someone else's behalf. Rather, it is a struggle about better, less violent, less narcissistic and more pleasurable. polymorphous lives for men as well.

(Sparke, 1994b, p228)

Although this response completed the published exchange, the contentions surrounding the debate took additional dimensions beyond the pages of Sociery and Space. In his last response to Olsson. Sparke referred to an article on Nevada Prostitutes by Richard Symanski from the 1970s and Barbara Rubin's subsequent reply 6 as exhibiting a number of similarities with his own exchange with Olsson. The citation provoked a personal response from Symanski to Sparke in the form of a rather disturbing set of letters. Symanski, formerly a geographer but now a biologist at UC Irvine, forwarded a letter to Sparke which was said to be written by an acquaintance of his. Rafe Korski: a character with a bizarre history who lives out in the Range country of central Nevada. This letter provided Korski's opinions upon the Olsson-Sparke debate written in a style. Symanski reflects in his 'covering letter', that should be put into perspective given Korski's supposed background. Despite what Symanski regards as 
some rather insinuating revelations, he suggests that Sparke uses both Korski's opinion piece and his covering letter as part of a commentary, for which he proposes the title "Geographers Olsson and Symanski Accused of Politically Incorrect Behaviour Towards Women."

Korski's letter, written appropriately in overtly sexist tones, proceeds, at some considerable length, to question Sparke's identity in a quite extraordinary fashion. Unfortunately due to its length, the letter cannot be reproduced in its entirety. however. a number of segments will enable the general content of the reply to Sparke Whippersnapper) to be provided:

Now, you know, there's a few things we ought to tell this WHIPPERSNAPPER of uncertain sexual proclivities before he REALLY gets lost. One is I never met a straight dude didn't enjoy looking at pretty women, and having DESIRES for lots of them ... Now if this WHIPPERSNAPPER says he doesn't have these desires, and that he can't remember scores and scores of them over the years ... ever since he began getting hair bristles around his nuts, then he must be from another planet ... or he lost his testicles and all that good testosterone soon as he come flying out of the birth canal. Or maybe he's just, as those Queer Nation people like to defiantly say, just plain QUEER. I mean is this WHIPPERSNAPPER for REAL ? Or MAD as a gimp and crooked-nosed hatter ! Or is he just so eager to wear a skirt that he can't even think half straight and wants to kick the living daylights out of anyone wearing long pants and boots?

This smart-mouthed WHIPPERSNAPPER, he sure gets all fired up about putting you and me and that egg-faced fawning grocery dink in Gerlach into the same ... what does he call us - -paternalistic hegemonic politically unacceptable voyeuristic narcissistic condescending objectifying penetrating CATEGORY. WOW ! I don't think the mad-as-a-hatter young boy has a right good thing to say about his own sex ... and he sure puts his own MANHOOD in question!?

Enough, the point is made. Symanski/Korski's response to Sparke illustrates a rather energetic desire to ridicule. It is clear that Symanski wishes to shock, and articulates to good effect what he hopes Sparke will consider to be sexist language. The point is not to stress the disgust one feels through reading such material, but rather to consider the objectives of Symanski/Korski's reprisal. It may appear to reassert authority since it plays upon exaggeration to make his message unpalatable and 
unbelievable, yet manages at the same to deliver his real message. However, I do not think this tactic works: the letter is simply rather nasty and unfortunate.

Sparke's close association with the editor of Society and Space and UBC colleague Geraldine Pratt. allows further insights into this incident. At the impending publication of Olsson's article, Pratt had only recently taken over editorship of the said journal, and asked Sparke to provide a commentary since she knew of Sparke's interest in some of the psychoanalytic theorists addressed by Olsson. It emerges that there were difficulties in publishing Sparke's critique ofter it had been given the go ahead by the editor, with the dircctor of the publishing company Pion in London requesting that changes be made. Sparke reflects that a battle ensued between the director, who happened to be a friend of Olsson's, and Pratt over the amended piece. Furthermore, prior to receiving Sparke's (slightly) rearranged and amended article, Pion had forwarded a copy of his original submission to Olsson for comment. When Olsson found that Sparke's article had been modified, he felt that Sparke was not 'playing by the rules' and was trying to trick him and wrote him a particularly unpleasant letter telling him so. despite the confusion emanating from the publishers in London.

Perhaps one fine morning I will even meet this unknown person called M. Sparke. When the social representative becomes an individual of his own identity, he may be surprised to find that a bar is not a slash, a slash is not a bar. (Olsson, 1994, p225)

Sparke did indeed get to meet Olsson following the journal exchange at the Annual Conference of the Association of American Geographers in San Francisco last year. It was in fact for the second time, the first occasion forgotten by Olsson because, Sparke (inter, iew, 1994) suggests, "he spent the whole time talking at me and never asked my name." The second meeting was not by chance, and had been suggested by Allan Pred (a good friend of Olsson's) in order to 'clear the air' and patch up this incongruity. Olsson bought whiskies for them and Sparke reflects, did "that fatherly number on me saying lets forget all about it now" (ibid.). If it had been a woman who had written the critique Sparke believes that there would not have been the same amount of effort to say "this is our young man and he's really all right" (ibid.); the incident would 
have been marginalised, written off and forgotten. By comparison, he was "presented as someone to whom the baton was being passed onto and it was important that everything be in a straight line"(ibid.). Although after the meeting Sparke felt co-opted and "really dirty going home that night" (ibid.). he argues that his critique remains out there for others to read.

all mouth and no trousers ?8

The incidents outlined above have taken place within the discipline in the last couple of years. The purpose of highlighting these specific cases should not be regarded as either an attempt to illustrate the unacknowledged sexism of many of geography's male practitioners, nor to paint feminist geographers, and 'sympathetic men' especially. as victims of disciplinary politics. Although 1 do not necessarily agree with the arguments put forward by either 'side'. I feel that the degree of intolerance which was shown in these exchanges represents an important challenge to the integrity of the discipline. Therefore, despite a number of concerns that 1 as a male geographer may express towards more radical feminist standpoints and arguments, I remain cognisant of the patriarchal structure, both implicit and explicit, which continues to shape the discipline. This may become more openly recognised through skirmishes such as those between Berg and Berry taking place in academic journals, but it is equally clear that such tensions are found at a more elementary level, be they between departmental colleagues, among students and indeed administrative staff.

In as much as this discussion aims to investigate the positive potential for men's engagement with feminist theories and an improved level of 'male gender awareness". the critical debates which have taken place between both feminist geographers and men, and among men, should not be overemphasised nor belaboured. Nevertheless, acknowledging the existence of, and indeed the widespread nature of, these tensions should not be avoided. As one of Peake's 'Young Turks', I remain hopeful that a certain level of tolerance and understanding within the discipline will prevent me from becoming an 'Old Turkey', and that the opinions expressed by those male geographers 
interversid ate indeatue of notable support amongst men to acheve at least a workable relation

\section{boys' talk}

From early September through to November 1994, telephone interviews were conducted with a selected number of geographers whose work was recognised as including an interest in feminist theory and/or questions relating to gender. Introductory letters had been sent during the summer to potential participants and the response rate was particularly high. The interviews were open-ended and the framework made sufficiencly flexible to enable the areas of conversation to reflect the interests of the participant himself. The methodological procedures undertaken, and the insights provided from these incerviews. shall be discussed below.

why open-ended telephone interviews?

As a suitable method of research, the open-ended interview possesses a number of advantages, both in accommodating flexibility and by providing researchers with a more constructive account of events compared to standardised statistical approaches (Schoenberger, 1992: Reinharz, 1992: Herod, 1993). This approach was found to be the most appropriate given the nature of the research being undertaken. In terms of deciding upon the more appropriate medium through which to conduct these interviews, the choice was inevitably restricted. Whereas a face-to-face interview perhaps provides the most effective form of interaction facllitating the gathering of information, the continental and transatlantic distribution of suitable participants made this option unrealistic. It was debated as to whether postal questionnaires would meet the objectives if the research endeavour; in the end, this option was rejected for two reasons. Firstly, since the issues being discussed are of an exploracory nature, the questions that could be asked in a written survey would have to be fairly general and, as such, limiting. Such a structure prevents the clarification of research objectives as well as restricting discussion to pre-determined questions. As a result, the potential value of new insights not addressed by the questionnaire is lost. Secondly, the success rate of 
postal surveys is not particularly reliable, typically resulting in a response rate of between 30 and $50 \%$. With this piece of research. I would suggest that this would have been particularly so given that the exploratory and often far-searching questions asked would require a certain investment of time on the part of the participant.

As a result, conducting telephone interviews was regarded as the most feasible method of obtaining the required information with a relatively good rate of success. Clearly there are both advantages and disadvantages in using this medium for such purposes. In terms of its advantages, the method shares the benefits of being able to interact and lead or follow discussion as appropriate during the interview, similar to a face-to-face discussion. Furthermore, given the diversity of the participants' backgrounds and the specific nature of several of the research questions, not all the issues that 1 wished to address would be relevant to all interviewees. The need to accommodate the flexible nature of these discussions ensured that interviews needed to be open-ended in structure. As discussed by Herod (1993). a number of prepared questions may be designed with the specific interviewee in mind, however typically they will need to be reformulated during the interview as information provided by that participant makes subsequent questions no longer appropriate and new questions necessary. Whilst it may be argued that such an approach loses consistency and uniformity, it is strongly contended that given the aims of this research and the questions being asked, this should not devalue the quality of the information gathered in any way at all. Indeed, the open ended interview can capture many of the subtle complexities underlying particular decision-making processes which may be missed by standardised statistical analyses.

Inevitably, there are a number of drawbacks to this method. Firstly, and perhaps most significantly, is the cost of carrying out a large number of long distance and international telephone interviews. Although this may not be a methodological fault, it inevitably places a number of restrictions on the research process. Secondly, the logistics of a telephone call all too clearly illustrate the significance of body language which is obviously present only at a face-to-face interview. The telephone can be a very intimidating device and a person's 'telephone manner' may be quite different than their day-to-day personal interaction. In situations where unease and discomfort may be 
apparent, and where it is impossible to read the accompanying body language. the success of the interview may be compromised.

who wos asked?

Unlike more common forms of information gathering, the selection of suitable participants for this research was by no means random nor representative of an accorded sample. Participants were selected on the basis that they would have offered some consideration in their work to gender relations and or issues raised by feminism. As such, the collected information which this Thesis represents is a record of the thoughts of a number of male geographers those selection was based upon my understanding of their interests. My aims were to explore the issues at stake and the potential directions which may be taken in the context of men's relation to feminism, rather than to expose or classify a random sample of geographers. The reason for this approach was twofold: firstly, the omissions concerning gender in much geographical research are well rehearsed and have been adequately illustrated by feminist geographers (WGSG, 1984: McDowell, 1988); secondly, advocating a categorisation of research, trying to reflect how feminist a male geographer is (and by implication 'better') in comparison to another, exhibits a great number of the fears feminist geographers rightly hold concerning men's appropriation of feminism.

Having been interested in critical/poststructural/feminist debates for a number of years, my choice of potential interviewees to a certain extent reflected my knowledge of their published material. However, the final list of male geographers to be approached, both members of faculty and graduate students, was put together from a more systematic consideration of relevant publications appearing in the last five years in major geographical journals, for example Environment and Planning D: Seciety and Space. Antipode. Area. Iransactions of the Institute of British Geographers. Annals of the Association of American Geographers and Professional Geographer, as well as paper presentations at recent conferences of the IBG and the AAG. In addition, a number of potential participants were suggested by faculty at Carleton University and from the other participants themselves. Since my geographical knowledge is restricted to English- 
language publications, the distribution of my selected participants reflects a concentration in English speaking countries, notably the United Kingdom, the United States and Canada. A number of potential interviewees were identified in Australia and New Zealand, however a decision was taken (for primarily financial reasons) not to include these men in my research.

The possibility of also speaking to feminist geographers, particularly those who have made reference in some way to men's engagement with feminism, was considered at an early stage; however this approach was rejected for a number of reasons. Firstly, I felt it necessary to maintain a clear focus upon the objectives of research which had to do with male geographers' engagement with feminism, and not to create what may have turned into a 'question and answer' or 'suggestion and critique' debate, where feminist geographers responded to those issues raised by men. If the framework is not suitably developed, such a structure may pre-define the nature of the debate and offset one group against the other by virtue of sexual difference. Secondly, there may have been a greater desire to appear more feminist on the part of male participants where women feminist geographers were also providing input. I do not, however, wish to negate or rule out the importance of women's responses to such discussions and this may indeed provide an interesting focus for future research.

Potential participants were contacted by mail, with a total of twenty-eight letters being sent out during August 1994. Both the letter and the informed consent form attached to it were approved by Carleton University's Ethics Committee (see appendix A p 182). The consent form also enabled participants to indicate suitable time(s) and date(s) for me to call them. Although my selected population of potential participants all illustrated an interest in questions of gender, the level of that engagement, and particularly the degree to which they had considered feminist frameworks, exhibited great variation. In order to accommodate this, I structured the introductory letter to ensure a certain level of common understanding. given a considerable variety of backgrounds. Familiarity with particular bodies of literature and debates could not be simply assumed. At the same time, the letter needed to initiate interest from male geographers looking at female work patterns at one end to those engaging with feminist 
and psychoanalytic theoretical frameworks at the other. In this regard, I sent out a slightly modified letter to those geographers whose interests focus upon questions of sexuality to include discussions of such work in the suggested framework. Here. I was certainly not wishing to ghettoise such interests: it was felt however that including such issues in a more general letter would have complicated the objectives of reaching a wide variety of geographers and not simply those at what may be considered the more 'radical' end. Obviously, concerns may be raised relating to the loss of consistency in research, however, given that my aims were to initiate wide-ranging discussions appropriate to each individual candidate and not to ask a list of standardised questions. this is not considered to be a limitation.

Of the swenty-eight letters originally sent out, a total of twenty-three replies were returned with twenty-one candidates agreeing to participate in the study. This success rate of $75 \%$ was quite extraordinary and greatly exceeded my expectations. Neither of the other two replying respondents who were not interviewed refused, to do so: one had been away from work and had not returned his consent form until after 1 had completed the interview process; the other felt he was inappropriate as a potential interviewee given the objectives of the study. Of the twenty-one successful replies, all participants gave permission for the telephone call to be recorded, and approximately one-third requested anonymity in the final thesis document. On the returned consent forms. further potential contacts were suggested to mo; however given the success rate achieved, as well as time and financial constraints, it was decided not to follow-up these suggestions. One participant requested that our discussions be conducted using email and this was accommodated without difficulty. Also, one of my respondents was a professor at Carleton University, and so I was able to conduct his interview face-to-face.

the interviewing process

Prior to the actual interviewing of respondents to my written request, 1 carried out a small pilot study using faculty members at Carleton University. The pilot provided valuable insights into the procedure of telephone interviewing in general, the potential reaction to the questions I was planning to ask, as well as an indication of the possible 
directions that my conversations might take. Following each pilot interview, the strengths and weaknesses of the conversation were discussed with the interviewees and suggestions as to how the procedure could be improved were incorporated. For example, an area of interest which I felt would be particularly useful to investigate was the link between academic concerns and personal reflection and change in terms of patriarchal relations. However, it became clear that the possibility of this line of questioning would be very much dependent upon the ease and comfort of the interview more generally. Although the pilot study proved to be undoubtedly useful, it should be stated that given the open-ended nature of the topic being discussed and the diversity in backgrounds of the participants selected, it is extremely difficult to be fully prepared for the potential outcomes. In such circumstances, being sufficiently prepared to face a plethora of potential situations may be a more appropriate goal for preparation.

In order to prepare for each interview, I considered recently published material by the participant and devised potential questions more specific to particular areas of interest to that geographer. This preparation enabled a clear insight into each participant's research and provided a greater opportunity to shape the discussion in such a way to maximise the value of information obtained. From early September through to mid November 1994, the nineteen telephone interviews were conducted. Despite the concerns voiced above, the interviews were overwhelmingly successful, enjoyable and particularly insightful. For this I am especially grateful to the participants who accommodated their more specific interests within the general framework which I had outlined in my introductory letter. The advantages of providing this outline, and telephoning my interviewees at a time chosen by themselves, ensured that my call was both expected and that the participants were appropriately prepared. In most situations, the proposed areas of discussion were approached, although the direction of conversation tended to be inevitably drawn towards the specific interests of each participant.

As the discussions progressed, the interview became very much a two way conversation, and I voiced my opinions when asked. Such involvement conflicts with positivist conceptions of the 'ideal interview-type' where the researcher should retain a 
necessary sccial distance io ensure that ne or she does not bas the outcome of the inecrview by making perional values apparent (Hercd. 1993) l found myseif on a numbe: of occasions following the interviewee's position !n order to obtain the maximum level of insight as possible. Gaining the trust of the participant. and therefore indicating support towards his viewpoint, was essential in this regard. Again, concerns surrounding consistency and 'objectivity' in this context are. I feel, inappropriate. It should be observed that my 'performance' as interviewer and therefore the success of the interview very much reflected the openness and friendliness of the interviewee. Where the interviewer became unnarved and uncomfortable. which fortunately only occurred on a few occasions, the interviews tended to be shorter and less insightful.

Even in contexts sisch as this research where both the interviewer and all the participants are of the same sex. I agree with Herod's contention that "gender relations not only shape the social interactions between researcher and interviewee, but they also underpin the very context within which the interview itself takes place" (Herod, 1993. p308). Whilst a male may adopt a particular form of paternalistic behaviour when being interviewed by a female researcher, it is equally probable that he will adopt different forms of context appropriate masculine behaviour given the topic, the specific issue or his perception towards his interviewer (Herod, 1993). Therefore it is not simply a question of institutional power where a man might interview a woman in which gender relations play a significant role; in situations where women interview women, and men Ir.terview men, gender relations do not merely vanish because the interviewer and interviewee are of the same sex. Indeed, feminist researchers have started to question the assumption that women are in a better position than men to question women and vice versa 9 . It is apparent that there are advantages and disadvantages for both parties in cross-gender interviewing procedures. On the one hand, a woman may be more prepared to speak to a male interviewer because she perceives his research to be important. while on the other, a female researcher may benefit from a perception on the part of, for example a multinational corporation, that her work is not potentially 'thrcatening' and are therefore willing to divu!ge more information that would have otherwise been withheld (Herod. 1993) 
Commenting upon the significance of gender relations in the dynames of my interviews is a particularly difficult task 1 can reflect upon the very high response rate and the friendiıness and openness of the participants to our discussions as possibly indicative of my position as a male researcher asking about issues which to some extent may be viewed as politically sensitive. It may be contended that the level of response. and some of the insights I obtained sirnply would not have been made avalable to a woman wishing to ask the same questions. One may speculate that if the interview was conducted by a female rather than by a male researcher, then it may be viewed by the interviewee as a trial determining his credentials and the problematic nature of his work. I did encounter a degree of concern in this regard; however, this would probably have been considerably greater had I not been male. Despite such immediate observations, it is important not to generalise about the significance of gender relations in interviewing based simply on broad categories of male and female. It was clearly apparent that the interactions in each interview exhibited considerable diversity, not only on the part of the interviewee, but also in my role as the interviewer. I developed certain impressions of each of my participants, and I am sure they did the same of me. This was compounded by the nature of our conversations and the lack of avallable body language.

My position as a British student studying abroad played an important role in the initial stages of the interview process. With the exception of three or four of $\mathrm{my}$ interviewees, all, including those at North American universıties. waı of British origin. Since my status was not apparent from the introductory letter, this provided an interesting preamble to the discussions, both from those in the United Kingdom (how long have you been/what are you doing over there!) and in North America (what is your background, how long have you been in Ottawa?). It enabled a comfortable rapport to be established prior to the more demanding issues raised in the interview. Clearly, the overwhelming presence of academics and graduate students of British origin raises a number of interesting questions. One may ask whether my sampling procedure reflected a bias, perhaps unconscious, cowards material I had some experience of, or greater familiarity with, having been through a Briesh undergradunte degree If, however, 
the selection of participants recognised in this study does accurately reflect those male geographers interested in such issues, then one may speculate about the reasons behind interests in gender and sexuality being over-represented among British academics. Obviously, this is not to suggest that all British geographers are interested in such concerns, but it may indicate a stronger interaction or wider acknowledgement of feminist insights and other contemporary critical frameworks in higher education in the United Kingdom.

tronscribing

The open-interview as a research method generates a considerable amount of data, but how these are interpreted can significantly shape how the discussions are understood and represented. The interview may provide a lot of superfluous information which might possibly have been avoided in a more structured form of data collection; however the advantages of a flexible format ensured that much of the information received was both particularly insightful and in a most applicable form. Each interview conducted was transcribed to provide a written record of the discussions. Where e-mail was used, each commentary was saved and reproduced to provide a full record of the issues raised and discussed. The task of transcribing the conversations, totalling over eleven hours, was an extremely arduous and time-consuming task. In total, it is estimated that this task took a month to complete, and gave rise to documentation of almost 100000 words in length. Kelly (1988), who carried out research on sexual violence in which she transcribed in-depth interviews, comments upon how meaning in the spoken word is often conveyed in gesture, tone of voice and emotional expression which inevitably are largely lost in transposing the spoken to the written word. Furthermore, in my transliteration to repro, ice the participants responses', questions of appropriste structure and syntax also need to be considered. While acknowledging these limitations, the written interpretation of my interviews aimed to provide a record as close to the spoken word as possible. In order not to paraphrase or take anything out of context what was said by a participant, quotations used will reflect this spoken word without correction. 
a general fromework

The outline suggested in the introductory letter sent out to potential participants provided a flexible framework in which to explore the issues in an open-ended fashion.

Five broad areas of interest were indicated in the letter: however in actuality either not all areas were addressed, or more typically, participant responses covered a number of these interest areas together. Therefore in some instances, questions became largely redundant while in others, new directions were opened up and pursued. As a result, it is difficult to illustrate the relevant strengths and weaknesses of particular questions because this very much reflected the individual interview contexts. Whilst recognising the interrelated nature of the issues covered throughout the discussions, a number of general themes shall be considered:

The background to the participants' interest in gender and sexuality issues. Is it a personal interest. a more theoretical interest. or does it largely represent an increasingly necessary consideration within their subdiscipline? Does the interest reflect a significant exposure to such material with a number of feminist geographers working in particular areas of specialisation? is the interest reflective of a progressive department and the interests of colleagues?

The issues faced by participants in their engagement with questions of gender and feminist theories. What hurdles, barriers and stumbling blocks have to be considered or avoided? For those men utilising feminism, how did they establish this relation to these theories and how effective is this in enabling the provision of a framework for studying gender? What are the questions male researchers have asked of themselves engaging with these issues? What are the questions being asked of them by both feminist geographers and other colleagues? Do the participants feel that the complexity of the relation places limitations upon their engagement and analysis? Are the debates surrounding men's engagement with ferminism different in degree or kind from other issues of positionality, representation and difference!

The question as to how these theoretical interests in feminism and questions of gender by male geographers are being reflected in academia. and indeed outside it, in practical ways. How have the participants altered their research and other academic commitments, for example in administrative issues and teaching? What has been the response of students to male professors engaging with such concerns in the classroom? How has this interaction with feminism affected more generally the private lives and outside interests of these male geographers? 
The potential benefits and possible dangers associated with developing a gendered geography in which questions of men and masculinities form an integral component. What useful directions do these participants feel such research could take if any? Are they looking at the question of masculinities in their current research, or do they have plans to do so in future? What are their concerns surrounding the advocation of a geography of masculinities?

The issues raised in the context of this last area of discussion were only directly applicable to a small number of participants, and their responses shall be reflected upon when the possible directions of a geography of masculinities are considered in Chapter six.

why the interest?

I think there are many strands within feminism, many tensions and many debates, and just as women adopt a position within feminism. I think its quite legitimate for men to say they subscribe to some tenets of socialist feminism for example but perhaps they're less happy with some that would include, not my position, separatist feminism for example ... I think the more men find out about feminism the more they'll be able to identify positions with which they are sympathetic and others that they'll find that they're less tolerant of. (Peter Jackson)

The i.icreasing contact with research where issues of gender and sexuality are central, and the often associated exposure to feminist discourse, are clearly primary features in giving rise to growing male awareness of such areas. Also, the influence of departmental colleagues and the composition and emphases of the programs offered by departments undoubtedly shape the wider intellectual environment in which academics work. The presence of faculty, courses and students which actively engage with questions of gender and sexuality may establish an environment where such topics are given a greater degree of consideration and therefore generate improved levels of respect for them as suitable areas of research. This should not suggest that all 'traditional' departments remain hostile to feminist discourse and the study of gender. nor should it imply that the academics of more 'progressive' departments are all equally supportive of such work. However, given a more favourable atmosphere, the potential for at least an improved awareness would seem to be available. Furthermore, the social 
and historical relations, both locally and nationally, of a particular university's community should be considered. In Geographical Imaginations. Gregory (1994b) reflects upon the significance of moving to Canada from Britain in exposing him to many issues and questions which would remain more abstract had he remained in the United Kingdom. and these views were reiterated in our discussions. His move to a country with a particular position in colonial history, and a multicultural, multi-lingual and in many ways more equitable society, made the arguments expressed in postcolonial and ferninist writing more readily observable.

when I came here [University of British Columbia] those questions were front and centre - so it wasn't simply that gender and sexuality never appeared on the research agenda in any prominent way while 1 was at Cambridge, or at least never appeared on mine, it was also that those questions never really entered pedagogic practice - and both of those things were transformed when I came here ... I mean I opened my eyes I suppose to those questions in terms of research but also in terms of pedagogy. (Derek Gregory)

I went that way for a variety of reasons, one of course is sort of a generalised reason - contact with colleagues and with writers who were arguing very persuasively that issues of gender were not something that one could avoid in any real sense. (Nicholas Blomley)

The level of engagement by male geographers with questions of gender and their use of feminist theories is largely reflective of their specialised areas of interest. Many male researchers have increasingly recognised the importance of gender as a key social variable in their work; however this does not necessarily reflect the use of feminist theory or insights. Although the boundaries between geographies of gender and feminist geographies are not clear, a definite distinction should be maintained. Such a division should not imply one method as better than the other in enabling a consideration of gender issues; the appropriateness of technique is arguably dependent upon the specific objectives of the research in question.

I'm still not really, in my heart of hearts, exactly sure what feminist theory is - I'm coming at it much more from a - I think gender is a really important social dimension - now if that, if dealing with gender is feminist theory then 1 guess I would say I was familiar with it but I'm not so sure whether feminist theory and dealing with gender are the same thing - I certainly feel that I 
would like to do a lot more reading in 'feminist theory' but I don't know whether you necessarily have to have that theory to be aware of the fact that gender is an important social dimension. (Anon)

A consideration of gender has been increasingly prevalent in many areas of research, and was notably a strong component of localities research in Britain during the late 1980s. In areas of the discipline where theoretical insights have been particularly challenging - one may possibly consider in this regard social and cultural geography - the engagement with feminist theories has been apparent, and this may be seen as reflective of the strong influence of critical theories in general in these areas. For a number of geographers, the insights afforded by feminist theories have been central to their areas of specialisation. Feminism's explanations of gender related issues are intricately linked to consideratinns of other relations of power and difference. such as in questions of race and sexuality.

I'd already worked out for myself that certainly it wasn't enough to sort of speak 'add women' in some kind of empirical way to geographical inquiry - and that these arguments about gender and sexuality would in the end be much more subversive to the geographical canon - that they would require us to rethink in really quite fundamental ways how we did research, how we taught, what we understood theory to be, how we worked with theory, how we understood and negotiated differing competing concepts of place and landscapes and so on. (Derek Gregory)

some of the feminist litera :ure struck me as raising the most interesting issues of social theory, so simply just coming across that literature and realising its significance for particularly in the approach I take into race (which is to do with social construction) with that approach applied to both gender and sexuality, and the second one as well I think just personal reasons of contact I had with friends who were feminists who challenged me to consider my own way of living my life. (Peter Jackson)

I guess my engagement with feminist theory is an ambivalent one and it's not so much to do with the peculiarities of feminist theory as with the particular turn that feminist as well as a lot of other radical theory has taken recently - and you know l'm very drawn but at the same time troubled. (Anon)

I very quickly found that I couldn't talk about issues of sexuality without talking about issues of gender - and so that took me immediately to a body of feminist geography literature - I have found it to be an increasingly problematic relationship - that is with the literature not necessarily with the people but with the literature and that really kind of reflects the problem 
I have with the poststructural/postmodern turn within feminist as well as other radical geography literatures. (Anon)

it's the kind of place I always turn to first when I'm working on something new I guess - because I think the feminist theory and queer theory are the places where good work's happening that can inform the kind of work I'm doing in geography. (David Bell)

For others, the relation is perhaps based less on social or political concerns and derived more from an abstract theoretical level which has led to the consideration of feminist discourses. This path towards feminism may reflect a number of particular concerns regarding poststructural fluidity and the use and appropriation of theoretical frameworks without the need to illustrate the political commitment which feminists would argue is necessary when engaging with such discourses.

that's how I encountered it [feminism] really and got inspired with it that way through going through continental philosophy but always with an eye towards political economy and materialism and increasingiy towards thinking about the body (Marcus Doel)

my organising interest is psychoanalysis. It is thus impossible not to read feminist engagements with psychoanalysis and impossible to treat those engagements as somehow outside psychoanalysis. In other words, for me, good or useful or right, psychoanalysis is constituted through feminist, postcolonial, critical thinking. I therefore do not see myself as using feminism (etc.) or reading feminists (etc.), but reading psychoanalysis. I believe that feminism (etc.) should not be ghettoised or pigeon-holed (i.e. treated as an internally self-identical discourse) or 'outsided'. (Steve Pile)

In reflecting upon his interest in feminism, Peter Jackson (quoted above, p) also mentions the importance of personal reasons and the wider reflections of the way in which one lives one's life outside academic research. The influence of personal experience and interest undoubtedly shapes many aspects of social research and an interest in issues of gender and sexuality is clearly an example of this. An individual's relation to feminism will be affected by the experiences of that individual and whether he or she feels that the issues raised are representative of one's own experiences. An engagement may also develop where men do not feel that feminism is wholly reflective of their own experiences, and therefore in this regard, the interest may represent more of a reaction (not necessarily negative) rather than a recognition. 
my background to an interest in gender and sexuality issues really doesn't come first from a theoretical place - being gay and being in academia and wanting to do something in academia that's meaningful you know to me personally is probably the first thing that took me to focus on these issues. (Anon)

a more serious point is that it did not accord with my lived life so to speak and that could well be because I obviously have a biased perspective and so forth but it seemed to me in terms of personal relationships the issue of power for example was not so clear cut. (John Rennie Short)

The importance of personal background, experience and the sometimes problematic conflation of these personal positions into wider generalisations when considering one's relation to, in this case, feminism, is illustrated by Gregory in his understanding of the dialogue with Gould in their recent exchange. It is particularly important that personal experiences are not homogenised and then employed as a general reflection of all interactions between men and feminism. Furthermore, it is necessary to be aware that political standpoints are not always a good reflection of personal positions, and vice-versa.

I suspect as far as the personal is the political is tha. very often general arguments are laid on the table but underneath the table so to speak there are very specific, very particular examples that people have in mind, they're very specific, very particular experiences from which they are seeking to generalise and there's often I think a disassuciation between the two. (Derek Gregory)

although both of us are used to using a very general language to conduct this argument, what lies behind his reaction and my response to it I think are a series of much more personal experiences and what one has got to somehow try to do is think about the context that gives those experiences meaning rather than simply just generalise glibly from them to all situations to all people. (Derek Gregory)

The recognition that viewpoints and understandings are individually shaped. dependent upon particular experiences, is central to recognising the diversity of men's relations to feminism (and how significant gender as a social variable is regarded) as well as feminist geographers' responses to the work and interest of these men. 
problemotising engogement

I do think that men have to tread very carefully around the question of gender largely because they've walked through it with brisk confidence for so very long - and I can certainly remember when feminist discussions first started to appear within say the IBG that the reaction of the profession, of many members of the profession anyway. was either to keep their distance from it or to treat it as a joke." (Derek Gregory)

"if women are going to set themselves up as the purveyors of truch in these matters and say no men allowed then they are simply reproducing the restrictive practices and the exclusions that supposedly feminism was supposed to be breaking down ... if you are going to do feminist scholarship and want men to take this stuff seriously then you've got to welcome them on board and encourage them and work with them - not simply say go away this is our turf. (Anon)

The wider concerns expressed regarding men's engagement with feminist theories have been directly applied in many cases by feminist geographers (and other male geographers) towards their male colleagues whose work illustrates an interest in such issues. Understandably, the difficulties and areas of contention are clearly apparent to these men whose research and other academic practices may come under scrutiny. A number of participants have experienced a certain level of hostility towards their work. and quite typically their intentions for engaging with such issues are viewed with considerable suspicion. Labels of 'gender tourist' and 'careerist' have been experienced; the latter, one may reflect, is a potential charge which may be employed upon anyone working in contemporary critical fields. One participant comments upon how the nature of his research. given its empirical basis, was found to be problematic in its description as a feminist analysis. However, many have found a workable position regarding their engagement with feminism and suggest that more recently there has been an increased acceptance of their research in these areas. Significantly, it is reflected that many of the contentions that have been articulated in this debate have taken place in the literature, whereas personal interaction and discussions with feminist geographers have been favourable and eypically supportive.

What l've found is that most feminist geographers I know are initially quite suspicious of my interest in this and also most of them have come around when l've talked to them more about it... I found that seems to be fairly general that this isn't a cut and dried thing even for the feminist 
geographers I know who are suspicious of men doing research on women that it's contingent on a variety of things. (David Butz)

particularly early on you think to yourself well maybe I shouldn't be doing this - maybe it is critical of blokes going into gender studies and especially since it's been feminists and women who've laid the path - but I think it's necessary for men to be involved in it and I think in a way it's stupid for men who can be judged by others as profeminist not to be involved. (Anon)

at the very beginning. people thought I must be taking it from an antifeminist standpoint, giving the men's side of the story, but overall - maybe I don't want to say I don't know what's been going on behind my back but I haven't found too many barriers personally. (Anon)

I started getting into some of these areas of women's access to jobs and I just felt a lot of open hostility. just why are you interested in this, why are you, a white, middle class traditional heterosexual male interested in this topic - certainly it couldn't be because of legitimate interest and concern - it has to be for some other reason, you know and l've had people say well maybe you've just done this just because you want to get a job easier. (Thomas Cooke)

what I found is that in geography we have a bizarre, I think it's bizarre, I think a completely arbitrary distinction between qualitative and quantitative research - and if you're interested in gender, if you're interested in feminism and gender you have the people who are the names - the established researchers - will lock you into one of two camps - you are either then empiricist or you are a theorist, but you can't be one and the other. (Thomas Cooke)

Some (many) feminist geographers have been hostile to my work - I have always tried to understand their anger and to change my attitudes/writing in the light of their criticisms. On the other hand, my work is organised around psychoanalysis and this is a particular set of ideas which can anger people no matter what you do. My only way through this is to talk to people (men and women) about what is going on and to try to be more sensitive to other people's pain and the everyday injuries of being marginal. Privilege is constantly and consistently insensitive. (Steve Pile)

to call me a gender tourist is a fairly essentialist statement to make, and it disempowers, it detracts from anything I am trying to say, it straightjackets me. I think less so now but maybe a few yea:s ago - I mean I stand up and talk about feminist issues and l've been attacked for not being able to represent women ... I think that kind of attack on men is lessening now and my feeling is that there's more sensitivity to the whole gamut of differences in men themselves and men are constrained by their sexuality. (Stuart Aitken)) 
I think [women] are very happy to see men thinking about these issues and I think it's more radical feminists who are trying to build a power base for women who feel threatened by men working in this area. I mean. I think we should be working in concert with each other to try to tear down patriarchy because we are all constrained by patriarchy. (Stuart Aitken)

on the one hand there are questions that you formulate as you read and there are other questions that you formulate as you meet people and talk with people - and I put it like that because certainly while I was doing much of the reading and continue to do much of the reading it seemed to me that it was in the reading that $I$ encountered most of the barriers and the opposition - and obviously it is not difficult to find people who say that men really havan't a place in the feminist argument or even in feminist politics ... but I haven't encountered that among the women that l've worked with or discussed these questions with. (Derek Gregory).

Participants' thoughts and reflection upon Rose's text Feminism \& Geography was a common topic of conversation. A number of participants noted that at some time since the book's publication, they have been involved in reading groups which have discussed the issues raised by Rose. Whilst there was general support for the message of the book and the arguments raised, the method in which this was achieved was often brought into question. Given that my study population reflected those who have been 'open' to feminist insights, this was important in considering the response the book has received more generally within the discipline.

I firid so much of this criticism really compelling, I thought Gillian Rose's book for example was a really compelling book - I really liked it a lot and yet in so many ways it left me feeling sort of bereft - I don't know where to go from the place she's taken me - particularly as a male - but I think I might feel that way as a female as well. (Anon)

I think that many of her criticisms are probably appropriate although the style of them I think ironically will probably put some of the men that she is trying to reach off - I mean in that sense it is written in anger, and having been guilty of writing stuff in anger myself I can understand the temptations to do so. (Simon Dalby)

I liked her deconstructed and hated her reconstruction, I hated her idea of oscillating between the poles to try and get beyond the dualisms. I have a real problem with that and I'm trying to battle that. (Stuart Aitken)

Reflecting the voicing of concern on the part of feminists, male researchers have been particularly wary in self-designating their material as 'feminist', or indeed 
themselves as 'feminists'. As shall be discussed, this is especially significant in the context of teaching and the resulting reactions of students, both male and female, in the classroom. Following the tradition of applying a prefix to illustrate their support for the feminist cause, a number of participants suggested that they may regard themselves, or would hope that their work was seen as, profeminist (but never feminist as such). It is also contended that the debates as to whether a man may, or needs to, situate himself as specifically a 'feminist' may be an inappropriate academic objective which only detracts from the more pressing concerns of exposing and illustrating issues of power and inequality. This is particularly reflected in the responses of participants whose interests derive primarily from within postmodern/poststructural frameworks (Dalby, Doel) and where the implications of fixing suggested by labelling would be contested.

I probably think of myself as a pro-feminist. I think there are certain things that women are perhaps better qualified to speak about when we recognise that we're both gendered and I am implicated in the gendering of women and I'm implicated in the gendering of man. (Nicholas Blomley).

I describe myself as profeminist but I would never claim to be a feminist. I think of feminism as a movement of women which men can and should support but I don't regard myself as feminist. (Peter Jackson)

I find it best to steer clear of describing yourself as a feminist or profeminist - in a way I don't really think that the label's that important, although it is important for other people to see where you're coming from ... I want everything I do to be profeminist, but at the same time. you need to have some active links with feminists rather than being excluded from everything and not being able to hear what they say. (Anon)

my response to that is I am deeply ambivalent about this whole thin: in terms of whecher a male can be a feminist or not insofar as wha: 1 consider myself to be doing as a postmodern/ poststructuralist rriter is unravelling how power hides in discourse ... it seems to me th.3t you can without necessarily taking a position that is identified specifically as feminist or not work on how questions of how power hides in discourse or for that matter in cartography - and do that without necessarily having to situate oneself in a particular position as feminist or not. (Simon Dalby)

I mean when you sent out your questions about men in feminism, it's something I never actually think about, I guess it's because l've always tended to work alone ... it's been very much just picking up things as and when for whatever purpose has required it at that particular moment rather than thinking about particular camps ... I'll quite happily be an 
eclectic, lifting things from everywhere and Foucault used to say you know abuse my work, I have that attitude towards everybody else - that: nothing is safe in that sense, you just pick up whatever's at hand and do whatever you want with it - so yes, in terms of kind of l've never been convinced really by that sense of kind of difference between masculine and feminine and men and women however you want to phrase it. (Marcus Doel)

The questions of difference, representation and whether men's position to feminist theory illustrates an inevitable problematic were key issues addressed in the int arviews. The difficulties represented by these issues, articulated through sexual difference in the case of men's engagement with feminism, have been well debated in recent years, as for example illustrated by the concerns expressed by gay researchers regarding inappropriate use of material by 'straight' geographers. The contentions which may arise were understood by, or are apparent to, a number of the participants: however in large part there was an optimistic sense that the tensions are not irresolvable nor disabling in conducting research.

There are unavoidable ethical problems for white middle-class ablebodied men in appropriating any marginal discourse for their own (masturbatory?) ends. On the other hand, it is extremely difficult for anyone to separate power and knowledge (I have never seen it done). (Steve Pile)

it's going to be very hard for men to address you know even how well intentioned they happen to be, but it strikes me that that's less disabling in many respects in taking the kind of fully fledged view that there's a kind of feminist research methodology that somehow only can be practised by women, and personally I don't accept that idea. (John Agnew)

one thing that you become very acutely aware of is the way that straight geographers do appropriate bits of the work that's been done on sexuality and incorporate it into their work in what seems to be a very kind of hamfisted way sometimes ... There are still boundaries and limits to how far you can go and how far you'd want to kind of try and move into those kinds of areas, but at the same time it's perhaps opened up a little bit more for men to use that work at least if it is done in the right kind of way I guess. I think a lot of people like myself probably still do feel that there are some kind of tensions but I think we've kind of been able to sort a lot of them out in our minds and develop a kind of position on them which is kind of always wary and always careful how you approach other people's work and how you appropriate it if you do use it. (David Bell) 
when it comes to things like working across racial difference, gender difference, what not, there's a lot of suspicion and a lot of I guess people wanting to check you out and know why you're doing what you're doing. why you ask the questions you're asking. what your agenda is - but I don't think that they are at all insurmountable ... I think it can very much depend on individuals. (Anon)

I think that it's very difficult. I cannot be a woman. I cannot fight other people's battles and I would agree with Stephen Heath in that any sympathy is paternal and very much unwanted - on the other hand I still can't help feeling both sympathetic and concerned for what I see as a social injustice and the position of women both in academia and within society more generally. (George Revill)

In advocating the potential engagement of men with feminism, a central observation among the participants was the need to critically reflect and continually call into question one's research and the implications of that work. A number of the arguments considered in Chapter two concerning positionality and self-reflexivity are relevant in this context. As such, it is suggested that a 'safe' and 'comfortable' place from which to speak is never achieved, but these 'working positions' are always being challenged by the researcher himself and by others. In working through his own situatior., Blomley considered his possible role as spokesperson, deriving the advantages he holds as an academic, yet at the same time continually questioning the context of his relation with those groups he is representing.

I tried to make the argument that I have used my academic cloaking and my position as a white male you know and so on to try and make arguments which I know other people are unable to do because they are marginalised and so on, so speaking very carefully for somebody, and in some cases people have sought me out to fulfill that role which is a very difficult thing to do you know because of course you are reproducing power relations. (Nicholas Blomley)

I think that's in a sense the whole debate about positionality - I don't pretend to study the experiences of people who are different from my own - at least there is a limit to which you can go in the interpretation of people who don't share your own characteristics. (Peter jackson)

I'm not as troubled as a lot of people are by people engaging with. listening to, and interpreting the experie: es of others so long as thr $y$ are reasonably self-conscious and self-critical about how their own position impinges upon their interpretation and their listening and you know their analysis - there's obviously no way that you can bridge the 
gap between being male and being fermale or being straight and being gay or being white and being non-white but what you can do is make your political commitments and your sort of theoretical and philosophical positions clear up front. (Anon)

I don't know if you've come across this idea that is worked through by quite a lot of feminist theorists of doubling or tracking back and forth between asserting identity and calling it into question. I think that same kind of double gesture can be brought to bear on this kind of issue [difference] too - so on the one hand you say well there are these significant differences which are being established in a racist. homophobic and capitalist society and they are making the people so defined as different and abnormal they're making their lives wretched. But once you've named that, you've come up with your list of processes. Doing that you've also got to remember that there might be some more around the corner and just not to let yourself get arrogant in the context of critiquing arrogance. (Matt Sparke)

In the great majority of cases, it is clear that the participants were very much aware of the concerns and issues raised by their engagement with feminist frameworks. Equally, whilst recognising these difficulties, they felt that it was possible for them to positively utilise such insights in their research. Accusations of gender tourism, hostility and suspicion have been encountered: however the general support of feminist geographers at the level of personal support is widely acknowledged.

putting feminist insights intc practice

it does seem to me that as a strategy and a way of situating oneself as a scholar and as a teacher that the crucial point to get through to students is the fact that gender matters as a matter of social research and as a matter of trying to understand how power works in this world and in fact it seems that getting the attention of the students along those lines works better than going in and standing up and saying $I$ am a feminist whereupon half the women sort of look at you and say oh yeah and half the men look at you and say oh god not another one. (Simon Dalby)

The influence of feminist insights and increasing male gender awareness are not, and should not be, restricted to theoretical discussions and research frameworks. It is apparent that such influences have had a notable effect in the styles and content of courses taught by the male geographers who took part in this study. Additionally, wider changes in many of the men's lives may be reflective of an increasing level of awareness. 
It should not be suggested that these evaluations on the part of men necessarily result from their academic engagement with feminism, but potential links may be postulated.

A great majority of participants commented upon the significance of feminist theory and interest in questions of gender and sexuality in shaping their teaching practices. Richer (forthcoming) recognises three factors which he as a male instructor experienced prompting his incorporation of feminist perspectives into his teaching practices, and given the responses of my participants, it is possible to examine their relevance more generally. Firstly, Richer identifies the value of feminist critiques of the androcentric nature both of knowledge and teaching curricula in providing a framework to examine the power/knowledge connection. Secondly, there has been a steady change in the gender and age composition of university students, notably indicated by the growing number of older' 're-entry' women. Finally, a long-held commitment to critical and/or radical teaching practices ensures that the value and necessity of feminist discourses become particularly salient.

The importance of men's gender when it comes to teaching feminism has typically exposed a careful consideration of the moral and political implications associated with their engagement. A number of issues arise from the questions asked, both of themselves and from students. The response of students to the male instructor's standpoints puts into context the theoretical discussions concerning the difficulties of labelling one's position vis-a-vis feminism, whether for example, one advocates one's own position as 'feminist', 'male-feminist' or 'profeminist'. Another relevant issue is the potential position maie instructors occupy to initiate interest in men as well as women regarding the insights afforded by feminism. Richer contends that feminism needs to be shown as an appropriate male pursuit but in order to achieve this. a delicate balance needs to be found in order not to a priori alienate men in the process. It is important to note that interest is there, from both men and women, in issues raised by the feminist challenge; equally, however, there also continues to be resistance, again from both men and women. A number of participants commented upon the concerns that feminist women have expressed towards a male instructor engaging with such material, but more frequendy criticism has stemmed from a seeming intolerance 
on the part of students towards the connotations (stereotyped?) of feminism more generally. An important consideration raised concerned the strategies employed to incorporate issues of gender and feminism without foreclosing the discussion for those uninterested or who saw it as not relevant to them. Integrating feminist insights and questions of gender in different contexts throughout a course prevents the possible alienation which may occur when feminist geography is isolated and taught as a separate component.

I completely restructured the course with a lot more feminist, gender related issues in the course and I was actually quite surprised at the rather conservative reaction I had from primarily male students but also female students. There were clearly - at the undergraduate level the word feminism pushes a lot of buttons that still seem to get these people very upset and I think I would be a little more sensitive to pushing buttons and talk perhaps more of gender issues rather than feminist theory. (Stuart Aitken)

one of the main forms of resistance I actually find is amongst women and $I$ have for example an urban graduate course and I want to do something on gender and there are three women and one guy, two of the women said we don't want anymore stuff on feminist theory. I think they've had it ... anything that becomes as dominant as that becomes as questioned as that - it becomes taken for granted - it's the establishment - and people resist the establishment. (John Rennie Short)

the men seemed as interested in the issue as women did - in the second year class there is some resistance to it - and I would say equal resistance by men and women - or at least equally vocal resistance by men and women. (David Butz)

there's no sort of explicit again - this is the gender segment of the course - I try not to compartmentalise it in that way. I try to sort of bring it in throughout - sometimes it's more successful and sometimes it's less successful - I think at a certain level you can only push the students so far because they tend to be a faily conservative bunch as a whole. (Anon)

I think its politically and pedagogically much more effective to make these claims in the course of substantive discussion rather than to put a ring fence around them and say well OK at this moment we're going to talk about feminist geography. (Derek Gregory)

I teach at a university which probably thinks of itself as relatively progressive and so it's not too hard to talk about issues of gender especially when they're couched in a way that isn't deemed threatening. 
If you actually engage with some more threatening issues or issues that men in particular feel threatened by then there becomes a problem. (Nicholas Blomley)

Despite observations that students tend to be rather conservative towards certain viewpoints and/or subject areas, a number of participants recognise considerable student interest which has inevitably led to the alteration of curricula to meet this demand. Although this interest is welcomed, concern is voiced as to whether this interest necessarily reflects changing attitudes amongst students (especially given the continued levels of resistance equally experienced) or whether it is merely indicative of a 'trendy' area of research; the kind of contemporary area which holds attraction when careers are to be shaped.

the one that they really seem to go for at the moment is as I say sexuality stuff, and say things like Gill Valentine's - well that goes down a treat - but if you see it as mixing it up, it's really just to keep knocking out different ideas for them to get a sense of what's going on really. (Marcus Doel)

I think that there's a sort of novelty value ... I hope there's a sort of a sense of a need for change as well although l'm somewhat more sceptical of that ... I think that that is a very worrying trend for feminists certainly but because it's interesting. because it's sexy, because there are careers to be made, here come the men sort of thing. (Peter Jackson).

The involvement of men in feminist frameworks further extends to having significant implications upon the personal lives of a number of my participants. Support and activism in community groups was a prevalent feature, as were general observations of aiming to live in equal relationships which were non-oppressive. The growing acknowledgement of the value of male friendships was also recognised as a notable characteristic of growing male gender awareness. Concerns were articulated regarding the need to extend one's academic interest in feminist insights to one's personal lives and actions which would not always appear to be the case. However, as Gregory suggests, it is extremely difficult to always recognise a relational link between public (acadernic) opinions and private realities. 
it's related a lot to my professional work with young parents and my understanding, for myself anyway, that I can't make it on my own. I need to talk to people about the issues that are raised for me in terms of $\mathrm{my}$ own gendered self; I need to talk to other men about that, and I need to talk to women about that too. (Stuart Aitken)

the need to recognise that day-to-day kind of thing stems out of my concern for academicising feminism and it's vital that it doesn't get academicised, and particularly now when more men look like they might get interested in it and write about it. The speediest way for academic men to try and get involved is for them to do what they do on a day to day basis anyway, which is read a new book and read a new article and then put it down in their reference list. It is important that it isn't limited like that and I think ... it just provides an alibi for people who basically go on living their lives as normal. (Matt Sparke)

I can think of a number of people men and women who would claim the high ground when it comes to discussing questions of feminism. cultural politics and what not, but who when it comes to personal interactions with other people seem to be inhabiting a starkly different world and for that matter vice-versa. (Derek Gregory)

implications for feminist-informed research

The success of this research largely derives from the targeting of individuals who were considered to have actively engaged in those questions to be discussed; however this should not detract from the insightful findings provided. Importantly, it should be stressed that the concerns expressed by feminist geographers have in the majority of cases been carefully considered by these men. Whilst understanding the reasons for suspicion and criticism offered by some feminists towards the intentions motivating men's engagement. I would argue that a number of the arguments do not appropriately reflect the mindful engagement that the research by many of these men represents. Equally, although criticism has been quite forceful in text from both feminist geographers and other male geographers. most participants acknowledge and are thankful of the personal support they have received from their feminist colleagues.

Despite the difficulties which will continue to surround this debate, the discussions clearly indicate that men do have something to contribute to studies of gender and sexuality within the discipline. Engaging in such research may involve 
problematising one's own position or providing an auto-critique as a constant reminder of the situation from which one speaks. A number of researchers have translated these considerations into advocating the value of studying issues which are reflective of one's own position. Therefore with increased gender awareness amongst men, and greater understanding concerning the questions of sexuality amongst heterosexuals, these areas represent a vibrant new area for men and heterosexuals to direct their research interests.

Although not arguing that men should restrict their interest to questions of masculinity (and if non-gay, to considering heterosexuality), the need to approach these issues to a greater extent has been illustrated by the recognition that men have a gender too. In doing so. the insights afforded by feminist frameworks can and should be employed. Political commitment is an important basis if such research is not to regress into a narcissistic account of male victimisation while losing reference to the social realities of gender inequality. Illustrating commitment should also not pre-determine an unquestioning acceptance of all feminist standpoints: as feminism has become increasingly institutionalised, men need to find a means of critique which avoids falling into the dangers of backlash. Central to all these observations from 'both' sides of the debate, is the need for greater toleronce in the academy. This is an important issue worth highlighting, and a number of participants voiced concern that arguments were being muffled as a result of intolerance. It was commented that geography as a discipline would appear to be quite intolerant both to outside influences and challenges as well as internally as reflected by the protective actions of subdisciplines.

I feel that whenever many people make an effort to say something - that doesn't have to be something definitive but to put their neck out and take a position on something - they come in for a hell of a lot of criticism that's sort of an infinite regress of criticism that I think has come at the expense of being able to say anything about the way in which the world works. (Anon)

very often the debates that are set in train when people do make these kinds of pronouncements are much more combative than they really need to be ... it seems to me that the academy is remarkably bad at finding spaces for differences - and I mean by that intellectually as well so that 
very often in debates I think one of two things happens: either a genuine difference is turned into an outright antagonism, ... or the difference is simply turned into a variation of a much more simple thesis for which you still hold the reigns so to speak. I don't think that's peculiar to discussions over ferninism mind: I think it's a much more general problem.

(Derek Gregory)

The political dimensions to academic research are obviously complex and are illustrated at all levels of the discipline. It is essential that important, crcss-alliance research is not forsaken due to troubled levels of tolerance between interest groups in geography. It is imperative that contentions and concerns are continually raised and nothing ever assumed, however, mechanisms must be in place to enable the discipline to move on from simply recognising such difficulties.

\section{endnotes}

I after Peake, L. (1994) "Proper Words in Proper Places ... or, Of Young Turks and Old Turkeys". The Canadian Geographer Vol. 38 no. 3. p204-206.

2 for example, see Bondi, L. \& M. Domosh (1992) "Other figures in other palces: on feminism. postmodemism and geography". Environment and Plannine D. Society and Space. Vol. 10, p199-213.

3 The dangers of generalisation here should be recognised. In particular, the work of Canadian ferminist geographers, for example, Suzanne Mackenzie, Fiona Mackenzie. Fran Klodawsky, Audrey Kobayashi and Damaris Rose has not reflected antagonism towards men's engagement.

4 from telephone conversation, October 1994.

5 Whilst recognising the dangers of this backlash, 1 remain cognisant th: : there are problems with certain formulations of Political Correctness. There is an argument to be made, but I feel that misrepresentation and exaggeration is an inappropriate means through which to do this.

6 Symanski, R. (1974) "Prostitution in Nevada", Annals of the American Association of Geopnphars 64. p357.377; Rubin, G. (1975) "Comment: Prostitution in Nevada". Annals of the American Association of Geographers 65, pl13-115; Symanski, R. (1975) "Comment in reply". Anmals of the American Associntion of Geoszaphers 65. p1 15.120.

7 from the enclosed letter by Rafe Korski to Richard Symanski.

A British (usually associated with London) expression where one's convictions are questioned. Usually used in the context where someone boasts greatly about what they will do, but it is known that the likelihood of seeing those actions through is most unlikely.

9 This issue is raised by Staeheli \& Lawson (1994). It was also noted at a session of the CAG Annual conference last year (1994) by Damaris Rose. 


\section{Chapter five: men, masculinities and spacing gender}

\section{introduction}

Putting maseulinity into the picture isn't about insisting that all men should be nice, and fit some stereotyped image. Nor is it about creating a confessional and a fetish of self disclosure. It's about making ourselves 'seen', about making our ... masculinities a basis for discussion instead of assuming that men as gendered subjects do not exist. (Rutherford, 1988, p46)

The question of men and masculinities has provided a focus for discussions concerning men's engagement with feminist theories. A recognition that men have a gender too - rather than simply assuming a universal position which speaks for all human beings - has reflected the significant growth in interest, both academically and culturally, in the challenges faced by men in contemporary society. At one level, discussions have focused upon the 'Wounded Man', who feels victimised by virtue of societal expectations of his gender roles, and the 'New Man' who would appear to have merely repackaged particular advantages without necessarily altering gender relations. At another level, men have become the focus of attention as solutions are sought for the social problems of poverty, crime and family breakdown.' Although of interest, focusing on specific groups such as the absent father or New Man only alludes to the changing and reshaping of men's lives more generally. One may argue that changes in men's lives at present are especially notable; however this should not suggest that men's and women's lives are not always in a process of reconstitution and signification (and that these changes are relational).

The recent interest in men and masculinities has been reflected by a dramatic growth in publications concerning this topic. As a number of commentators have observed, much of this material has concentrated upon understanding men as individual subjects, not on wider discussions concerning gender relations (Cornwall \& Lindisfarne. 1994). However, there has been invaluable research undertaken where a more sociological approach has been advocated, for example as seen in the work of Segal, 
Ramazanoglu, Hearn and Connell. This macerial is characterised by the incorporation of feminist theories as central to discussions of men and masculinity. Indeed, it is in the study of men and masculinities by men, where men's engagement with feminism may be more easily justified (Jackson, 19916; Hearn, 1994). In this regard, the work of Hearn and Connell shall be discussed in some detail. Both researchers have aimed to elaborate upon their theoretical questions by way of numerous and specific research projects, for example the form of public patriarchies and masculinities (Hearn, 1992), working class masculinity in Australia (Connell, 1991) and working class homosexuality (Connell. 1993).

The insights afforded in this material shall be considered here. Although this body of work has been influential, I would argue that it does not provide a completely satisfactory framework for considering questions of men and masculinities. Most significantly, it is my contention that such frameworks could be more instructive where the operations of power are reconceptualised. Furthermore, and this is a concern that has been addressed in other areas of this thesis, the conflation between 'man', 'masculine' and 'masculinity' on the one hand, and 'woman'. 'feminine' and femininity' on the other, continues to be maintained in these analyses. Problematising and destablising the implicit assumptions which conflate 'men' and 'masculinity' and 'woman' with 'femininity' clearly provides a challenge to some feminist theories. However, given the diverse positions in feminism, this is not necessarily a critique of feminism per se, but rather an observation which can be accommodated within particular feminist frameworks, notably those more receptive to insights afforded by the critical/ poststructuralist theories discussed in Chopter two. Questioning the discursive strategies structuring much of the research on gender relations provides potential for a consideration of such relations which are not grounded in a language that continues to maintain a pre-determined sexual dichotomy. This, it should be noted, is certainly not an easy task. What does it really signify to designate an attribute as 'masculine' or feminine', and what is meant when a women displays 'masculine' behaviour? 
In this regard, the renewed focus upon the significance of the body, and work on the constituted subject is especially important. In particular, Butler's work on gender as performance provides a means by which the limitations of both essentialist and constructionist positions may be transcended. The body acts as a site of mapping where subjectivities are congealed in context-specific situations (Bordo, 1992,1993; Fiske, 1993: Pile. 1994). Recognising that masculine and feminine identity, or indeed identities, are not stable but are continually in a process of signification and resignification in different social spaces introduces the spotiolity of gender. the constitution of particular gender performances takes place in specific contexts. Specific social spaces do not necessarily reflect or dictate a certain gendered performance, but this does not mean that oppropriate (and therefore those which become dominant) performances will not be suggested. Therefore, while I am critical of the conflation between sex and gendered attribution and the explanations of how masculinity or femininity become institutionalised in particular contexts and spaces, I do not reject the value of recognising that gendered differences do operate through contingent relations which become congealed (but never concretised) by a 'stylised repetition of gendered acts'. Complex and fractured identities are mediated in social space, and it is my contention that recognising the importance of geographical relations is central to establishing a theoretical framework where issues concerning men and women, and constructions of masculinity and femininity can be addressed.

\section{feminism and masculinity}

Problematising masculinity is not the basis of a theory and practice which complements or balances feminism: it is the application of feminist theory and practice to the study of men in ways which identify masculinity as a problem for men as well as women. (Ramazanoglu, 1992, p339)

As feminist discourses have increasingly recognised the inadequacies and limitations concerning a tendency to treat masculinity as a universalised 'Other', the contradictions and diversity of complex representations of numerous masculinities have been acknowledged (Segal, 1990. Ramazanoglu, 1992). Just as women's experiences and standpoints may be seen to exhibit difference based upon many axes, for example class 
interests and sexuality, it needs to be recognised that the same divisions, arguments, silences and exclusions should necessarily be built into studies of masculinity. Ramazanoglu acknowledges that feminism has given little sympathetic attention or necessary theorisation to men's positions and contends that feminism has primarily focused upon what women should and can do, leaving the changing of men very much to men themselves. The mechanisms of change are very difficult to identify since there is no gender theory of masculinity because "men do not stand uniformly in the same relationships to sources of power nor do they experience as a gender the same oppressions" (Ramazanoglu, 1992, p341). As a result, critical studies of masculinity which advocate political change amongst men are "even more contested and impractical than the various versions of feminist practice" (ibid., p341). Ramazanoglu suggests that it is therefore not surprising that much of men's politics fails to adequately move beyond the level of personal change.

The absence of an effective political mechanism reflects the concern that much of 'Men's Studies' has not directly addressed questions raised by feminism and lacks a relational basis in its discussions of gender. This has been particularly apparent in the United States where the mythopoetic movement - exemplified by the work of Bly and Keen - has been successful not only in dictating much of the direction in Mer's Studies research, but has also appealed to a large number of (typically white, middle-aged. middle-classed) men and commanded sizable audiences. Equally, and again this reflects much of the tension illustrated in Chopter three, it is suggested that where feminist frameworks are examined, Men's Studies carry the risk of marginalising feminist knowledge and determining that it 'needs not be taken too seriously' (Ramazanoglu, 1993). Even where differences illustrated by feminisms are acknowledged by male theorists, concern remains that where men deconstruct feminism into contradictory and partial feminisms, the inevitable tendency is to neutralise the explanatory power of feminist analysis. 
Inspired by the academic breakthroughs of women's studies, men's studies addresses similar questions to the study of men and masculinity. Men's studies seeks neither to replace or supplant women's studies; quite the contrary. Men's studies seeks to buttress, to augment women's studies, to complete the radically redrawn portrait of gender that women's studies has begun. (Kimmel, 1987, pl0)

Claiming to share common goals with feminist scholars, many writing in Men's Studies have paid significant lip service to feminism, although many feminists would argue that their level of engagement is overly simplistic and typically self-serving (Cornwall \& Lindisfarne, 1994). For example, Brod (1987) claims to advocate a socialist feminist analysis of masculinity, yet suggests that such a framework is best carried out under the auspices of 'New Men's Studies' which can offer a 'necessary corrective' to the female bias of gender studies. The above quotation by Kimmel also begs a number of questions, most importantly the implication that by studying men and masculinity (as clear and distinct categories), an understanding of gender can be 'completed'. One may ask how this completion is defined, and on whose terms. Furthermore, Ramazanoglu argues that although men are increasingly attentive to the lessons of feminism and are utilising them in their analysis of men and masculinities, the diverse positions of men fail to be recognised in this material. Interest in masculinities, both academically and in practical movements, remains a predominantly white, middle-class, heterosexual and intellectual project (even where the subjects of interest tend to centre upon questions of race, class and sexuality). This problem reflects concerns expressed by Connell that the 'therapeutic' literature which dominates work on masculinities has provided a discourse on masculinity that is race and class blind and has been "constructed out of the lives of (at most) $5 \%$ of the world's population of men, in one culture-area, at one moment in history" (Connell, 1993b, p600).

heorn's gender classes ond connell's theory of proctice

Despite the above, not all male researchers looking at issues of masculinity and engaging with feminist frameworks, have exhibited such a problematic relation. As Hearn (1994) suggests, a number of approaches and assumptions have become apparent: 
firstly, the need for men concerned with gender issues and feminism. and committed to working towards practical solutions to sexism, to focus on men and masculinities: secondly, the need to ensure that this is done in a critical way and thereby offering a critique of men; and thirdly the need to position oneself in terms of a 'standpoint'. Hearn contends that his standpoint rests upon the recognition of the pervasiveness of gender inequalities and his position as part of the gender closs of men: "Inevitably I am writing as part of the gender class of men. By the term gender class, I am referring to the notion that all men, like it or not. exist in a power relation of dominance to all women" (Hearn, 1994, p48). He argues that this standpoint of 'men's anti-patriarchal praxis' only becomes possible in the context of "developing structures of groups. networks. and organisations created by men as a positive response to feminism" (ibid.. p48).

In developing his notion of the gender class. Hearn considers the suitability of categories such as men and women. His analysis however does not adequately question some of the assumptions necessary to enable his standpcint. He suggests that men are the class that benefits from particular relations over women, positing hierarchic heterosexuality, fatherhood, the professional control of carework, and state relations as relevant material relations. For example, it is argued that all men benefit from the family mode of production and the social institution of paternity even though not all men are husbands or fathers. Another relevant example is the case of pornography: not all men 'use' such material, but Hearn contends that all men as a gender class benefit from it in some way. Hearn stresses that his conceptualisation does not negate historical, geographical and cultural variations in 'masculinity', nor does it fall back upon biologically determined essences, but rather enables changing political practices around gender. Despite a considered discussion as to how one may transcend the tensions between structure and agency, critics of Hearn's work have argued that his approach (and his continued insistence on structures such as the 'gender class') reflects a structurally dominant version of structuration theory which fails to escape from a Marxist-informed theoretical background. Such an apprnach may divert attention from the need to consider questions concerning the subject, self-identity and fragmented identities. 
The work of sociologist Bob Connell has perhaps provided one of the key theoretical discussions concerning masculinities in the last decade. There are a number of similarities between Connell's and Hearn's frameworks: the importance of avoiding the tendencies of essentialism and relativism; the potential of moving beyond the structure-agency duality; the complexity and difficulties of categoricalism; and the pervasiveness of power in gender inequalities. However, I would argue that Connell's framework, focusing upon a theory of practice provides the more flexible approach to considering issues of gender, and in many ways reflects the notion of the 'constituted subject' as discussed in Chopter two. Connell's arguments, outlined in his influential text Gender and Power (1987). aim to elaborate a social theory capable of weaving together personal characteristics and social structures without falling into biological determinism on the one hand, or relativism on the other. Drawing upon psychoanalytic and sociological frameworks. Connell illustrates the 'sheer intractability' of gender relations whilst recognising that concrete relationships and practices can and do change. As discussed by Segal, such a framework represents a practice-based approach to personality whereby "human agency is contextualised within the personal. intersubjective, discursive and broader structural dynamics of particular groupings at particular moments" (Segal, 1990. p168). Gender organisation may therefore be regarded as an ongoing concern, implying that structures are not pre-given but reflective of the historicity of social life.

Connell's framework reads largely as a critique of 'categoricalism' noting its numerous restrictions, most notably the dangers of false universalising. Categories may enable a consideration of power. but Connell suggests that they delete from analysis the elements of practical politics such as choice. doubt, strategy, error and transformation. He is also critical of sex-role theory which he suggests inevitably collapses into an assertion of individual agency, squeezing out the dimension of social structure. Sex role theory fails to provide an analytical means to consider the distribution of power, the institutional organisation of gender, or the gendered structuring of production (Connell, 1987). Connell's critique further adds that: 
Change is always something that happens to sex roles, that impinges on them. It comes from outside, as in discussions of how technological and economic changes demand a shift to a 'modern' male role for men. Or it comes from inside the person, from the 'real self that protests against the artificial restrictions of constraining roles. Sex-role theory has no way of grasping change as a dialectic arising within gender relations themselves. (Connell, 1987, p61)

Instead, he argues that the focus should be on the problems of conceptualising gender in terms of strict categories rather than on processes of construction. He contends that, at least in principle, categoricalism can be resolved by a theory of practice. focusing on the actions of people and how the social relations in which they live are constituted. Connell argues that social practices constructing gender relations do not express natural patterns, nor do they negate these natural relations. Rather, they are mediated in a practical transformation. This implies the possibility of different formations of gender reflecting the dominance and subordination of particular social interests. Furthermore, the 'natural' or 'pre-social' qualities of objects are important to the practices that deal with them. As Connell suggests:

Practice issues from the human and social side of the transaction: it deals with the natural qualities of its objects, including the biological characteristics of bodies. It gives them a social determination. The connection between social and natural structures is one of practical relevance, not of causation. (ibid.. p78)

A transforming practice therefore mediates what it starts with in order to produce something new. As well as being transformative. practice is also situational in its response to a particular configuration of events and relationships. Since practices inhabit a dialectic relation, one cannot be masculine, for example, in a particular way without affecting the conditions in which that form of masculinity arose. Drawing upon the work of Sartre. Connell suggests that the biological differentiation of sex has a set of corresponding conditions that give rise to a limited range of practices and consequences; these may be refered to as 'practico-inert', enabling a social definition of gender. In such frameworks, recognisable social 'categories' can be suggested, where people can be grouped together in 'logically primitive' collectivities to reflect parallel situations imposed by an external logic. It is argued that to construct the social category of 'men' 
or 'women', with a common identity and interest, requires the "negation of the serial dispersion characteristic of the array of parallel situations constructed by the biological categories." (ibid., p8I) Sustaining this dichotomy of gender is a continuing effort because the practico-inert practices which correspond to the biological logic cannot sustain the gender categories.

Three primary structures are identified by Connell as central to a consideration of gender relations which accords with his theory of practice: the division of labour, the structure of power and the structure of cathexis (sexuality). Although three structures are defined. Connell acknowledges that these are complexly interrelated and lead to a notion of 'compositions'. Indeed Hearn (1994) queries whether a separate structure for cathexis can be advocated when it is inextricably tied to the other structures. Two further concepts may be recognised as of key importance in grounding Connell's theoretical discussions. Firstly, it is asserted that masculinity as personal practice cannot be isolated from its institutional context. Secondly, since the gender order can and does produce competing masculinities and femininities. hegemonic and subordinate masculinities and femininities can be recognised. In the case of institutionalised masculinity. Connell suggests that most human activity is institutionally-bound, and that discussions regarding 'masculinity' and 'power' necessarily involve addressing the 'institutionalised masculinisation' of State activities. As an aspect of institutions. masculinity is seen to be produced in institutional life as well as being a component of personality or produced in interpersonal transactions. I agree with Connell; however. there is a need for further exploration of the relation between masculinity(ies) and institutional character and this will be discussed below.

Connell recognises lobour as a social structure to the extent that the operations and allocations of labour become a constraint on further practice. The construction of the sexual division of labour is not simply a matter of the allocation of work to people and the problems of potential discrimination. It also involves the designation of work based upon gendered attributes and the valorisation of particular qualities given specific situations. Unequal training (a woman's may be interrupted through childrearing responsibilities, domestic routines as well as employer discrimination) and men's 
unfounded assumptions of superiority, for example as expressed through sexual harassment, create particular gender relations in the workplare. Cockburn's (1983) insights into the '.ondon newspaper printing trade and Johnston's (1990b) study of the patriarchal relaticns engrained into factory operations in the Australian textile industry provide interesting examples in this regard.

Connell suggests that the division of labour is in its starkest form where the relative value of paid and unpaid labour is considered. He argues that women's role in childcare is basic to the division of labour, giving men greater freedom to participate in economic, cultural and political activity. Although labour markets continually undergo considerable restructuring as a result of changing technologies. shifting global circuits of investment and disinvestment, and the growing incorporation of women into the workforce, the gendered structures shaping these labour markets remain relatively resistant to change. However, where such labour structures are threatened and a man's position as provider, as being in control, and of economic advantage, is disrupted, 'crises' in patterns of male authority are created. In more advanced economies which have experienced la ge scale unemployment, particularly in traditionally male dominated industries, there has been little fundamental restructuring of household duties even where the man remains unemployed and the woman is engaged in the paid labour force. On the other hand, where men may wish to actively engage in fulfilling the role of househusband or domestic father, both State and society in general continue to look upon such situations unfavourably (Pleck, 1993; Haas, 1993).

That relations of power function as social structures and as patterns of constraint on social practice is, as Connell comments "in one sense all too obvious," (ibid., p/07) but in another appropriately complex. They are clearly manifested in the workforce, as suggested above, but power relations also exist within the family unit, in the operations of institutions and in streets and public spaces. He suggests that if outhority can be recognised as legitimate power, then one may contend that the main axis of gender power structures is found in the connection of authority with masculinity. For example. the maintenance of men's authority in the family is diverse in its forms, and it is difficult to suggest a simple relation. Even in households considered 'liberated', with shared 
nurturing and Jomestic responsibilities. power may remain in terms of earning power or control of financial matters Indeed. the "liberated" relationship may reflect a redefinition, but at the same time may continue to reinforce male advantage. In other households, the power relation may be far more explicit. for example being 'exercised' through the exertion of physical aggression and the use of domestic violence. Connell suggests that men are empowered in gender relations, but in specific ways which produce their own limits. As with labour, the structure of power is an object of practicc as well as a condition of those practices. The link between culture and the maintenance of particular power relations is central: culture provides a milieu in which, as participants of a collective project, humans validate and sustain the power of men and the subordination of women.

The third major structure, cathexis. draws upon a Freudian term to refer to the psychic charge or instinctual energy which is attached to a mental object, for example an idea or image. Cathexis considers notions of sexuality, emotion and desire and the complex relations between them. Connell argues that identifying this structure provides a means to incorporate considerations of trust and distrust, jealousy and solidarity, the emotional relationships involved in rearing children, as well as acknowledging socially structured antagonisms based upon gender (misogyny, misandricity). Many of these gendered psychological issues can be understood in terms of the structures of labour and power, but not completely. Connell believes that the ways people create emotional links between each other, and the daily conauct of emotional relationships, seem to follow a different (yet still social) logic. If one considers the case of desire, social patterning manifests itself most obviously as a series of prohibitions: taboos surrounding incest, laws concerning rape and the authorised age of sexual consent. The institutionalisation of these prohibitions by the State exhibits variation reflective of different social structures over time.

The dichotomies drawn between male and female, heterosexual and homosexual, form the central tenets of Western philosophy's conception of sexuality. Connell argues that historically and cross-culturally. partnership has not always been organised in terms of such dichotomies: however, in most contemporary industrialised 
societies sexuality is firmly organised such that one is either a hecerosexual or homosexual. The construction of these labels, and in particular the construction of the homosexual in the 19th century has been clearly exposed by gay and lesbian theorists drawing upon the work of Michel Foucault. Male homosexuality has been controlled and policed since the late 19th century especially. Segal (1990) suggests, in moments of panic over dominant positions of manhood with official and unofficial attacks on homosexual people and practices. Recently in the United Kingdom there has been extensive debate and $a$ vote in the House of Commons regarding the lowering of the legal age of homosexual consent from twenty-one to either eighteen or sixteen (the latter being the legal het ar osexual age). Many of the arguments against were based upon the assertion that boys pass through a homoerotic phase in adolescence and that the law acts to protect such people whose sexuality has not yet 'settled down'. The defeat of this bill in Britain has been paralleled in Ontario with the rejection of passing the same-sex rights bill by the Provincial Government.

Although Connell recognises that these structures cannot provide an explanatory basis for all aspects of gender relations or regimes, the theory of practice does enable a framework which weaves together personal characteristics and social structures and therefore holds an advantage over both sex role theory and categoricalism. The recognition of these social structures illustrates the means through which competing masculinities and femininities are created in the constitution of gender relations. There is not a singular, monolithic masculinity nor femininity to be discovered, but a plethora of competing social groups. In explaining the development of hegemonic masculinity(ies) and subordinate relations (central in all three of his structures identified in the theory of practice) Connell is buildi. ig upon the research he conducted with Carrigan and Lee (1985) which introduced the concept of hegemonic gender orders.

Hegemonic masculinity is far more complex than the accounts of essences in the masculinity books would suggest ... It is, rather, a question of how particular groups of men inhabit positions of power and wealth and how they legitimate and reproduce the social relationships that gunerate their dominance ... An immediate consequence of this is that the culturally exalted form of masculinity. the hegemonic model, so to speak, may only respond to the actual characteristics of a small number of men. Yet very large numbers of 
men are complicit in sustaining the hegemonic model.

(Carrigan et al, 1985, p592)

In explaining the characteristics of hegemonic masculinity. Donaldson (1993) suggests that hegemony is best illustrated in the work of Gramsci and particularly in Prison Notebooks. Power is seen to be exercised through a means of persuasion which is made to appear natural, ordinary and normal. Where political struggle ensues for scarce resources, it follows that there will be a mobilisation of power and the pursuit of tactics on the behalf of a particular interest. The ability to impose a definition on a specific situation, to set the terms in which the events are understood and issues discussed, to formulate ideals and define morality, are essential aspects of this process. The concept of hegemony therefore provides an interpretation of the ways in which ruling classes establish and maintain their domination, a process which involves the winning of power and the formation and destruction of social groups.

Donaldson illustrates how hegemonic masculinity involves a specific strategy for the general subordination of women. It represents a culturally idealised form of masculinity maintained at a personal and collective level through 'common sense' notions regarding breadwinning and manhood. The public face of hegemonic masculinity may only reflect the realities of a small number of men but is supported by the large majority since it acts to benefit their own interests and sustains particular relations of power. Indeed, it may not in some regards reflect the practices of any men, but be representative of fantasies and ideals about what masculinity should symbolise. Ideologies are constructed and recreated in social relations in a wide range of contexts. At an extreme level, New Right and fascist groups are vigorously constructing a particularly aggr assive and violent model of masculinity based upon the reassertion of the ideals of a master race. More generally, the weavers of the fabric of hegemony, or Gramsci's 'organising intellectuals', pervade all aspects of social relations. Donaldson suggests that influential agents include priests, journalists, advertisers, politicians, designers, academics, and generally those who occupy positions that control economic. cultural, educational and political power. These people regulate and manage gender 
regimes by having the means to articulate their interpretations, perspectives and fantasies regarding gender relations.

The fact that hegemonic masculinity subordinates many men as well as women in oppressive power relations is central to understanding the operation of that power. Indeed. Donaldson contends that the crucial difference between hegemonic and other masculinities is not the control of women, but the control of men and the representation of this as "universal social advancement. Two of the most fundamental foundations of hegemonic masculinity are compulsory heterosexuality and homophobia. Under this structure. women exist as potential sexual objects for men while men are negated as sexual objects for men. Thus women act as a form of validation to prove the heterosexuality of men, and men compete with each other in this regard. Equally. antagonism and hostility towards gay men is inherent in the construction of this hegemonic form of heterosexual masculinity. Connell suggests that hegemonic masculinity is threatened by homosexual identities since the egalitarianism offered by gay relationships by virtue of its transitive structure challenges the hierarchical and oppressive nature of male heterosexuality. Although the power relations producing hegemonic structures suggest a certain degree of stability, neither hegemonic nor subordinated masculinities can be regarded as static and unchanging. ${ }^{2}$ The theory of practice stresses that not only can various hegemonic models co-exist, tut also that different hegemonic masculinities can be called into play at particular times, and will in the process produce different subordinated masculinities.

Both Hearn and Connell have attempted to provide theoretical frameworks which enable the mediation of social structures and individual agency in discussing the constitution of gender relations. Connell's theory of practice is more successful in its challenge to categoricalism which, I feel, Hearn's gender-classes fail to adequately address. With an emphasis on the practice and transformation of gender relations. Connell's work parallels in many regards the frameworks put forward by Butler, Mouffe and Young advocating in various forms the notion of coristituted subjects. The compatib, :ty of his standpoint with poststructuralist-informed feminism is further illustrated in his focus upon the body as central to social practice. The strength of 
Connell's framework is illustrated in his applications and the use of life history methodologies to illustrate the spatial and temporal characteristics associated with the practice of gender. A potential limitation rests in Connell's acceptance of structural configurations of power whilst not necessarily considering the constitution and meaning of those particular relations. Nevertheless, his notions of hegemonic and subordinated masculinities are particularly useful in this regard and can be, as shall be discussed. adapted to enable a more critical interpretation of power.

reformulating the link between men, mosculinity and power

It is a particularly difficult task to suggest possible responses to the limitations of frameworks such as those of Connell. Indeed. I feel that many of these limitations result from his very attempts to provide a workable framework incorporating social structures and relations of power, attempts that poststructuralist theorists have largely failed to achieve. However, my tentative critique rests upon two closely related and dependent factors: firstly, the assumptive confiation between men and masculinity, and women and femininity, in explanation; and secondly, the use of a rather inflexible account in considering the operations of power. This is not simply directed at male sociologists addressing gender issues, but also at many feminist analysts who remain confined to the prescriptive nature of existing discursive frameworks. Effectively, and this was an argument introduced in Chopter two, the terms in which frameworks that describe and accourit for social configurations of power and oppression are established, inevitably reflect o priori the very relations they wish to destabilise. Thus for example, the valorisation of patriarchy comes to depend upon the assumption of a uriversal difference between men and women. It remains universal, despite claim: otherwise, even when patriarchal relations are shown to be spatially and temporally constructed.

It is necessary to question the very terms which provide the foundations, and structure the assumptions of the theoretical frameworks one may wish to use. This does not signify a continual need to 'reinvent the wheel' nor the rejection of terms such as patriarchy. It does however recognise the importance of preventing assumptive formulations and simplistic conflations which only proceed to reassert taken-for-granted 
assumptions. In offering an alternative framework, I do not wish to reject Connell's theory of practice; however I would suggest that the incorporation of insights afforded by writers such as Butler may provide a means by which certain assumptions may be called into question more effectively. In particular, the frameworks offered in Cornwall \& Lindisfarne's edited collection Dislocatine Masculinity (1994) are especially useful.

\section{dislocoting mosculinity}

Imprisoned as we are in the structures of our language, it is difficult to escape using the terms 'men'. 'male' and 'masculinity' and 'women'. 'female' or 'femininity' without implying a binary notion of gender. (Cornwall \& Lindisfarne. 1994, pli)

So pervasive is the dichotomy between 'male' and 'female' in Western discourse that ... attempts to describe the complexities of certain gendered behaviours have foundered on measures which recreate the dichotomy in an intermediate form. (ibid., p36)

Many theorists have been particularly instructive in their destabilisation of a binary notion of gender, illustrating the fluidity and situational qualities of everyday actions. However, this recognition has not typically translated into a fundamental reconfiguration of the use of terms such as 'male' and 'female', 'masculine' and 'feminine' and, more problematically, has not weakened the apparent willingness to conflate such attributions. This is notably characteristic of psychoanalytically informed material, where notions of 'masculine' and 'feminine' are central to analytical frameworks. Freud himself noted the problems of employing such terms, but his research inevitably continued to rely upon their usage. Problematising notions of 'masculinity' and 'femininity' has tended to promote the need to acknowledge the existence of multiple and fragmented masculinities, yet in ways similar to the dissolution of identity discussed in Chapter two, this recognition of plural masculinities merely displaces more theoretically challenging questions (Fuss, 1989).

Cornwall \& Lindisfarne (1994) suggest that conventional usage of gender is dependent upon a series of explicit and implicit premises. Firstly, masculinity and maleness are defined oppositionally as what is not feminine or female. Secondly, gendered identities are created through the social acquisition of appropriate attributes. 
Thirdly, anatomy, learned behaviour and desire are conflated so that heterosexual orientation and desire come to be defined as 'normal'. Fourthly, through biological, sexual and social connotations, ideals associated with masculinity become reified, institutionalised and universalised. In order to understand how this occurs, instead of simply assuming certain constructions and operations of power, it is necessary to problematise such premises and destabilise the conflations between men, masculine and masculinity (and equally women, feminine and femininity). Cornwall \& Lindisfarne argue that a more beneficial focus would be to consider the thetorical relation between male and female which could provide a means to assess where, how and by whom apparent boundaries between men and women are imposed, as well as enabling a reflection upon the criteria by which 'sex' and 'gender' are defined in various settings.

It is important to acknowledge multiple, contradictory masculinities; however, to understand why these exist, it is essential to recog, ise that in reality people, both men and women, operate according to many different notions of masculinity and femininity and indeed according to a wide variety of other information. McElhinny suggests that instead of asking 'what are the differences between mien and women?', frameworks concerned with questions of gender should be articulating the question in terms of 'are there differences between men and women?' She argues for the use of a more flexible definition of gender, one that recognises "the degree of agency accorded to people in developing a style of living, behaving, speaking and being based upon their own occupational choices, personal histories, sexuality, life-styles" (McElhinny, 1994, p166). Being masculine or ferninine is not an exclusive identity, it can involve self-presentations which include behaviour typically associated with both masculinity and femininity. Equally, completely variant notions of masculinity can refer both simultaneously and sequentially to the some individual. Although particular situations may necessitate a certain gender practice, a certain gender 'act', that same situation will produce a plethora of different acts from different men, and may produce a variety of acts from a single individual over time. It cannot be assumed that there is, in any particular setting, a single way of being a man. Furthermore, a social act is rarely interpreted as solely 'masculine' or 'feminine', more typically an act will also be perceived in a context constructed of a wide diversity 
of other information such as the actor's personality, age, regional background, ethnicity and class. As Cornwall contends:

Masculinity is often conflated with being 'male' or 'being a man'. These notions lack any definitional ground and may be more usefully regarded as loosely bounded clusters of family resemblances. The meanings ascribed to these terms by different actors may overlap to certain degree, but also vary significantly in different domains of discourse. Dislocating 'masculinity' and 'femininity' and taking a closer look at the ways these terms are defined and attributed reveals the power effects of gender attributions. (Cornwall, 1994. pl I6)

Where additional information is taken into consideration in any particular context, it is argued that a more dynamic view of the linkages between gender and power is produced since it allows the recognition of those sites of resistance which can challenge the binary gender norm already available in each context.

In order to provide a more appropriate framework which breaks away from an assumed linkage between gender ('male' and 'female') and gender ed attributes ('masculine' and 'feminine') McElhinny draws upon the work of Ochs (1992) and asserts the importance of recognising the distinction between referentiol (direct) and indexical (contingent) markers of gender. Referential markers are those which may be considered unequivocal and unambiguous. Therefore the use of categorical prefixes 'Mr' or 'Ms' would not be typically questioned but seen to relate to male and female identity respectively. By contrast, indexical markers are those which are non-exclusive. constitutive and probabilistic. They are non-exclusive in that indexical markers may imprint other social information, for example age, sexuality and personality traits. Being constitutive reflects associations made based upon a simplistic binary notion of gender which enables traits to be linked and grouped together such that 'rationality' becomes linked to 'objectivity' which in turn is linked to 'masculinity'. Indexical markers are also probabilistic in that certain attributes may be linked to masculinity, but not exclusively so, for example emotionlessness.

Recognising that indexical markers of gender are both discursively produced and available to both men and women, enables one to consider the operation of power 
involved in the specific enactment of particular behaviours. It provides a more dynamic understanding of gender relations and exposes the complexities of personal behaviour and action in specific contexts. McElhinny suggests that the conflation of 'men' with 'masculinity' and the failure to adequately address the difference between referential and indexical markers of gender in feminist theory has provided an enabling framework to illustrate gender inequality. Through establishing a link between masculinity and objectivity, a critique of prevailing academic practices (which have often excluded women and the study of women) has been made possible. However, maintaining this necessary insistence on a link between objectivity and masculinity ensures the failure to recognise both the historicity and the indexicality of this link, and refuses the possibility of altering such associations. In effect, this indexical marker is treated unequivocally as a referential one and as a result pre-determined notions of femininity and masculinity are left unchanged. Therefore the binary associations which shape Western knowledge, dichotomising on the one side masculine/objective/rational/strong/cultural and feminine/subjective/emotional/weak/natural on the other, remain unchallenged. It is important to note that McElhinny's assertions should not be seen as directed towards all feminist discourse: in particular, the work of Donna Haraway is recognised as contributing much to such understanding.

Given these insights, the overarching nature of the association between masculinity anci institutional power needs to be problematised. This is not to deny the characteristics of institutions, but to remove the tendency to make indexical markers referential. McElhinny illustrates this in the case of female police officers and their behaviour in what would be considered a traditionally male-dominated environment. She suggests that women officers need to exhibit objectivity and lack of emotion in particular contexts in order to perform their duties satisfactorily, but do not feel that in doing so. they lose their identity as women. By not automatically associating 'rationality' with 'masculinity', these women officers also question the implication that all men are necessarily rational. Rather than replicating pre-existing notions of gender relations, by recognising a distinction between referential and indexical markers their participation in 
such work environments acts to redefine and reconstitute gender relations and understandings of masculinity and femininity.

Breaking free from the binary notion of gender clearly reflects the arguments offered by Queer Theory, as discussed in Chapter two. For example the masculinisation of the gay man from a traditionally effeminate representation to a 'macho' imagery exhibited in its extreme form by the gay skinhead, problematises the conflation of heterosexual orientation, masculine identity and physical appearance. Equally, more promising readings can be provided on butch-femme and lipstick-lesbian practices (Bell et al 1994). Cornwall (1994) discusses the transgendered identities of the travestis of Salvador, Brasil and how gendered identities are assumed and accorded by others given specific contexts. The travestis are a group of (sexed) male prostitutes whose bodies possess both, penises and a hormonally produced feminine figure. They adopt clothing. gestures and styles gendered female, and attract feminine terms of address. The continued presence of the penis distinguishes the travestis from men or women who have undergone sex changes. As such, the travestis move across the boundaries marking gendered difference, and in so doing pose a challenge to the taken-for-granted association of men-male-masculinity and women-female-femininity.

Cornwall's example may provide a destabilisation of the conflation in perhaps rather an 'extreme' form: however, it illustrates many of the as sumptions that need to be questioned concerning all gendered individuals as they are represented in mainstream discourses. The gendered attributions which are considered to structure personalities and behaviours fail to recognise that each individual exhibits both 'masculine' and 'feminine' practices, and indeed that every practice can be both masculine and feminine. A parallel can be offered in the existence of the 'White Negro' discussed by Back (1992. 1994). In his ethnographic studies of south London working-class communities. Back suggests that white male youth both denigrate and valorise certain images of black masculinity. Whilst there would appear to be a considerable degree of racism in such communities, there are at the same time a number of key elements which attract them to black masculine styles. For example the imagery of black masculinity in heterosexual codes of hardness and hypersexuality is regarded as particularly attractive. As such, a 
particular version of black masculinity is adopted in the styles and rituals of white men without necessarily transforming the whites' use of racist discourses (Back, 1994). The linguistic and nuusical codes adopted by these white men are symbolic of this adopted style, epitomised in one form by the white rap or reggae artist (a classic example of this was provided by the Toronto based white rapper Snow and his hit single "Informer"). The transactional nature of racial attributes problematises 'blackness' and 'whiteness' as it does 'masculinity' and 'femininity'.

reconfiguring power

It is my contention that the complexity of power relations is lost to a certain extent in many hegemonic discourses, certain ferninist fran:eworks included, where structures are identified and hierarchical organisation stresses difference between groups. At its most general foundation, feminism is dependent upon the contention that men oppress women and inequalities result from hierarchical power relations. Even where multiple masculinities and femininities are recognised, this pre-defined framework remains necessary in some form. Difficulties arise because such relations of power tend to become assumed and unquestioned. and this results in a failure to actually understand how those power structures operate instead of simply illustrating preexisting notions.

The question of power has been a contentious one in the dialogue between poststructuralism and feminist theories. particularly in the examination of Foucault's work (Ramazanoglu, 1993). In his approach, Foucault regards power as relational; it is an eiusive, negotiated aspect of all social transactions whose existence depends on a multiplicity of points of resistance. Power is implicated in all aspests of social life. regarded as a capillary nc.work in which individuals represent rodes through which this power flows. Rather than being a totalising system, power is diffused throughout the whole social order, from the body, through the workplace to the structural institutions of society (McDowell, 1995). It therefore is not seen as pre-existing in particular groups or individuals, but continually negotiated depending upon specific contexts. This 
formulation enables a movement away from structural notions of power. and in this context, the disruption of the conventional association of men and power.

The implicated fluidity of power relations and the de-emphasis on the structural nature of power has met with considerable concern from a number of feminists. A key concern addressed is that Foucault fails to adequately account for the importance of gender configurations, or indeed his own gendered position (Hartsock, 1990: Cornwall \& Lindisfarne, 1994). Hartsock contends that a Foucauldian analysis offers little beyond a means of criticism and denies those presently marginalised in existing power structures the right to participate in the definition of any new terms of interaction. Her criticisms are primarily twofold. The first is reflective of seeing Foucault as 'with power' in that he understands the world from the perspective of the ruling group and this leads Hartsock to remark that "Foucault's world is not my world" (Hartsock, 1990, p167). She illustrates Foucault's perspective as that 'with power' in that in his work 'other' knowledges appear illegitimate, 'insurrectionary', 'disordered' and 'fragmentary'. To classify counter-discourses in this way, it is suggested, negates their systematic and organised basis. Additionally, Foucault only calls for resistance and exposure of systems of power relations and not necessarily to bring about change. As a result. Hartsock regards such notions of power and resistance as reinforcing the relations of domination and in so doing ensuing that those marginalised groups remain so.

The inability to consider and locate the systematic nature of power provides Hartsock's second major concern with Foucauldian analysis. Foucault is criticised for his stress on heterogeneity and the specificity of every situation in that he loses track of wider social structures. Too much emphasis is placed on the individual as a node through which power circulates. The image of power as capillary and as a result everywhere is seen by Hartsock as implying that power is ultimately nowhe $r$. ince power must not be seen as either an individual dominating others or as one group dominating others, it is very difficult to locate any form of domination. Foucault's argument that an ascending analysis of power should be conducteo which would start from 'infinitesimal mechanisms' and then see how these have been transformed into 
forms of domination is also criticised by Hartsock, since this implies those marginalised are in some way responsible for being so.

Although suggesting that Foucault's formulations are compelling. Cornwall \& Lindisfarne also recognise a number of difficulties with his conceptions. Despite disrupting universalised power configurations, it is argued that power per se is not dissected, nor are the reasons behind gendered attribution properly explored. Indeed, although the capillary nature of Foucault's analysis enables conventional associations between gender and power to be problematised, such associations continue to be implicated in his own work. Thus whilst the problems are recognised, they are not only not resolved but reproduced. Foucault is further criticised for inappropriately theorising his discussion of resistance by not adequately considering the extent to which power is exercised in specific settings. how those under control are constrained, and how those metaphors of control continually change.

In seeking to transcend these limitations, Cornwall \& Lindisfarne draw upon the work of James Scott (1990), which he self-categorises as building upon the insights afforded by Foucault but which aims to provide a more effective analysis to enable resistance to be taken into account Scott also treats configurations of power as relational and elusive, but his stress is placed upon an interest in everyday forms of resistance to counter Foucault's emphasis upon domination. As such it is suggested that Scott's interest primarily considers "the weapons of the weak: in the mundane, informal, diffuse and often individualistic activities through which the relatively weak can influence and frame their responses to dominant ideologies" (Cornwall \& Lindisfarne, 1994. p24). Scott argues that all relations of power are characterised by dual transcripts. those which may be regarded as official, and tho:se classified as hidden. The official transcript articulates, legitimises and constrains the position of superiors and simultaneously maintains the mechanisms which ensure the control of subordinates. Hidden transcripts provide both validation and integrity to subordinates, and also an effective means through which resistance to superiors can be practiced enabling the maximisation of their own benefits given such a configuration. 
Scott contends that only as an extreme measure do the subordinated resort to open activism against official transcripts; more typically and far less visibly, the weak operate so as to maximise their positions within the disempowering environment. As a result hegemonic and subordinated discourses are mutually constructed. Those who dominate are constrained in any particular context by the operation of the hidden transcripts of subordinates, whilst the subordinates are neither passive nor in a powerless position but through these hidden transcripts are capable of negotiating that position in relation to those more powerful. Furthermore, although transcripts may be indexically linked, such that official transcripts are deemed masculine and hidden transcripts feminine, both men and women can refer to official transcripts to legitimise their control over others. Equally, men as well as women may employ hidden transcripts in contexts where such actions would be considered appropriate. Therefore as McElhinny illustrates in the case of Philadelphia women police officers. official transcripts traditionally regarded as masculine are adopted as "professional tools" in the context of their work. Of central importance to Scott's formulation of power relations is therefore this dependency upon contextualisation, where both the wider political economy and more immediate issues at stake are considered. No situation of domination or oppression is ever static: both external effects and internal negotiations in any social interaction alter both official and hidden transcripts.

The focus on resistance offered by Scott provides a useful counterbalance to Foucauldian analysis, but is open once again to critique that explanatory power is greatly reduced by valorising more fluid relations which are context specific. Power cannot be associated simply with masculinity, nor can it be assumed that all men have access to power, nor that the power they possess is referentially linked to the fact that they are men. However arguing against the conflation of 'men'. 'male' and 'masculinity' should not lead to a rejection that gendered power configurations are pervasive at all levels in social life. Exposing the problems of referential linking does not remove its existence. Power becomes implicitly and explicitly gendered through discursive strategies which naturalise the association between male masculinity and power through expressions such as 'men are more aggressive than women' and through the use of metonymic 
associations which produces a commodity logic to masculine identities. Thus. for example, a rhyme common in military environments: 'l've got a rifle, l've got a gun; my rifle's for killing. my gun is for fun!' naturalises the association by reference to the body. and these associations may be transformed or inverted to produce a wide range of meanings.

Power is further referentially (rather than being more correctly indexically) masculinised through its association with those who have control over resources and who wish to naturalise and perpetuate the structures of such relations of production. This relates to Connell's institutionalised masculinity: the organisation of institutions has been traditionally male dominated such that individuals working in those positions become included in particular gendered constructions of power whether they are male or female. Cornwall \& Lindisfarne suggest that attributions and metaphors of 'masculinised' power are so pervasive in society that they also become associated with contexts which actually have little to do with men or masculinity. For example one may consider the portrayal of the active sperm and the passive, receiving egg in the process of fertilisation. That power is gendered, or that gendered attributions instruct all aspects of social relations and institutions is not questioned. However, it is hoped that through destablising the assumptions which structure commonly used associations in theoretical frameworks a more appropriate understanding of the operations of power can be suggested. As Cornwall \& Lindisfarne contend, that whilst there is no notural association between men and masculinity, the relationship cani:ot and should not be considered completely arbitrary either.

The need to both unravel the conflation between men and masculinity and also to conceptualise a more useful framework for considering configurations of power are clearly interrelated. In considering power relations, it needs to be recognised that hegemonic or official discourses always co-exist with subordinate or hidden discourses; the relation between these is far from a simple equation of domination and oppression. A dialectic exists which ensures that configurations of power are never static and fixed, but continually called into question and redefined. However, whilst appearing critical of the use of terms such as 'patriarchy' as overarching and inappropriate, even where 
spatially and temporally mediated, I recognise the mechanisms that operate to ensure that attributes typically associated 'masculine' and 'feminine' become institutionalised and engrained in language. Furthermore, even though relations of power are always context specific and unique, the repetition of acts ensures a degree of congealing such that those relations come to be considered 'natural'. In attempting to resolve these tensions, I shall focus attention upon the mapping of gendered identities onto the body which may be regarded as a site of both resistance and power. It shall be discussed how discourses about gender and sexuality are embodied in transactional relations dependent upon different actors in different social spaces.

embodying the body

anatomy is not really destiny: destiny comes from what people make of anatomy. (Stoller, 1976. p293)

The body is the primary site of social experience. It is where social life is turned into lived experience. To understand the body, we have to know who controls it as it moves thruugh the spaces and times of our daily routines, who shapes its sensuous experiences. its sexualities, its pleasures in eating and exercise, who controls its performance at work, its behaviour at home and school and also influences how it is dressed and made to apprar in its function as presenting us to others. The body is the core of our social experience. (Fiske, 1993, p57)

Advocating the constituted nature of the subject as a means to reconcile the essentialist/constructionist debate, discussed in Chopter two, focuses attention upon the body as a site of mapping and transformation in the practice of gender (Butler, 1990). The neutrality of the body implicated in constructionist approaches is widely critiqued. Gatens (1983) argues that proposing the neutrality of the body carries with it an implicit assumption that posits a split between body and mind, physical presence and consciousness. This therefore denies both the active subjectivity of the person inhabiting the body and how the changing body undoubtedly affects that person's subjectivity. She further suggests that subjects transactionally develop socially and historically specific images of the body, marking and privileging sites of certain experiences and attributes over others. Grosz (1990) contends that there is no such thing as an 'unmarked' body. 
arguing that anatomy is as much a cultural construction as is gender. Similarly, Cornwall warns against treating gender as an additive building upon biological difference, arguing that bodies are not "mere biological material providing a canvas for the bold strokes of gender to be painted on" (Cornwall, 1994. p I14).

McDowell argues that there is no transhistorical male or female essence, but rather "what is called the "body" is a site and expression of different, interested power relations in various times and places" (McDowell, 1995. p79). Bodies should be regarded as sites of inseription where disciplinary procedures and self-regulation of everyday life through functions such as work, rest, diet, dress and sexual mores become marked. As such bodies become particular kinds of body. where "they are rendered social through ethnic or other markers, physiological through surface and metabolic transformations, and psychical through moral dispositions and experiences of pain and pleasure" (Cornwall \& Lindisfarne, 1994, p37). Although biological sex cannot be accorded any direct or referential relationship to character - there is no simple correspondence between sexed bodies and male and female perspectives - as Gatens (1983) argues, masculinity and femininity mean different things dependent upon the bodies of inseription. Grosz contends that "gender is an effect of the body's social morphology. What is mapped onto the body is not unoffected by the body onto to which it is projected" (Grosz, 1990. p73 emphasis mine). Therefore male bodies and female bodies, although both 'open' to masculine and feminine perspectives, experience those meanings differently. This differentiation would suggest indexieal relationships between the gendering of individuals and the sexing of bodies, but it should be stressed that such relations are context specific and are in no sense fixed.

Strathern (1988) offers a theory of embodiment which aims to question conventional definitions relating to gender and how these structure our understanding of how gendered differences are produced and experienced in social transactions and discourse. She focuses upon the characteristics of local discourses of agency, causation and identity to illustrate how gender difference is not simply a consideration of the relations between sexes, but how it is part of a more general system which produces and valorises difference. The notion of the dividual person, introduced by Marriott 
(1976) and utilised by Strathern in her anthropological studies of gender relations in Melanesian societies, provides a particularly useful approach to consider how the bodies become gendered. The 'dividual' person allows human beings to be regarded as having permeoble, changing boundaries and recognises how bodies experience continual movement between different aspects of social life. Marriott explains the transactional nature of the 'dividual' as follows:

dividual persons absorb heterogeneous material influences. They must also give out from themselves particles of their own coded substances -essences, residues, or other active influences- that may then reproduce in others something of the nature of the persons in whom they have originated. (Marriott, 1976, plII)

Gender provides one axis on which the movement of dividuals is conceptualised. The plural, divisible and ever-changing elements of that movement is reflective of the contradictory nature of binary notions of gender. Strathern (1988) employs this notion of the dividual to illustrate how being 'male' or 'female' can only emerge as an holistic unitary state under particular circumstances. The unity of the person - the individual - is made possible by the suppression or removal of the causes of internal differentiation. Thus when either a singular person or a collective group comes into relation with another, that relation can only be sustained to the extent that each party is irreducibly differentiated from the other. Gender practices transform androgyne dividuals into gendered individuals through this process:

In the dual mode [gender dichotomy], a male or female can only encounter its opposite if it has already discarded the reasons for its own internal differentiation: thus a dividual androgyne is rendered an individual in relation to a counterpart individual. (Strathern. 1988, p14)

The body presents an image of an entity both as a whole and as holistic, and although being composed of diverse and plural relations, acts as the site upon which the dividual becomes an individual. Accordingly, the individual, whether classified as male or female, should be recognised as containing within it a suppressed composite identity. 
However, the emphasis placed upon the individual or 'bounded body' as a unitary agent in dominane discourses discourages a more comprehensive analysis as to how people experience themselves and others as 'dividuals'. As a result, it is difficult in these discursive frameworks to visualise how the partible bits of people - scents, tastes. thoughts, emotions, psychic and material conditions of well being and misfortune which can transform and be transformed through interaction, are of importance to the representation of gender difference (Cornwall \& Lindisfarne, 1994).

Althougn Strathern argues that agents themselves do not create asymmetrical power relations between men and women, she suggests that dominance may be enacted through the adoption of relative, momentary and provisional positions. As part of negotiation and reconstitution, the control, discipline and surveillance of bodies is important in the production of docile bodies which conform to historially and spatially dominant forms of representation (McDowell, 1995). ${ }^{3}$ Gendered difference and inequality are negotiated, redefined and recreated in interactions which are frequently repeated but, importantly, never wholly replicated. A recognition of the performativity of gender and the repetition of acts involved pirovides a framework which both disrupts binary notions of difference (including gendered difference) and identifies that as human beings we comprise many different subjectivities. Thus, "people's everyday experiences of inequality, and differentiated access to resources, can be located ... without reintroducing ideas of essentialised, gendered "whole persons"' (Cornwall \& Lindisfarne, 1994. p45).

The aims of transcending notions of gender difference clearly relate to the discussions concerning the transactional and transformative nature of the constituted subject, proposed in a variety of forms by poststructuralist informed writers such as Mouffe. Young. Alcoff and Butler. It is my contention that the 'poststructural challenge' and its apparent threat to the validity of concepts as fundamental as male and female. man and woman, cannot be ignored. Instead, its value in exposing the limiting nature of pre-defined structures characteristic of hegemonic discourses should be recognised. Following Butler's approach, which considers gender as performance and constructed through acts, is not to deny the existence of inequalities experienced between men and 
women. Rather, it provides a mechanism to understand how hierarchical relations can and do emerge through the 'stylised repetition of acts' but does not assume those relations. Of key interest is the contention that this repetition of acts, which leads to the development and maintenance of indexical relations bounding male bodies to masculine attributes and female bodies to feminine attributes, takes place in differene social settings. The spatial dimensions of gender enactment shall provide a focus on considering how a reformulated gendered geography may be developed.

\section{gendered geographles}

An interest in masculinity and masculinities has become increasingly apparent in the geographical literature and conference presentations of recent years. Much of this interest obviously stems from men's engagement with feminist theories, and looking at men' has been regarded as a viable and appropriate field for those male geographers interested in issues relating to gender. The work of Peter Jackson and his explorations of the cultural politics of masculinity has also attracted considerable attention and initiated further research in this area. Indeed, at the 1995 Annual Conference of the Institute of British Geographers, a session organised by the Woman and Geography Study Group was devoted completely to the issues of masculinity, sexuality and representation. 4 it is currently, to use the terminology of a number of my interview respondents, a 'sexy' and 'trendy' area of research. These discussions concerning masculinity (which move beyond acknowledging the masculinism of the discipline) have not been restricted to male geographers, and there has been a recent upsurge in interest in these issues on the part of such feminist geographers as McDowell and Massey. Recognising that men are gendered subjects too has been an important component of this; it enables a consideration of men as men rather than as universal representatives of humanity. As such, an understanding of the implications of economic, political and cultural change on men's life practices provides an interesting focus for research, as for example illustrated in Stuart Aitken's 'young families project'5 which is looking at how familial relations and the practices of both mother and father are transformed over time following the birth of a child. 
Whilst such research represents a more complex and detailed consideration of the construction of gender relations and difference, 1 suggest that it is important to more fully incorporate insights afforded by the destabilisation of traditional configurations of power between sexes as well as problematising the conflation between gender and gendered attribution. It is necessary to question the nature of discourses being utilised and how difference is constructed through those discourses. Do they provide a more critical understanding of masculinity and femininity? Although I would suggest that some feminist frameworks are problematic in this regard because they fail to transcend referential associations between sex and gender, 1 also recognise that feminism accommodates a plethora of standpoints and that poststructural-informed frameworks do enable a more appropriate approach for considering how bodies are gendered. It is my contention that a careful engagement with feminist theories, yet a preparedness to offer constructive critique, should be central to men's (and women's) reconceptualisation of gender.

\section{spacing gender}

Gender ought not to be construed as a stable identity or locus of agency from which various acts follow; rather, gender is an identity tenuously constituted in time, instituted in an exterior spoce through a stylised repetition of acts. (Butler, 1990, p/40 emphasis mine)

Where dominant notions of unity and difference are disrupted, the connection between subject formation and spatiality can be recognised as central to understanding how fractal identities of 'dividuals' appear as individual unitary subjects through the performance of gender. Different identities are negotiated and constructed in different social spaces. Although such spaces may suggest or necessitate a tendency towards particular configurations of gender performance, they do not referentially imply a specific performance. As a result, it is possible, through the spatial translation of a repetition of gender acts to recognise spaces attributed as 'masculine' or 'feminine' through their indexical relation with men and women respectively. Following Butler, acts become stylised and congealed through repetition, but they should never become concretised (and therefore referentially linked to sexed bodies). A useful approach as to 
how particular performances become inscribed on the body is to consider how this 'information' relating to fragmented subjectivities is mopped onto single agents:

I think that the legitimate course of action is precisely to interrogate the making (mapping) of subjectivities in ways which both disclose masculinities and also the ways in which people are mapped, but never elosing the mapping down onto one authorised version which relinquishes other maps and other voices. (Steve Pile).

In a dialectical fashion, as much as social spaces can be considered gendered. spaces can be seen to maintain or redefine configurations of gender relations. Through travelling or movement between different social spaces, bodies necessarily alter gender performances accordingly, to comply to dominant ideologies associated with those spaces. The question as to how flexible a person can be considered in their possible range of gender performances is a difficult one. On the one hand, dividuals provide quite distinguishable gender acts given different contexts. (e.g. performances in familial settings versus those in an 'emotionless' environment such as a job interview). On the other hand, one can generally recognise in any particular person personality characteristics which bound those variable gender performances. To repeat Gatens' contention: masculinity and femininity mean different things according to whether they are lived out and experienced by male or female bodies.

Whilst one can recognise how a single person can enact a variety of gender performances in a variety of contexts, the nature of a person's gender performance can also be shown to undergo changes given a longer-term movement into different social contexts. This relationship between spatiality and fluid subject formations reflects Gregory's experience as he moved from Britain to Vancouver, where in the context of Canada's multicultural postcolonial society and the departmental interests at the University of British Columbia, his 'eyes were opened' to questions of gender and sexuality. Through his movement into a different social environment, not only did he become aware of the centrality of such issues, but it is also probable that to some extent this movement has influenced his own gender performances. His experience is reflected in his consideration of how a geography of masculinity might proceed: 
I think geographies of masculinities really need to explore the relationship between spatiality and subject formation where both of those terms are highly mobile, so that there are multiple conceptions of space that can be constructed and, through that. multiple subject positions that individual subjects negotiate as they move through space and in and out of different spaces. (Derek Gregory).

Gregory has developed this framework in his recent research which explores the travel experiences of Florence Nightingale and Gustav Flaubert through 19th century Esypt. Through reading the respective accounts of their progression along the Nile valley. Gregory postulates that as they moved through this landscape and through these cultures, the transactional nature of their experiences actually changed them. These observations can be recognised more generally in human relations. Every person is representative of multiple subjectivities, and space can be conceptualised in multiple formations: each transaction in a particular setting represents a gender performance subject to continual negotiation. Using this framework, it is insightful to consider the constitution of gender performances and configurations of power at a number of geographical scales.

To enable a discussion of the spatiality of gender performativity two concepts must be problematised. Firstly, by advocating the centrality of social-spatial relations in considering the gender performance of bodies, there is a danger of falling into the potential trap of spatial determinism. In order to understand the difference that space makes' in this context, one must be careful not to attribute causal powers to space per se rather than the social relations in operation in that space. In her examination of social structures and the geography of production. Massey (1984) observes that as there are no purely spatial processes, there are equally no non-spatial social processes. As Sayer argues, social theory must acknowledge that all objects have spatial extension, that "processes do not take place on the head of a pin and that no two objects occupy the same place at the same time" (Sayer, 1985, p55). Yet the question remains: what does this say about actual spatial forms? There is a recognition that it is not simply a question of mapping social relations on to space, but also a need to understand the significance of how and why those relations occur over space. 
Secondly, the value of hegemonic and subordinated masculinities and femininities needs to be reintroduced: in the construction and negotiation of gender performance in different social settings, hegemonic ideologies and interpretations are produced through the repetition of particular gender acts.

notions of gendered difference are constantly created and transformed in everyday interactions. Relations of power are constituent parts of these interactions. The experience of hegemony lies in the repetition of similar, but never identical, interactions. This experience is never comprehensive; it changes over time and space.

(Cornwall \& Lindisfarne, 1994, p10)

Through the operation of discourse. particular gender acts congeal to provide an assumed performance in a given setting. It is essential to stress that these acts never become concretised, nor that referential links can be drawn by their apparent stability. To recognise differences in 'masculinities' in different spatial contexts, illustrates how hegemonic notions of gender performance considered appropriate through socialisation are enacted in particular spatial settings. To identify particular relations and gender attributes as dominant necessitates the suppression of the multiplicity and fragmented nature of both the single dividual and the social group to which that then constituted individual is considered to belong. What is really being considered in this regard are hegemonic heterosexual mole mosculine performances and associated heterosexual female feminine performances. By the nature of our discursive frameworks. there lies the temptation to reify this conflation and concretise indexical relations by making them referential. As a result, when different indexical relations are enacted, whether by the butch-fermme lesbian or the effeminate gay, gendered identities considered 'subordinate' are constructed. Where the relation is further complicated, for example through the skinhead/macho gay male or the lipstick lesbian, then the implications as to what can actually be derived from recognising such hegemonic performances is necessarily questioned. 
do regionalised masculinities exist: Or, do Timmins men possess a different notion of hegemonic mosculinity than Ottawo men?

Gender is constituted differently in Jifferent places, and like class and race relations, is mediated by place and space (Pratt \& Hanson, 1994). As a result, dominant forms of gender relations will exhibit a certain degree of variation at a number of geographic scales. The transaction between the social and the spatial highlights the importance of considering place specific characteristics and the locally defined linkages between work practices, family and community relations, and institutional structures. The fox: ity, and the reinvigorated interest in place and regional studies in geographical research, have been both popular and highly contested since Massey's influential text Spatial Divisions of Lat ?ur (1984). The 'localities debate' during the late 1980 s stemmed from concerns that research focusing upon particular locales, which was attracting a significant proportion of government social science research funds at that time, was simply reintroducing a spatially determined parochial agenda for human geography. The central contention focused upon the acknowledgement that there are, of course, spatial patterns in social phenomena, yet it should not be possible nor appropriate to infer spatial importance from this (Sayer, 1985). Jonas argues thar: the temptation must be avoided of conflating the very different realities of locales with a priori concepts held of the locality, such that the locality per se does not become the object of study rather a more approp-iate consideration of the "competing concepts of locality which may be held by groups of co-located people." (lonas, 1988, p108).

Massey's popular geological rictaphor 6 and her earlier conceptualisations of place, although highly influential, met with significant critique within the context of the 'localities debate' (Warde, 1985: Duncan, 1988; Savage \& Duncan, 1990). However, 1 would suggest that much of the discussion represented a considerable crossing of wires; the arguments offered and the contribution of both 'sides' in the debate were valid. The concept of localities is useful, but equally researchers should be continually aware of its many related pitialls. It is my contention that the more recent interpretations of locality offered by Massey (1993a, 1993b) provide buth a satisfactory outcome to the debate as 
well as providing a framework which enables a more flexible consideration of the social spatiality of gender relations.

Acknowledging the dangers of parochialism where a focus is placed on attempting to define a unique exclusivity to any particular place, Massey suggests that localities can also be viewed where a stress is placed on linkages with the wider world and that this "interdependence contributes to uniqueness" (Massey, 1993a, pl46). Relations tie a locality to many others in a myriad of different ways; places cannot be at all satisfactorily understood or explained in isolation from wider contexts. She argues that it is important not only to consider how 'local' practices are affected by global processes, but also how people at this local level act, through those wider links, to transform or reaffirm the conditions of people's lives in other locations. In developing this framework, Massey (1993b) advocates the effects of power geometries in conscituting a progressive sense of place. This is of particular interest, since it is contended that just as people can be recognised as having multiple identities, then the same understanding can be offered with respect to places. It follows that the uniquene.is of a plare or lo:ality is construed out of:

particular interactions and mutual articulations of social relations. social processes, experiences and understandings in a situation of co-presence, but where a large proportion of those relations. experiences and understandings are actually constructed on a far larger scale than we happen to define for that moment as the place itself. (Massey, 1993b, p66)

Recognising that places do not have singular unique identities but consist of a plethora of internal differences and conflicts clearly parallels with recognising gender as performance and the mapping of bodies at any one time. This is further illustrated where any identification of particular characteristics of a place should be seen as representing moments where those many competing and contradictory forces congeal. As masculine and ferminine gender performances necessitate the suppression of internal difference and the outward representation of difference to create the individual from the fragmentef diviosal, then the representations of place can be considered in the same fashion. This 'photograph' or snapshot of the locality will be very different, given 
different contexts and different photographers. However, like hegemonic gender relations congealing (but never concretising) through a stylised repetition of acts, the same may be postulated for the configuration of all social relations represented in the various dimensions of that place. The transactional relation between social spatiality and the mapping of subjectivity is clearly illustrated by Ross:

to conceive of space not as a static reality, but as active. generative. to experience space as created by an interaction, as something that our bodies reactivate, and that through this reactivation, in turn modifies and transforms us ... creates a 'non-passive' spatiality space as a specific form of operations and interactions. (Ross, quoted by Massey, 1993b. p67)

Of key importance in discussing the potential for regional variation in the configuration of gender relations is the consideration that patriarchal relations are not universal: they exhibit variation in both degree and kind over space and time (Walby. 1990: Duncan, 1994). As Duncan (1991) suggests, social systems do not simply operate in spatially organised contexts, but indeed constitute their own geographies. The social systems are unevenly developed so that the strength, pervasiveness and nature of these systems will not be the same in all places. All social processes are influenced by their spatial existence and are constituted in particular places and in particular contexts Given the critique of dominant notions of power discussed above, my position on patriarchy is held in tension between the limitations and assumptions that such a theory requires on the one hand, and the recognition that general structures of oppression do exist and operate on the other. As an abstract concept, the feminist use of patriarchy was developed to stress the general oppression of women by men. As such, it provides a powerful and critical tool of analysis. Amidst fears of falling into potential essentialism (which it indeed does if conceptualised incorrectly) ${ }^{7}$, the concept of patriarchy has fallen out of favour as an explanatory tool in gender studies (Duncan, 1994). However, it is my contention that these difficulties do not necessitate a rejection of patriarchy; instead, a more critical approach can be provided where patriarchal relations are viewed as stylised gender performances which are by no means fixed or static. 
In this regard. Duncan's (1994) distinction between necessary and contingent structures is useful, and protects against the conflation of referential (necessary) and indexical (contingent) associations. ${ }^{8}$ By recognising this distinction, variations in both degree and kind of patriarchal relations can be accommodated. Furthermore, it provides 2 more appropriate unds, standing of power so that the ability of those in subordinate and constrained positions to resist or qualify patriarchal practices can be taken into consideration. Thus some women can and do benefit from patriarchy, whilst not all men make effective patriarchs. Although Duncan suggests that the reconceptualisations offered by Walby in Theorising Patriarchy (1990) has refocused the patriarchal debate. he suggests that the reformulations nes:- 10 go further. As a resul: he advocates the integration of Walby's 'six dimensions of patriarchy'9 with the insights afforded by Scandinavian feminists' research on the gender contract.

At the level of the State. Duncan argues that the gender contract represents the operationalisation of the gender system: each society and time develops a contract between the genders where rules establish what people of different sexes should do. think and be. Therefore the contract may be seen as representing the congealing and institutionalisation of gender practices which are both voluntary and constrained as well as being context specific. A focus upon the Scandinavian countries, and their established traditions of social democracy, illustrates how the gender contract has responded to and reflected changing social, economic and cultural relations. After many decades of pursuing gender equity, high levels of women's engagement in paid work, and their equal representation in government and institutions are matched by enviable childcare provisions and paternal leave available to fathers as well as the mothers of children. As a result of such frameworks in place, hegemonic notions of 'masculinity' and 'femininity' in, for example, Sweden would be expected to reflect quite different gender relations than those seen in other countries. Such differences can be empirically recognised and Scandinavian societies would appear more egalitarian in questions of gender equality. However, Duncan contends that the gender contract, in whichever form, has typically acted in favour of men. The potential crisis instigated by women's increased involvement in the public sphere has been negotiated and offset by State apparati instead of 
necessitating fundamental changas to the operation of gender relations at a more personal level. Conversely, although men have been legally entitled to take paternal leave for many years, in reality the practice is not regarded as appropriate by either employers or other men (Pleck, 1993: Haas, 1993).

Whilst Duncan's focus is the State, such gender contract variations can be seen at smaller geographic scales. As various geographical locales may exhibit quite specific class and labour relations, they also give rise to quite different dominant notions of appropriate masculine and feminine performances as expressed through gender relations. The complex and multiple nature of gender performativity ensures that how gender acts become stylised and congealed will very much represent their interaction with a plethora of other factors, such as local economic histories and labour relations. familial structures, local State organisation, religious and cultural considerations. An excellent example of this process is provided by Parr (1990), who illustrates how distinctive cultures of gender relations emerged in her study of two Ontario industrial towns between 1880-1950. A depiction of similar processes but in a quite different context is offered by Loizos (1994) in his reading of Greek society. He describes how a range of hegemonic masculinities and their subordinate variants are produced when various institutions such as the military or the church intersect with regional differences, for example inheritance rule, at different stages of men's lives.

The process of creating a sense of stability and hegemonic relations through the repetition of acts should always be considered as both transactional and mutually transformative. As Pratt \& Hanson (1994) depict in their study of women's labour patterns in Worcester MA, the social characteristics of men and women living in differer.c local areas define the character of the place, and once such characteristics are congealed through repetition in space, these places act to harden boundaries between social groups. This also is clearly reflected in Robinson \& Sadler's examination of the reproduction of social relations in the steel town of Consett in Northeast England follor $g$ the works closure: 
The works was of fundamental importance in the determination of routine action in the town. For example. the fabric of Consett was for many years maintained by the routine action of steelworkers clocking on to their allocated shifts, drinking at their favourite pubs or clubs, at the same time maintaining a gender division of labour which kept the women at home. This fabric was re-inforced by a time-honoured tradition of sons working in the same part of the works as their fathers. (Robinson \& Sadler, 1985, p1 17)

Many of the 'localities' studies carried out in Britain have focused upon areas undergoing significant upheavals in the process of economic restructuring, such as coal mining communities and steelmaking towns. Similarly in Canada, the restructuring of the pulp and paper industry has provided a focus for localities informed research. 10 A particularly insightful study in this context is provided by Corman et al (1993) who consider the effects of global restructuring upon the city of Hamilton, Ontario, and specifically on the Stelco Steelworks. Initially, the authors' were interested in the challenges facing women entering into a traditionally male-dominated environment, and how gender performances were negotiated and transformed in this process. As the workforce struggled through recessionary pressures from the early 1980s onward, their interest in changing gender relations focused more on the social and economic consequences of men being laid-off, the unpredictability of being 'called back' and fluctuational unempl. nent. The restructuring of local labour markets in these areas historically dominated by primary industries has left many skilled men out of work and led to an increasing participation of women in low-paid, part-time employment. Although such a trend may be apparent not only in different regions but also across the more industrialised economies, it does not necessarily lead to similar responses of altered regional patriarchal configurations and therefore dominant gender performances and relations. Negotiation and transformation are always context specific. Here, Massey's reconceptualisation of the locality as a unique (and momentary) representation of the interaction between local and global activities is useful. 
different worlds?: congealed spaces and spoces that congeol

You automatically try to prevent coarse language. When $I$ am at home I don't swear, but as soon as I walk in that gate, something happens and you start swearing. It is just a natural thing. Because you figure, oh well, there is all guys here. I think you find two different personalities. I'd just say everybody, almost everybody. has two different personalities. (Corman et al, 1993)

Different masculine and feminine identities are constructed through the stylised repetition of gender performances which are enacted through time in different social spaces. At a result, situated masculinities are constituted and structure how activities and occupations come to be gendered. That space is gendered is well recognised; however one can equally consider how spatiality encourages, constrains or compels particular gender performances. Two social environments which would appear to be quite different shall be considered to illustrate the relation between space and gender constitution: firstly, the socialisation of Shona men in Zimbabwe; and secondly, the social spaces of merchant banking, the stock market and the trading floors of advanced economies.

In reflecting on his childhood in Zimbabwe. Shire (1994) emphasises the importance of well defined masculine and feminine spaces in the development of appropriate gender performances of Shona men. Social spaces come to be regarded as male or female through the repetition of gender acts, so that those spaces are indexically associated with a particular gender. Shire suggests that particular usage of languoge is central to the negotiation and construction of masculinities in both male and female defined spaces. In male spaces, men can show their male qualities by skillful language use which acts to contest and confirm particular masculinities. As a result competence in the 'language of men' and the use of specific forms of discourse is essential for acceptance in such spaces. In the village, the most important male space is the Dare, a meeting house where various ideals about maleness are continually reshaped and embellished through the use of metaphor and proverbs only fully understood by those who exhibit linguistic versatility. As young boys pass into the Dare, they learn the language of men and are taught about the gender of certain material objects central to 
the construction of particular male identities. It also provides a space in which men exchange experiences and are taught about making love and pleasing women.

Shire illustrates how spaces designated female are also central to the shaping of masculinities, and indeed argues that women help construct masculinities throughout the lives of men. Women in female spaces have a material culture which is the exclusive preserve of women and men are not particularly welcome in these environments.

During childhood, however, it is quite common for Shona boys to move between gendered domains. When they enter female spaces, it is wholly inappropriate to talk about masculinity or other men since male discourse is restricted by the women. Male gender identities are constructed in fernale spaces through both processes of exclusion and also through the teaching and advice given by older women. Indeed. Shire argues that more than anyone, the Aunt, or Votete, reinforces and congeals myths of maleness. This apparent dichotomisation of gendered space is very much mediated in the spaces of personal relationships, where 'lovers' discourse', or modonho omugudzo, enables the mutual reaffirmation of masculinity and femininity in a positive manner.

The masculine identities of Shona men, like all men, are not homogeneous but associated with particular language uses and particular gendered terrains. Movement between different spaces at different times in their lives are mediated through gender specific languages. In 'traditional' Shona society, power relations tend to be gendered but do not necessarily follow a single-sex structure: they can be organised as much around female as male dominance. However, Shire argues that as Shona men migrate to cities or are forced onto farming compounds, the negotiation and construction of gender and power relations take place in different spaces and contexts. Although identities are being continually defined in traditional communities, the redefinition in these other spaces akes place in a context which is dislocated from hegemonic r.otions which are usually congealed in particular Shona masculinities. For example, in the city, it is suzgested that the masculinities of urban Shona men are constructed through their relation to wage labour and their assimilation into a society structured by colonial discourses. In terms of language usage. Shire contends that the discourse of men in urban spaces comes to reflect the valourisation of misogynistic and phallocentric attitudes. 
Whilst negotiation and construction of masculinities is clearly illustrated by the movement of Shona men through different spaces in different times, the implicit spatiality of gender constitution can be recognised in all societies. A popular focus of gender studies has been the consideration of how identities are produced and reproduced in work environments such that occupations are associated with particular gender attributes. In their study of merchant banking, MeDowell \& Court (1994) reflect that although many studies have recognised the existence of male and female occupations, there has been little consideration as to how these gendered associations come to be negotiated and constructed. They argue that occupations and the configuration of social practices that constitute them are constructed so as to "embody socially sanctioned but variable characteristics of masculinity and femininity" (McDowell \& Court, 1994, p231). Both formal and informal work practices are not gender neutral but are 'saturated' with specific meanings which, it is suggested, construct gendered subjectivities at work.

The visibility of women in merchant banking has, until recently, been extremely minimal. This was particularly so in what may be considered the highly defined masculine spaces of the trading floor. During the rapid growth of employment in the financial services sector during the 1980s, there was a dramatic increase in female participation although in percentage terms, they remain a small proportion of all traders. McDowell 8. Court suggest that the space of the trading floor requires a very particular form of masculine performance which reflects the domination of those spaces by men and the nature of the work itself. As a result, women who wish to compete do so by becoming 'honorary males' and adopting appropriate masculine behaviours:

The relationship between a female body and lack of power is, of course, part of the reason why women have been forced to act as if they were men to achieve success ... gender and appearance is at odds with the masculinist nature of the occupation that they fill and the tasks they perform. (ibid., p233)

The space is continually renegotiated as a masculine space through quite specific language and metaphor use. (Hetero)sexist connotations dominate both dealing and 
personal discourses on the trading floor and although often offensive in nature. particularly when people are new to the floor, are utilised by both male and female traders. This initial reaction is succinctly portrayed in a newspaper article by a young female dealer's assistant who said 'she felt like a stripper on a stag night' when she visited the trading floor (Lafferty, 1994). Where a male dealer is being notably successful in 'working the markets', he may be referred to as 'Big Swinging Dick'; when a female dealer is so, she becomes an 'Honorary Big Swinging Dick' or a 'Big Swinging Dickette." Gender in this environment is very much a well defined performance for both men and women, and it necessitates appropriate, context-specific interaction. Consider the following reflections provided by young male traders on the floor:

The people who work in the City are not great ones for improving the lot of mankind; they are people who are prepared to compromise their beliefs. Their attitudes towards women also get compromised. It would be terribly prissy and insulting to be particularly polite towards women who choose to work in this very male environment. The women tend to be treated as if they were one of the boys and will talk in much the same aggressive way. (Lafferty, 1994)

we are all chameleons. My accent will flip depending on who I am talking to. A well-spoken public schoolboy will talk like someone from Essex when he's at work, otherwise he'll become a spoon. (ibid.)

McDowell and Court also recognise quite different masculine performances in the upper echelons of corporate finance. Also male dominated, the valued masculinity in these spaces reflects a 'staid and sober paternalism'. Furthermore. women working in these spaces, or adjunct to these spaces, fulfill feminine roles which would be considered more traditional. The value of McDowell \& Court's research lies in its recognition and movement away from static notions of men and women complying with expected roles in an already gender-differentiated work environment. Furthermore, the constituted nature of the multiple subject and the importance of language are acknowledged. However, although the authors discuss the existence of masculine and feminine performances, both a tendency for conflation and the advocacy of notions of power in which men's don.ınation and women's oppression are assumed warrant further examination. 12 Rather than a priori accepting these structures, it is beneficial to 
understanding if and or why such power relations operate. A more recent article eminating from this same piece of research resolves many of these tensions, where MeDowell (1995) excellently considers the significance of the body and largely transcends problematic conflations between gender and gender attribution.

o voluoble framework

Notions of maleness, designations of manhood and attributions of masculinity have no essential referent, nor even a finite range of referents. Rather each of the three terms can be used to describe a wide variety of different and even flatly contradictory aspects of human bodies and human behaviours.

(Cornwall \& Lindisfarne, 1994, p9)

It is my contention that the framework developed in this chapter provides a valuable approach to a more critical analysis of gender. The limitations of dominant theoretical approaches result from an inability to destabilise pre-given assumptions concerning configurations of power and to transcend the inadequacies of existing discursive frameworks. This latter point is reflected by the tendency for conflation between indexical and referential markers in gender analysis which leads to the advocation of rather assumptive associations between men and masculinity, and women and femininity. Dislocating these corollaries does not deny their real existence, but necessitates a more comprehensive understanding as to how those relations are established.

A recognition that gender is constituted through performance and particular enactments emphasises the significance of the body in the transformation of the dividual comprising multiple and contradictory subjectivities into the sexed individual. Bodies act as site of mapping and transaction, and spatial processes are of fundamental importance in this regard. As has been illustrated at a variety of scales, different gender relations are negotiated and constructed through particular acts in different social spaces. Although spaces may suggest or necessitate certain configurations of gender performance, they do not referentially imply a specific performance. Acts become stylised and congealed through repetition, but they can never become coneretised. As a result, it is possible to 
recognise spaces attributed as 'masculine" or 'feminine' through their indexical relation

with men and women respectively.

\section{endnotes}

I For example, in Britain, after 15 years of the 'trickle-down wealth' philosophy enacted by a right-wing Government, increasing polarisation between rich and poor is being experienced in an already deeply dwided society. Sociologist Charles Murray (of 'Bell Curve' notoriety) suggests that Britain is moving steadily towards the experience of the United States in the creation of a New Victorian Middle Class and an Underclass. based primarily on rising illegitimacy rates and the lack of responsiblity of uneducated. unemployed absent fithers.

2 Nor are they unrelated to one another. The documented cases of lesbian abuse is only one example. It is usually tied to internalised heterosexism and sexism.

3 McDowell contends that there are specific practices that produce particular feminine versions of docile bodies, reflected for example in conformation to idealised notions of feminine beauty and heterosexual attractiveness (Bordo. 1992: 1993). I would argue that those processes recognised by McDowell in terms of fermale bodies can also be seen to a different form and degree in the practice of male bodies.

4 The session in question included the following research interests:

WGSG - Sexuality and Power Module 4: Masculinities Sexuality and Representation

CHAIR: Pat Patten (Nottingham Trent University)

"Racism and myths of masculinity in the mythopoetic men's movement"

Alaistair Bonnet (Newcastle University)

"'Are we not men!' Popular topographies of marooned masculinity"

Gregory Woods (Nottingham Trent University)

"Rethinking (safer-) sex and the geographies of power and resistance"

David Woodhead (Queen Mary and Westield College. University of London)

Outside this devoted session. other papers which focused upon a consideration of masculinities were:

"Reconceptualising consumption: the geography of masculine identities"

Kate Housiaux (Southampton University)

"Masculine utpoias and nation building: Patrik Pearse and St. Edna's"

Elaine Sisson (Trinity College. Dublin)

5 intormation derived from interview.

6 Using the geological metaphor, each locality may be seen as being composed of a variety of strata which together ereate unique local characteristics ( $p \mid 43)$ :

"Spatial structures of different kinds can be viewed historically as emerging in a succession in which each is superimposed upon. and combined with, the effects of the spatial structures which came before. Each new layer, each new round of investment, brings with it potentially new economic bases of social organization"

In subsequent material, Massey has pointed out that the geological metaphor often attributed to her was indeed derived from another source.

7 No matter what form is taken by gender divisions, the essence remains in place of male dornination female subordination which remains the same throughout history and across different types of society.

8 Duncan's use of the terms necessary and contingent recognises his theoretical underpinnings in realism. For a more comprehensive discussion on realism. see Sayer (1985, 1993).

9 Walby suggests that while gender relations could potentially take on infinite number of forms, a number of widely repeated features may be recognised. In this regard, six structures constituting pariarchy are idencified: paidwork, housework, sexuality, violence, the State and culture. Their complex interrelation creates a myriad different lorms of patriarchy.

10 Glen Norcliffe. John Holmes, Valerie Preston. Damaris Ros?. Roger Hayter and Suzanne Mackenzie. are presently involved in a comprehensive research project wit. h is considering the implications of the restructuring of the pulp and paper industry on production sites' proximate localities across Canada from Comer Brook. Newfoundland to Red Deer, Alberta. 
11 Interestingly, although the differentiation between these two phrases would appear minimal, eaming the title 'honorary big swinging dick' implies 'becoming' a man, whilst 'big swinging dickette' implies a gendered attribution. where dick becomes dickette and according to dominant linguistic forms, feminine.

121 do not wish to provide a full discursive analysis in this regard, however consider for example the limitations imposed by discourse by the following comments. Refering to insurance selling. McDowell \& Court suggest it is a job that might draw on quintessentially feminine attributes. It invokes the presentation of self as pleasant, sympathetic and non-threatening, congenial attrtude" (p237). Equally, after defining particular characteristics of the trading floor. it is contended that "masculinity seems almost an inevizoble corollary of these attributes." (p240). Emphases mine. 


\section{Conclusion: transcending difference}

The original aims of this research were twofold: firstly, a consideration of men's engagement with feminist theories and practice; and secondly the potential for a greater incorporation of questions regarding men and masculinities in geographical gender studies. It is my contention that the key issue in both areas is the question of longuoge and the power associated with particular discursive strategies. A better understanding of how discursive strategies operate within social-spatial contexts to construct difference, and in particular gendered difference, enables a more effective approach in considering issues of gender.

mole feminism

It is my contention that much of the debate regarding male feminism focuses upon the inevitably problematic nature of this relation and that this is a result of predefined and unquestioned assumptions concerning gender. This is reflective of dominant Western discourses' continued reliance upon advocating difference and, spec 'fically. binary notions of gender. The result is a tendency to conflate our understandings of 'men', 'male' and 'masculinity' and equally those of 'women', 'female' and 'femininity'. Associations which should be seen as contingent or indexical become reified, referential and natural. This is not only seen in material labelled essentialist, but also in work which advocates anti-essentialist frameworks. As has been argued, social constructionist approaches remain dependent upon inappropriate conceptualisations of sex/gender (Fuss, 1989; Butler; 1990). How do these limitations of discourse make men's engagement with feminism problematic! There has often been a tendency on the part of male theorists to intertwine the feminine with the feminist, and also an apparent desire to 'write as a woman', which ensures that they themselves make their own positions difficult to justify. Equally, on the part of these men's feminist critics, their engagement with theoretical frameworks which remain dependent upon recognising a difference between men and women, and which also tend to unquestioningly conflate men, masculinity and masculinism, establishes barriers preventing a resolution to a pre. determined impasse. 
The interviews held with male geographers reflected a high level of awareness of the concerns surrounding men's engagement wit'? feminist frameworks, even when it was acknowledged that such issues were ditr wit to transcend. Problems of 'gender tourism' and arguments that men have appropriated, objectified, universalised and misrepresented feminist discourses have been noted. Many of the geographers interviewed had met a certain degree of criticism related to such concerns about their work. Although I would argue that many published responses to men's er:gagement with feminist discourses within the discipline have been rather hostile and illustrative of an unfortunate level of intolerance. I acknowledge the widespread personal support these male geograohers have typically received from feminist colleagues. Furthermore, as the skirmishes among male geographers illustrate, sexism remains a prevalent problem within the discipline.

Through dislocating gendered attribution from referential associations with sexed bodies, many of the assumptions which structure the men-in-feminism debate can be destabilised. However, I am not suggesting that in this process men's engagement with. feminism becomes unproblematic and accepted: exposing some of the theoretical contradictions cannot resolve the more politicised implications to be addressed. Indeed. even if the latter are recognised, many contentions remain unresolved. From this standpoint, proposing certain strategies to resolve the conflicts inherent in men's engagement with feminism wuld fail to recognise the need to reconceptualise how discussions of gender are structured by discourse. My own position draws upon the insights provided by poststructuralist-informed feminism, and in particular the works of authors such as Mouffe, Butler, and more recent discussiuns by Segal. I remain continually aware of the need not to homogenise feminist thought, but would argue that mainstream discourses in feminism tend to remain tied to the contradictory limitations which have been discussed. I we ild suggest that this has especially been so in geography. Therefore it is not simply a case of accommodating men's interest within existing feminist frameworks; the often contradictory nature of those frameworks need to be exposed. In this regard, I do not fully support Back's position and his contention that: 
It is important for men to find a voice ... but we also need to be careful. If feminism has partially shaken up academic discourse, men might find it strategically beneficial to pick up on feminised academic areas which are now associated with ethical and political virtue. We need to develop a fully $g$ andered perspective without appropriating and transforming feminist social theory and epistemology. If there are changes occurring in male academic life, we need to be sure that they are happening for ameliorative reasons, not simply for personal advantage. (Back, 19?2, p230)

I agree that, as men, it is paramount that we/they neither misrepresent nor merely appropriate feminist theories because they are seen as strategically beneficial and politically virtuous. However, to be concerned as to whether our engagement may transform feminist social theory acts to objectify, even mummify, Back's understanding of feminism. Feminism cannot and should not be regarded as a set of fixed. unchanging procefures; it does not provide a recipe to be adhered to in order to obtain a desired result. Men shc slo be concerned that we/they do not appropriate and then dictate the directions of feminist discourses, defining what are 'suivable" or 'unsuitable' topics for research. Men's involvement should however enable useful critique which can challenge feminist discourses, and as such contribute to the continually shifting boundaries which feminist theories already represent irrespective of the inclusion of men.

It is the structure of dominant discourses, not just feminism, that create linguistic barriers which prevent the very issues at stake to transcend a priori conceptualisations. therefore determining the outcome before any degree of analysis has been undertaken. Notions of difference are central to theoretical constructions, ; ct the definition and constitution of those differences cannot easily be problematised without reducing the explanatory powers of that particular framework. In considering issues of gender. discussions have often been reduced to ensuring irresolvable barriers between men and women. In its starker forms, an effective gender war is apparent in a plethora of contex $w$ in contemporary society. I am certainly not ateributing responsibility here solely to feminism: it is a situation which arises out of limitations of language which both genders may fall victim to or may use to their benefit. Furthermore, much of the invested power within discursive strategies remains the preserve of men. However. 
feminist discourses (again, I do not wish to universalise feminism) have to accept a certain degree of responsibility in this regard.

The question of a bocklosh to feminism has become an increasingly complex one. On one side of the argument, it is apparent that policies aiming to promote gender equality. for example affirmative action, have come to be viewed with growing disdain by a tide of right-wing resurgence in the United States ignoring or negating feminist writers' illustrations of the continued oppression being experienced. For example. Faludi (1992) contends that despite the struggle for gender equality, especially since the 1960s, very few gains have actually been made: indeed, towards the end of the 1980s. some of those improvements were threatened or being dismantled. Additionally, books which I would argue represent a male backlash, although their authors may contest this categorisation, have enjoyed considerable success in mainstream society. Morgan's Not Guilty (1993) and Farrell's The Myth of Male Power (1994) provide good examples of such material, and even more blatant (yet very popular) arguments are offered by the likes of Rush Limbaugh.

However, on the other side of this debate, it becomes clear that the motivations and debates concerning backlash are not quite so clear cut. Feminist writers such as Roiphe (1993) and Sommers (1994) have questioned many of the assumprions and factual information utilised by other 'popular media' feminists to assert their claims. Sommers has exposed some quice dramatic inaccuracies made in the arguments of writers such as Faludi, MacKinnon and Steinem; indeed Steinem is entitled the 'Heao of the Ministry of (Ms)Information.' In her critique, Sommers denounces the objectives of a 'gender feminism' which has no other outcome than to position women against men: "This Thelma And Louise ferninism is going nowhere. We have to save feminism from the feminists. We should not marginalise women into male-hating angry people" (Sommers, quoted by Grieg, 1994). Whilst concerns over backlash expose the hostility and misrepresentation on both sides of the argument, it is important to remember that more fundamental issues remain incact. To the women who have experienced poverty. abuse and unequal chances in life 35 a result of gender inequality, these issues remain as 
real as ever. Equally disturbing has been the failure of existing discursive frameworks enable a more effective understanding of particularly sensitive issues, such as date ra and recovered/false memory syndrome, which have been constructed in ways that inevitably frame women against men and vice-versa.

The backlash debate and its intractability are inevitably heightened through media representation; however the inability to transcend gender-defined positions is reflective of frameworks which (although less explicit) continue to structure our theoretical understanding of issues concerning gender and sexuality. The dangers of simplistic assumptions leading to problematic relations are excellently exposed by Segal's (1994) discussion on how dominent feminist discourses on sexuality have evaluated heterosexual practices. The challenges made to notions of heterosexuality. Segal contends, have subsumed straighe women's positions within radical frameworks. This marginality has been most difficult for those close to feminism, so that:

In recent years it has been feminist polemic, rather than male backlash, that has done most to confuse and discourage new thoughts on sexuality. Heterosexuality has been coupled consistently with male violence, and presented as bott. he cause and enactment of men's power over women. (Segal, 1994, p16)

The aims and beliefs which fuelled sexual liberation during the 1960s have been dismantled and heterosexual pleasure is regarded as something only representative of "enjoying the seeds of victimhood" (ibid.. p 17). Segal asserts that dominant discourses concerning sexuality, promoted by popular writers such as Catherine MacKinnon, fail to represent the realities of most women's (and therefore men's) lives. The notions structuring our understandings of heterosexuality need to be reconceptualised. In this regard Segal draws upon the work of Butler to suggest that not only are all sexual acts. including lesbian and gay ones, 'hetero' in some form, but also that the sexual act more than anything represents the faltering and blurring of taken-for-granted gender identities. Equally, she argues that the importance of language must be recognised in enabling sex and gender hierarchies to survive despite their increasingly obvious contradictions. 
straight women (and men) should also play a part in this subversion [of symbolic codes and constraints of discourse]. Instead of guilttripping heterosexuals, we would do better to enlist them in the 'queering' of traditional understandings of gender and sexuality, questioning all the ways in which women's bodies have been coded as uniquely 'passive', 'receptive' or 'vulnerable'. But we must also look at male heterosexual desire (and how their bodies become 'receptive' and 'vulnerable') since the two are inextricably linked. (ibid., p18)

Similar to advocating the involvement of heterosexuals in discussions of sexuality, the inclusion of men in gender studies should be regarded as central, and if this is to be more than simply a token inclusion, then the discursive frameworks which structure our understandings need to be re-evaluated. From this position an inevitable question arises concerning the political commitment and willingness on the part of men to contribute purposefully to a more incorporative gender studies, and of equal importance, a willingness to make changes in their lives which would necessitate the rescission of previously held aJvantages. As Segal suggests, it is important not to lose sight of a social reality which continues to maintain and enforce a gender hierarchy which would appear particularly resist it to change. Men's interest and involvement in such issues remain minimal, and as Connell argues, this is understandable given the positions of privilege that men nold:

Both experience and theory show the impossibility of liberating a dominant group and the difficulty of constructing a movement based not on the shared interest of a group but on the attempt to dismantle that interest. (Connell, 1990, p465)

Despite the seeming intractability of gender relations, 1 suld argue that negotiations and reconstitution are continually taking place, albeit in 'slow motion' (Segal, 1990). Whether recent changes are merely reflective of 'crisis-management' and adjustment which maintains extant power configurations, or if they do indeed represent an irreversible trend (Wilkinson, 1994), it is essential that these developments are not inappropriately conceptualised due to inadequate frameworks. As the Seven Million Project' has indicated in Britain, the value maps of the fourteen million (seven million men, seven million women) Thatcher generation - those aged between 18 and 34 - are considerably different than those of older generations. This is perhaps not wholly 
surprising: more so is the definite rejection of traditional sex roles and stereotypes among beth women and men. The project illustrates how the attitudes of men and women in the younger age group have in general become more 'feminine', coupled with the belief by the majority of men that qualities such as gentleness, sensitivity. independence and strength are no longer the preserve of either sex. A disillusion amongst this generation with feminist politics and the women's movement, indicated by many surveys, is reflective of a wider dissatisfaction with conventional politics. Feminism both academically and in practice would appear to have become dislocated from the experiences and opinions of the younger generations. As Wilkinson argues, the fault for this does not merely lie with the male-dominated media:

The failure to win a new generation also reflects the failure to develop new messages that $g \circ$ beyond the assertion of rights relative to men and demand for quantitative changes. These arguments antagonise a younger generation of women who value a blurring of gender difference and who find the demanding language of the movement ali: nating. Given that there are bigger differences in values between older and younger women than between younger women and younger men, we should probably not be surprised. (Wilkinson, 1994. p46)

spocing gender

Reconfiguring our understanding of difference, and how gendered attributes derive from them, enable the limitations of existing frameworks to be transcended. Problematising existing notions of power relations and exposing the dangers of conflating men and masculinity, women and femir,inity indicates the need to account for the multiplicity and fragmented nature of the subject and retain a consideration of the influence of social structures in the constitution of that subject. The inadequacy of both essentialist and social constructionist positions which fail to attribute any meaning to sexed bodies has been exposed, and a potential resolution has been afforded by poststructural frameworks. The insights afforded by Butler have been particularly important in this regard. Treating gender as performance recognises both the contextspecific nature of that particular enactment, and also that any one agent can adopt a plethora of different performances. By advocating this position, the existence of 
categories such as 'men' and 'women', or the practices of 'heterosexuality' or 'homosexuality', do not cease to exist; rather the constitution of each of these groups or acts is acknowledged as being particularly complex and full of contradiction.

In developing these ideas, the notion of the dividual is particularly useful. Each dividual represents multiple subjectivities, and gender represents one axis on which the constitution of dividuals is conceptualised. The dividual only represents a holistic unitary state, becoming an 'individual' male or female through the suppression or removal of the causes of internal differentiation. Thus when a gendered individual comes into relation with another, that gender relation can only be sustained to the extent that each party is irreducibly differentiated from the other. As a result, any particular representation of the individual necessitates the momentary fixing of certain relations and the removal of others. The importance of the body as a site of mapping needs to be recognised in this regard: furthermore, although no association should be drawn between between sex and gender performance, it is clear that masculinity and femininity mean different things according to whether one is considering male or female bodies (Gatens, 1983, Grosz, 1990).

Approaching gender as enactment or performance does not deny the existence of men and women, masculinity and femininity; rather than assuming pre-existing notions of power and inequality, such a framework provides a means of understanding how such hierarchical structures can and do emerge through the stylised repetition of acts. Although no two acts can be considered identical, a repetition of closely similar acts leads tc a congealing of structures and relations based upon those acts. As a result. 'he development and maintenance of indexical relations which tend to associate male bodies to masculine attributes and female bodies to feminine attributes occurs. This process should in no way represent a fixed and static structure, each relationship is subject to renegotiation, reinforcement or challenge through each and every performance. Therefore whilst structures can be observed, it should be remembered that at any one moment they only represent a congealing made pojsible through interial suppression of contradictory and multiple subjectivities. 
In considering the performativity of gender and the mapping of subjectivities upon the body, the centrality of social-spatial relations in these processes becomes apparent. As much as gender is a primary dimension of geographical relations, geography should be recognised as a fundamental component in the constitution of gender relations. It is in this consideration of the importance of spatiality to the performance of gender giving rise to differently constituted individuals from multiple dividual entities in any one space at any particular moment - that a focus on a reconceptualised geography or gender can be advocated. Different gender identities are continually constructed and negotiated in different social spaces and these spaces are instrumental in the congealing of repeated acts. As part of this process, understanding the importance of language and the power invested in discourse, whether on the football terraces in England, the dare of Shona communities in Zimbabwe, or the 'intellectual' discussions articulated in a seminar in a North American university, are crucial.

To provide a concluding illustration, the spatiality of gender performance and the constitution of gender identities as wonderfully portrayed in Bill Forsyth's film 'Gregory's Girl' (1980) shall be briefly considered.2 The story centres upon Gregory's desire for the school football (soccer) team's new forward, Dorothy. In Britain, the spaces of soccer are strongly coded masculine, both on the pitch and on the spectator terraces. The infamous nature of English soccer hooligans and the troubling presence of right-wing activists (albeit extremely small) in the crowds has established soccer's reputation as a rather violent pastime. ${ }^{3}$ By contrast, it is interesting to noce how soccer is gendered quite differently in North America where it represents only a minor sport. Larger numbers of women are actively involved in the game, and this is reflected in representations of the sport in the media and advertising. This general observation is not to deny the active participation of women players in Britain; indeed, there are organised leagues and annual championships. However, the gendered construction of the sport continues to ensure that women's involvement is seen as unexpected or unconventiona!

Within this context, the message relayed in 'Gregory's Girl' can be more fully appreciated. The setting of the film is especially significant, particularly when considered 
in the context of another of Forsyth's films, 'That Sinking Feeling'. Here, the plot focused upon a similar age group, excellently portraying the mundane routine and boredom experienced by a group of young men in Glasgow, set against a backdrop of inner-city deprivation and dreariness. By contrast, in 'Gregory's Girl' the modern, clean environment of Cumbernauld New Town, twenty miles outside Glasgow, is portrayed as symbolising all the hopes of a 'New Scotland'. Using this new space as the location for the film. Forsyth effectively parodies and inverts, in an intentionally contrived fashion. traditional relations structuring society and the taken-for-grantedness of gender roles. Gender role inversions are found throughout, from Dorothy's position on the football team, to the far superior wisdom of Gregory's younger sister, to the scenes where the girls are pictured in the science lab and the boys in cookery class. Adults are remarkably absent, and where thev do appear their characters are treated with appropriate irony. Configurations of power are associated with wisdom, and the pre-teen characters are portrayed as very much more worldly-wise, as are the girls at school compared to their rather pitiful male colleagues. As forsyth moves through the social spaces of Cumbernauld, frequently employing long range shots of 'our town', the centrality of spatiality to the construction of our notions of gender is illustrated very poignantlv. As Eric, the school photographer, and Gregory conclude about Dorothy and her soccer playing:

Gregory: "Her like a boy? - No, she's just modern"

Eric: $\quad$ "Right - It's modern, It's the future. In another million years they'll be no men, no women. It's logical evolution evolution's a thing."

\section{endnotes}

\footnotetext{
The seven million project represents a comprehensive analysis of the changing values and attitudes of the 7 million men and 7 million women aged between 18 and 34 in the UK. They are recognised as the first post-equality generation, brought up after the achievement of equal opportunities legislation and a culture which has turned against diserimination. The project, conducted by the independent think-tank DEMOS, illustrates how the 'value maps' of younger generations - what is of importance and value to them - are converging berween men and women, whilst the divergence between older and younger generations remains in place. The research involved extensive surveying thousands of people over a period of owenty years.

2 For a more detailed consideration of the geographical significance of Bill Forsyth's films, please see Aitken. S. (1991) "A transactional geography of the image-event: the films of Scottish director, Bill Forsyth". Inntactions of the Institute of British Geogizphers NS.16, p 105.118. Bill forsyth has been
} 
particularly successful in defining a characteristic Scottish film industry, and the use of environment has been extremely important in this regard. His other films include Local Hero. That Sinking Feeling. Comfort \& Joy, and Housekeeping (which did not have one male character).

3 Britain's unfortunate reputation speaks for itself. but for a good discussion see Bulord. B. (1990) Amons te. Thugs London: Secker \& Warbure.

4 At the present time (March 1995) there are three advertisements on television which involve soccer. In both the Reebok and Milk Marketing Board advertisements, women are pictured as soccer playen. In Nissan's, young boys and girls are playing the game together. 
Appendix A : Sample Letter

Geozraphy Department, Carleton University.

Oetawa. Ontario.

KIS SB6, Canada.

\section{August 1994.}

Prolessor

Department Address

Dear Prolessor
2201 Riverside Drive \#2203,

Otuwa, Oneario.

KIH BK9, Canada.

Telephone (__)

I an writing to inquire whecher it will be possible to enlist your assistance in research being undertaken as part of my Master's degree in geography at Carleton University. Ottawa.

In recent years, there has been considerable debate concerning the issue of identity. representation and the politics of position as it affects geographers and their research (Jackson, 1991; Keith \& Pile. 1993). Central to the debate has been the need to incorporate the strengths of an identity politics (whilst negating its weaknesses) in research by racognising the potential to create new political irameworks which break away from traditional dichocomies ('us' vs 'them') and illustrate the potential for allance building. The potential form and function of progressive political caalitions is subject to considerable debate. where concem may be voiced regarding the possible creation of counterproductive alliances made up of unsuitable 'bedfellows' (Keith \& Pile. 1993).

Male geographers have increasingly engaged with issues concerning gender, either as an imporant social variable in research frameworks or by actively engaging with and incorporating feminist geography in their work. In my thesis I hope to explore the influence of feminist theory in gender research being carried out by male geographers and the possible debates which may arise from this. Interesting questions arise where the position as male researchers using such frameworks may be contested. I hope to have identified some of those male geographers in the UK and North America who have engaged with gender issues and identities and or have incorporated/discussed the use of feminist theory in their research. This selection is based upon recent publications, paper presentations and discussion with faculty members.

As part of my research. I would be grateful if I could arrange a telephone conversation with you at a convenient time where a number of the issues outlined below could be discussed. The outline suggested is wide ranging and certainly not exhaustive. Some of the issues put forward will be more relevant to your research interests and approaches than others. It would be equally beneficial if you wished to discuss one or two particular issues raised by this topic, and this is why it is felt it would be more advantageous to have a short discussion over the telephone. Given the nature of the research. I would find it particularly helpful if I could, where consent is given, audio-tape the telephone discussion. Since this part of my research is also geared towards discussion with a relatively small number of male geographers, it would be beneficial to quote individuals in my thesis report.

Suggested framework for discussion:

- A background to your interest in gender and sexuality issues will be useful. Is this reflective of a significant number of feminist geographers in your area(s) of specialisation? is your interest reflective of a progressive department and the interests of colleagues? 
- Has your research considered gender issues and relations without necessarily incorporating feminist theory? Does the contestation of the dichotomy man/women in posestructural identity polities make it possible for men to engage with feminise theory in their studies? Beyond considering the implications of and a discussion of feminist theory. has a feminist approach provided a framework for any of your research (either self-defined or classified by others)! How did you establish this relation to feminist theory and how effective is this in enabling you to provide a framework for studying gender?

- Do you feel there are limications placed upon your analysis and the use of feminist theory as a result of being male? Is the working together of male and female geographers in a research team a preferable means for male geographers to engage in gender research! If men wish to engage in feminist theory. do you feel that such alliances may be made less problematic if it represents the coatition of marginalised groups. for example incorporating those peripheralised by race and sexuality?

- A number of writers have commented that it is not necessarily differences that matter, but significant differences. Is cross gender alliance in the form of men wishing to engage in a gendered geography using feminist theory more problematic than alliances between. for example white and black women! is it possible to define limits or boundaries in considering difference?

- A gendered geography which is relational and treats men as having a gender too opens up new avenues for research, as suggested by jackson (1991). A number of geographers have begun to consider questions relating to men and masculinities. There is also a growing literature on masculinities from sociology and men's studies departments. What useful directions do you feel such research could take?

I hope that you will be able to take part in this study - due to financial constraints it is unlikely that our discussions will be too long - I anticipate that it would be no longer than twenty to thirty minutes. It would be much appreciated if you could return the consent form enclosed and specify a suitable time(s) for me to call during September or early October. It would be especially helpful if I could arrange to telephone at times of favourable rates, therefore after 3pm on the West Coast, after 6pm on the East Coast and between noon and 2pm in the UK. Additionally, if you know of colleagues working in this ficld who I perhaps have not considered for this study. I should be very gratelul if you would suggest contacts to me. This research is being carried out as part of a wider discussion considering how big should the room be?' which will provide the focus for the feminist theory and practice session at next year's Canadian Association of Geographers' conference at UQAM in Montréal. I very much hope you will be able to participate in this study and I look forward to hearing from you soon.

Yours sincerely,

Simon Pinnegar

Supervisor - F. Klodawsky. Advisor - I. Wallace 


\section{Sample Letter incorporating Sexuality}

Geography Department. Carleton University.

Orowa, Ontario. KIS 586, Canada.

\section{August 1994.}

Professor
2201 Riverside Drive \#2203,

Ottawa, Ontario,

KIH 8K9, Canada.

Telephone (_

Depatment address

Dear Prolessor

I an writing to inquire whether it will be possible to enlist your assistance in research being underaken as part of my Master's degree in geography at Carleton University. Ottawa.

In recent years, there has been considerable dibate conceming the issue of identity. represencation and the politics of position as it affects geographers and their research (Jackson, 1991; Keith \& Pile. 1993). Central to the debate has been the need to incorporate the strengths of an identity politics (whilst negating its weaknesses) in research by recognising the potential to create new political frameworks which break away from traditional dichotomies ('us' vs 'them') and illustrate the potential for alliance building. The potential form and function of progressive political coalitions is subject to considerable debate, where concern may be voiced regarding the possible creation of councerproductive alliances made up of unsuitable 'bedfellows' (Keith \& Pile. 1993). My particular interest focuses upon the conflicts which may arise where male researchers engage with issues of gender and sexuality in geographical stcidies. The question of voice and authority is clearly particularly important, and who has the right to speak for whom and how. I am oarticularly interested in how the fluidity of identities affects the construction of such positions. Geographers have begun to consider the question of masculinities and in so doing have importantly considered the intersection between sexuality and gender. In terms of published material. research concerning gay or coloured masculinities has provided a significant proportion of male geographers' contributions to this literature.

In my thesis I hope to explore the influence of feminist theory in gender research being carried out by male geographers and the possible debates which may arise from this. Interesting questions arise where the position as male researchers using such frameworks may be contested. I hope to have identified some of those male geographers in the UK and North America who have engaged with gender issues and identities and or have incorporated/discussed the use of ferminist theory in their research. This selection is based upon recent publications. paper presentations and discussion with Faculty members.

As part of my research. I would be grateful if I could arrange a telephone conversation with you at a convenient time where a number of the issues outlined below could be discussed. The outline suggested is wide ranging and certainly not exhaustive. Some of the issues put forward will be more relevant to your research interests and approaches than others. It would be equally beneficial if you wished to discuss one or two particular issues raised by this topic, and this is why it is felt it would be more advantageous to have a short discussion over the telephone. Given the nature of the research, I would find it particularly helpful if I could, where consent is given, audio-tape the telephone discussion. Since this part of my research is also geared towards discussion with a relatively small number of male geographers, it would be beneficial to quote individuals in my thesis report. 
Suggested framework for discussion:

- A background to your interest in gender and sexuality issues will be useful. Is this reflective of a significane number of feminist geographers in your area(s) of specialisation? Is your interest reflective of a progressive department and the interests of colleagues?

- Has your research considered gender issues and relations without neiessarily incorporating feminist theory? Does the contestation of the dichotomy man/women in poststructural identity politics make it possible for men tu engage with leminist theory in their studies? Beyond considering the implications of and a discussion of feminist theory, has a feminist approach provided a framework for any of your research (either self-defined or classified by ochers)! How did you establish this relation to feminist theory and how effective is this in enabling you to provide a framework for studying gender?

- Do you feel there are limitations placed upon your analysis and the use of ferminist theory as a result of being male! is the working together of male and fernale geographers in a research team a preferable means for male geographers to engage in gender research? If men wish to engage in feminist theory. do you feel that such alliances may be made less problematic of $x$ represents the coalition of marginalised groups. for example incorporating those peripheralised by a ice and sexualicy?

- A number of writers have commented that it is not necessarily differences that matter, but significant differences. Is cross gender alliance in the form of men wishing to engage in a gendered geography using feminist theory more problematic than alliances between. for example white and black women? is it possible to define limits or boundaries in considering difference'

- A gendered geography which is relational and treats men as having a gender too opens up new avenues for research, as suggested by jackson (1991). A number of geographers have begun to consider questions relating to men and masculinities. There is also a growing literature on masculinities from sociology and men's studies departments. What useful directions do you feel such research could take?

I hope that you will be able to take part in this study - due to financial constrants it is unlikely that our discussions will be too long - I anticipate that it would be no longer than twenty to thirty minutes. It would be much a: preciated if you could return the consent form enclosed and specily a suitable tume(s) for me to call durnig September or early October. It would be especially helpful if I could arrange to telephone at times of tavourable rates, therefore after $3 \mathrm{pm}$ on the West Coast, after $6 \mathrm{pm}$ on the East Coast and between noon and 2pm in the UK. Additionally. if you know of colleagues working in this field who I perhaps have not considered for this study. I should be very grateful if you would suggest coneacts to me. This research is being carried out as part of a wider discussion considering how big should the room be?' which will provide the focus for the feminist theory and practice session at next year's Canadian Association of Geographers' conference at UQAM in Mon.real. I very much hope yoll will be able to participate in this study and I look forward to hearing from you scin.

Yours sincerely.

Simon Pinnegar

Supervisor - F. Klodawsky, Advisor - I. Wallace 

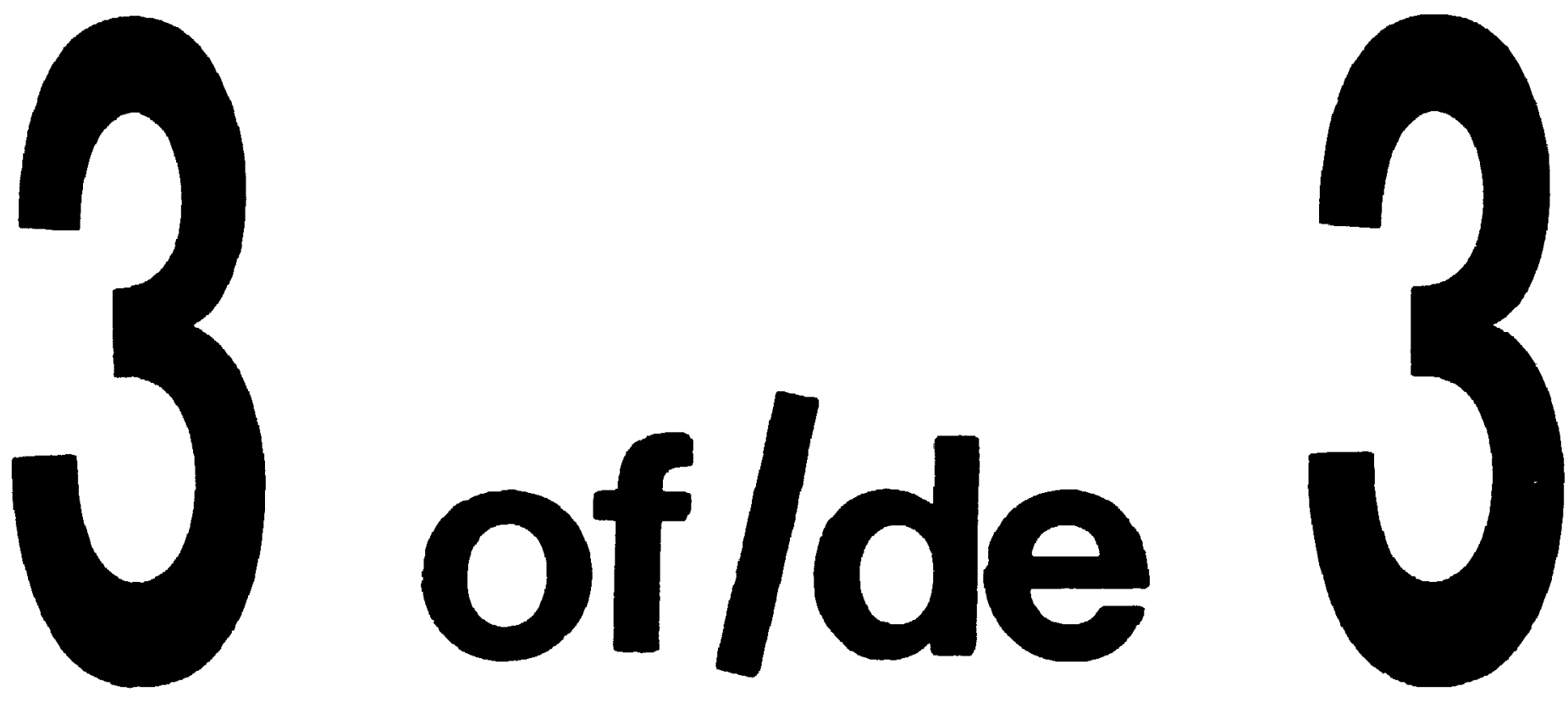

PM-1 31/2"X 4" PHOTOGRAPHIC MICROCOPY TARGET NBS 1010a ANSI/ISO "2 EOUIVALENT

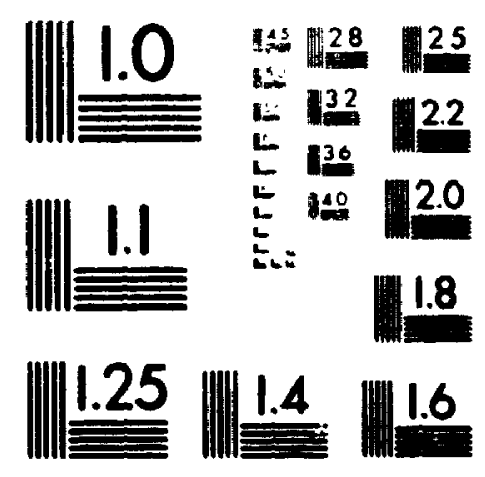

PRECISIONSM RESOLUTION TARGETS 


\section{Letter of Consent}

I. Pinnegar of the Department of Geography. Carleton University. Oitawa. The intended goals of the study have been outlined to me.

I understand that participation in this study will involve:

a semi-structured telephone discussion at an arranged and convenient tume during September and October 1994. The issues discussed will focus upon the queries suggested in the ineroductory lexter, but this is flexible to reflect the respondents particular interests

- the incerview being audio-taped. Only Simon Pinnegar has access to the audio tapes, which shall be erased upon completion of research. If the taping of the conversation is not felt appropriate. I shall indicate this request below:

$$
\begin{aligned}
& \text { rights to record given () } \\
& \text { rghts not given }
\end{aligned}
$$

- quotations being acknowledged by name in the thesis report. Such use of acknowledged quotations applies solely to the report. If publication or paper presentation arises from this research. I shall be asked again to verify whether I wish to give consent for their use. II I wish to remain anonymous within the report. I underscand that identifying details will be eliminated

$$
\begin{aligned}
& \text { allow quotations to be acknowledged } \\
& \text { anonymity requested }
\end{aligned}
$$

- the thesis report resulting from this research will be circulated, deposited on file in the Resource Centre at Carleton University, and may also be microliched.

Signature :

Date :

Appropriate time(s) for telephone conversation to be held (please give date(s) and time(s)). telephone number at which you can be contacted at this time:

Other comments, queries : 


\section{References}

Antken. S. (1991) "A transactional geography of the image-event: the films of Scoctish director. Bill Forsyth". Iransactions of the Institute of British Geopraphers NS-16. p105-1 18.

Akoff. L. (1988) "Cultural Feminism Vs. Post-Structuralism: The Identity Crisis in Feminist Theory" Siens: A Joumal of Women in Cukure and Society Vol. 13 no. 3. p405-436.

Back. L. (1992) "Gendered Participation: Masculinity and fieldwork in a south London adolescent community". chaper in Gendered Fields (eds) P. Caplan. D. Bell. W. Karim. London: Routledge. p215-233.

Back. L. (1994) "The "White Negro" Revisized: Race and masculinities in south London". chapter in Dislocatine Mrsculinity (eds) A. Cornwall \& N. Lindisfame. London: Routledge. p172-183.

Bell. D. (1992) "What we talk about when we talk about about love: a comment on Hay (1991)". Area 24. p409-410.

Bell. D. (1994) "Erotic Topographies: On the Sexuatry and Space Network". Antupode 26:1. p96-100.

Bell. D. J. Binnie. J. Cream \& G. Valentine (1994) "All Hyped Up and No Place To Go", Gender, Place and Culsure Vol. I no. I. p31-47.

Bell, D. \& Valentme. G. (eds) (1995) Mapping Desire: zeognphies of sexualuties. London: Routledge.

Berg. L (1994a) "Masculinity. Place and a Binary Discourse of 'Theory' and 'Empirical Investigation' in the Human Geography of Aotearoal New Zeanand". Gender. Place and Culture Vol. I no. 2. p245-260.

Berg. L (1994b) "Masculnism. Power and Discourses of Exclusion in Brian Berry's "Scientific" Geography". Urban Geography Vol. 15 no. 3, p279-287.

Berry. B. (1993) "Should UG become PC?". Urban Geography Vol. 14 no. 4. p315-316.

Berry, B. (1994) "Response to Berg", Urban Gegognphy Vol. 15 no. 3. p288-289.

Bhabha. H. (1994) The Leation of Culture. London: Routledge.

Bly. R. (1990) Iron John: A Book Abour Men, Massachussets: Addison-Wesley.

Bondi, L. (1992) "Gender and dichotomy". Progress in Human Geogeraphy 16.1. p98-104.

Bondi. L. \& M. Domosh (1992) "Other figures in other palces: on feminism, postunodernism and geography", Environment and Plannine D: Society and Space. Vol. 10, p199-213.

Bondi, L. (1993) "Gender and geography: crossing boundaries". Progress in Human Geography 17.2. p241-246.

Bondi. L (1993) "Locating Identity Politics". chapter in Phase and the Politics of Identix. (eds) M. Keith \& S. Pile, London: Routledge, p84-107.

Bordo, S. (1992) "Postmodern subjects, postmodem bodies", Eeminist Studiar 18, p159-175.

Bordo, S. (199:' Unbearable Weipht: Ferminism western culture and the body. London: University of California Press.

Boone. J. (1992.) "Of me(n) in ferninism: Who(se) is the sex that writes?". chapter in Berwaramen and Eeminism. London: Routledge, p13.34. 
Bourne. J. (1987) "Homelands of the mind: Jewish feminism and identity politics". Race and Class 29. p1. 24.

Braidotzi (1987) "Envy: or With Your Brains and My Looks". chapter in Men In Femmism. (eds) A. jaidine 2. P. Smith. New York: Methuen. p233-241.

Brittan. A. (1989) Masculanizy and Power Oxford: Blackwell.

Brod. H. (1987) The Makine of Masculinities: New Men's Studies. Winchester. Mass.: Allen and Unwin.

Buford. B. (1990) Amone the Thues. London: Secker \& Warburg.

Butler. J. (1989) "Gender Trouble. Feminist Theory, and Psychoanalytic Discourse". chapter m Eeminism/Postmodernism. (ed) L. Nicholson, London: Routledge. p324-340.

Butler, J. (1990) Gender Trouble: Feminism and the subversion of identicy. New York: Routledge.

Butler. J. \& Scott. J. (1992) Feminusts Th-orize the Political. New York: Routledge.

Butler. J. (1992) "Contingent Foundations: Femmism and the Question of 'Postmodemism".. chapter in Eeminists Theorize the Political. (eds) J. Butler \& J. Scotc. New York: Routledge. p3-21.

Butler, K. (1994) "You must remember this". The Guardian Weekend July 23, p6-12.

Caplan. P. Bell. D. Karim, W. (eds)(1992) Gendered Fields. London: Routledge.

Carrigan. T., Connell, B. \& Lee.J. (1985) "Towards a new sociology of masculinity". Theory and Sociey Vol. 14 no. 5. p551-603.

Chouinard. V. (1994) "Reinventing radical gecioraphy: is all that's Left Rught?". Environment and Plannine D: Sociery and Space Vol. 12, p2-6.

Clatterburgh, K. (1990) Contemponax Perspestiver on Masculiniry: Men. Women and Polisics n Modern Society, Boulder. Colorado: Westriew Press.

Clifford, J. (1992) "Travelling Cultures", chapter in Cultural Studier (eds) L. Grossberg. C. Nelson \& P. Treichler. London: Routledge.

Cloke, P.. C Philo \& D. Sadler (1991) Approachine Human Geozraphy: An Introduction to Contemporax Theoretical Debares. London: Paul Chapman Publishing Led.

Cockbum. C. (1983) Brochers: Male dominance and technolosical change. London: Pluto Press.

Cocks. J. (1989) The Oppositional Imagination: Ieminism, critique and political theory. London: Routledge.

Cohen. T. (1993) "What Do Fathers Provide! Reconsidering the Economic and Nurturant Dimensions of Men as Parents", chapter in Men. Work. and Family (ed) J. Hood. London: Sage Publications. pl-22.

Connell, R. (1987) Gender \& Power Stanfort. Stanford University Press.

Connell, R. (1990) "A Whole New World: Rernaking Masculinity in the Context of the Environmental Movement", Gender and Sociesy Vol. 4. p452-478. 
Connell. R. (1991) "Live Fast and Die Young: The Construction of Masculinity among Young 'Norting.

lass Men on the Margirn of the Labour Market". Ausuralian and New Zealand Journal of Secinlsay Vol. 27 no. 2. p|4i.171.

Connell. R. (1993a) "Men and the Women's Movement". Sosal Policy Summer.

Connell. R. (19936) "The big picture: Masculmities in recent world history". Theory and Society 22. p597. 623.

Connell. R. M. Davis \& G. Dowsett (1993) "A Bastard of a Life: Homosexual Desire and Practice among Men in Working-class Milieux". Australan and New Zealand Jeumal of Sociology Vol. 29 no. I. pll 2-135.

Cooper, D. (1992) "Johnny Noxzema to the Gay Community: 'You Are the Enemy"'. The Village Voice June 30. p31-33.

Corman. J. Luxton. M.. Livingstone. W.. Seccombe. W. (1993) Recastine Steel Labour: The Steke Story. Halfiax. NS: Fernwood.

Cornwall. A. (1994) "Gendered identities and gender ambiguity among 'travesus' in Salvador. Brazil". chapter in Dislecatine Masculinity (eds) A. Cornwall \& N. Lindisfame. London: Routledge. pIII-132.

Cornwall. A. \& Lindisfarne, N. (edis) (1994) Dislocatine Masculiniry, London: Routledge.

Cornwall, A. \& Lindisfarne, N. (1994) "Dislocating Masculinity: Gender, power and anthropology", chapter in Dislocating Masculinior (eds) A. Cornwall \& N. Lindisfarne. London: Routledge. p/I-47.

Crang. P (1992) "The Politics of Potyphony: reconfigurations in geographical authority". Environment and Plannine D: Society and Space Vol. 10. p527-549.

Cross. M. \& M. Keith (eds) (1993) Racism, the Ciry and the State London: Routledge.

Davies, P. (1993) "On the bal"." The Guardian Weekend August 13. p23-25.

de Lauretis, T. (1986) Eeminiss ssudies, critual soudiess. Bloomington IN: Indiana University Press.

Deleuze \& Guattari (1983) "On the line". Semiorexte.

Derrida. I. (1987) "Women in the Bechive: A Seminar with", chapter in Men In Feminism. (eds) A. Jardine \&. P. Smith. New York: Methuen. p189-203.

Deutsche, R. (1991) "Boys Town", Environment and Plannine D: Sociesz and Soace Vol. 9. pj.30.

Doel, M (1993) "Proverbs for paranoids: writing geography on hollowed ground". Innsactions of the Institue of British Geogenphers NS.18. p 377-394.

Donaldson, M. (1993) "What is hegemonic masculinity?". Theory and Society 22. p643-657.

Duggan. L. (1992) "Making it Perfectly Queer". Ladialist Review Vol. 22 no. 1. p I1.32.

Duncan. S. (1991) "The geography of gender divisions of labour in Britain". Iransactions of the Institure of British Geeeraphers NS.16. p420.439.

Duncan, S. (1994) "Theorising Differences in Patriarchy", Environment and Phanning A Vol. 26. p1307. 1338.

Eco, U. (1986) "On the Crisis of the Crisis of Reason". Iouches in Hyper-Realizy New York: Picador. 
England. K. (1994) “Getting Personal: Reflexwity. Positionaluty, and Femunust Research”. Prolessiond Geagenpher 46(1). p80-89.

Eyles. J. (1993) "Feminism and Interpreuve Method: How Different?". The Ganadian Geographer Vol. 37 no. I. p50.52.

Faludi. S. (1992) Backlash: The Undeclared War Apainst American Women. New York: Doubleday.

Farrell. W. (1993) The mych of male power; why men are the disposable sex. New York: Simon 8 Schuster.

Ferguson. K. (1993) The Man Quession; visions of subjectivity in (eminurs theon. Berkeley CA: University of Califomia Press.

Fisher. K. (1994) Men's Nerwork News Vol. 5 no. 1.

Fiske. J. (1993) Power Plays Power Works. Verso: London.

Flax. J. (1989) "Postmodernism and Gender Relations in Feminist Theory". chapter in Feminismil Postmodernism. (ed) L Nicholson. London: Routledge. p39-60.

Flax, J. (1992a) "The End of Innocence", chapter in Feminists Theorize the Political (eds) J. Butler \& ). Scotc. New York: Routledge, p445-462.

Flax, J. (1992b) "Beyond equalicy: gender, justice and difference", chapter in Beyond Equality and Difference: Cituzenship. feminist politics and female subjectivity (eds) G. Bock \& S. James. London: Routledge. p193-210.

foucault. M. (1980) "Two Lectures". chapter in Power/Knowledze, Selected interviews and Other Writings 1972-1977 by Michel Fouczult. (ed). C. Gordon. New York: Pancheon Books.

Fraser, N. \& L. Nicholson (1989) "Social Criticsm without Philosophy: An Encounter Betwenn Feminism and Postmodernism", chapter in Feminism/Postmodernism. (ed) L. Nicholson, London: Routledge.

Fuss. D. (1989) Essentnlly Śpenking. Feminism. Narure and Difference. New York: Routledge.

Fuss, D. (1991) Inside/Out: Lesbian Theories. Gay Theories, New York: Routledge.

Gallop, J. (1987) "French Theory and the Seduction of Feminism", chapter in Men In Feminism. (eds) A. jardine \&. P. Smith, New York: Methuen.

Gatens, M. (1983) "A critique of the sex/gender distinction". chapter in Bexond Marx! Interventions After Max. Sydney: Intervention.

Gibson-Graham. J. (1994) "'Stuffed if I know: reflections on postmodem femunist soctal research". Gender. Place and Culiure Vol. I no.2. 205-224.

Gould. P. (1994a) "Sharing A Tradition - Geographies from the Enlightenment", The Canadpan Geographer Vol. 38, no. 3. p194-202.

Gould. P. (1994b) "Reply". The Canadian Geographer Vol. 38, no. 3, p209-214.

Gregory. D. (1994a) "Visions of Geography: An Open Letter to Peter Gould". The Canadian Geographer Vol. 38, no. 3, p206-209. 
Gregory. D. (1994b) Geographical Imaganations. Cambridge: Blackwell.

Grieg G. (1994) "Get your facts straight, sisters". Ihe Sunday Immes. October. 1994

Grosx, E. (1990) "Inscriptions and body-maps: representations and the corporeal", chapter in Feminme. Masculine and Representation (eds) T. Threadgold \& A. Cranny.Francis. London: Allen a Unwin.

Haas. L. (1993) "Nurturing Fathers and Workıng Mothers: Changing Gender Roles in Sweden", chapter in Men. Work. and Family (ed) J. Hood, London: Sage Publications, p238-261.

Hanson, S. (1993) "Geography and Feminism: Worlds in Collision?". Annals of the Arsocintion of American Geopaphers 82(4). p569-586.

Haraway. D. (1991) Simians, gybores, and women: the reinvention of nature, New York: Routledge.

Hardng. S. (1586) The Science Question in Feminism. Ithaca: Cornell University Press.

Harding. S. (1991) "'Strong Objectivity' and Socially Situated Knowledge". chapter 6 in Whose Science! Whose Knowledes?. p138-163.

Hartsock. N. (1989) "Foucault on Power: A Theory for Women?". chapter in Eeminism/ Postmodernism. (ed) L. Nicholson. London: Routledge.

Harvey, D. (1989) The Condision of Postmodernity, Oxford: Basil Blackwell.

Harvey. D. (1993) "Class Relations, Social justice and the Politics of Difference", chapter in Place and the Polutues of Identity. (eds) M. Keith \& S. Pile. London: Routledge, p41-66.

Hayes. S. (1994) "Coming over all Queer". New Statesman \& Sociexy 16 September, p14-15.

Hearn. J. (1987) The Gender of Oppression. Men. Masculinity and the Critique of Marxism. Brighton: Wheatsheaf.

Hearn, J. (1992) Men in the Public Exe: The Construction and Deconstruction of Public Men and Public Patriarchieg. London: Roull edge.

Hearn. I. (1994) "Research in Men and Masculınities: Some Sociological Issues and Possibilsties". Austrolian and New Zealand Joumal of Sociology Vol. 30 no. I. p47.70.

Heath. S. (1987) "Male Feminism", chapter in Men In Feminism. (eds) A. Jardine \& P. Smith. New York: Methuen, pl-32.

Heath, S. (1987) "Men In Feminism: Men and Feminist Theory", chapter in Men In Feminism. (eds) A. Jardine \& P. Smith. New York: Methuen, P41-46.

Herod, A. (1991). "The production of scale in United States labour relations". Area 23.1, p82-88.

He. 2d. A (1993) "Gender lssues in the Use of Interviewing". Professiona/Gesegnoher 45(3), p305-317.

Hesse, B. (1993) "Black to front and black again: Racialisation through contested times and spaces", chapter in Place ind the Polutics of Identity. (eds) M. Keith \& S. Pile. London: Rourledge, p162-182.

Hood, J. (ed) (1993) Men. Work. and Family London: Sage Publications.

hooks, b. (1990) Yerming rase sender. and suleurl politics. Toronto: Between the Lines. 
Hutcheon. L. (1982) A Poetics of Postmadernism: History. Theory and Fiction. London: Routledge.

Jackson. P. (1989) Maps of Meaning. London: Unwin Hyman.

Jackson. P. (199/a) "Guest Editorial: The C.isis of representation and the politics of position". Environment and Planoune D: Society and Space. Vol. 9. p131-134.

jackson. P. (199/b) "The Culcural Policics of Masculinity: towards a social geography". Iransactions of the Institure of British Geographers NS-16. pi99-213.

Jackson. P. (1993a) "Editorial: Visibility and voice", Environment and Planning D: Society and Space. Vol. II. p123-126.

jackson. P. (19936) "Changing Ourselves: A Geography of Position". chapter in The Challenge of Geognphy. A Changing World: A Changine Discipline. (ed) R.J.johnston, Oxford: Blackwell, p198-214.

Jackson. P. (1994) "Black Male: advertising and the cultural politics of masculinity". Gender. Phace and Culcure Vol. I no. I. p49-;9.

Jardine, A (1985) Gynesis: Configurations of Woman and Modernity. Ithaca NY: Cornell University Press.

Jardine. A. S Smith. P. (1987) Men In Feminusm. New York: Methuen.

Ja dine. A. (1987) "Men In Feminism: Odor di Uomo Or Compagnons de Route?". chapter in Men In Eeminism. (eds) A. Jardine \& P. Smith. New York: Mathucn. p54-61.

jardine. A Smith. P. (1987) "A Couversation", chapter in Men In Feminism (ods) A. Jardine P. Smith. New York: Methuen, P242-263.

Johnson, B. et al. (1994) "The Male Mych: Men hunt for a new identity". Macleans January 31. p38-47.

Johnson, L (19902) "New Courses For A Gendered Gecgraphy: Teaching Ferminist Geography At The University of Warcako", Australın Geopraphical Journal Vol. 28 no. 1. p16-28.

Johnson, L. (1990b) "New Patriarchal Economies in the Australian Textile Industiy". Antipode 22.1, p1-32.

Johnson. L. (1994) "What Future for Feminist Geography!", Gender, Place and Culture Vol. I no. I, p103113.

Johnston, D. (1994) "The burden of being male". The Otuwn Gitizen, Saturday January 8. pB4.

Jonas. A (1988) "A new regional geography of bcalities?", Area 20.2. p101-110.

Keith. M. (1992) "Angry Writing: (re)presenting the unechical world of the cthnographer". Environment and Ptanning D: Society and Soace Vol. 9. p31-57.

Keith. M. \& Pile. S (1993a) "Introduction: The place of politics", chapter in Place and the Politics of Identity. (eds) S. Pile \& M. Keith, London: Routledge, p22-40.

Keith. M. \& S. Pile (19936) "Towards new radical geographies", chapter in Place and the Politics ofldentity. (eds) S. Pile \&. Meith, London: Routledge, p220-226.

Kelly, L. (1988) Surchine rescual violence. Cambridge: Polity Press.

Kimmel, M. (1987) Changine Men:New Directins ir Besearch on Men and Masculnity, Californiz: Sage. 
Kummel, M. (1993) "Sexual Balkanization: Gender and Sexuality as the New Ethnicities". Secial Research Vol. 60 no. 3. p571.587.

Knopp. L (1990) "Social Consequences of Homosexuality". Geognphucal Maparine May 1990. p20-25.

Knopp. L (1992) "Sexuality and the spatial dynamics of capitalism". Environment and Phnnine D: Sociexy and Space Vol. 10. p651.669.

Kobayashi, A. \& L. Peake (1994) "Unnatural Discourse. 'Race' and Gender in Geography”. Gender. Place ind Culture Vol. I no.2. 225-243.

Kremer, B. (1990) “Leaming to say no: Keeping Feminist Research for Ourselves”, Women's Studies international forum Vol. 13 no.5. p463-467.

Laclau, E. \& Mouffe. C. (1985) Hegemony and Socialist Strntegy. London: Verso.

Lafferty. F. (1994) "It's a man's world in the Square Mile". The Daily Mail September 1994.

Lindisfarne. N. (1994) "Varınt masculinities, variant virgunitues: Rethinking honour and shame"". chapter in Dislocating Masculinity (eds) A. Cornwall \& N. Lindisfarne. London: Routledge. p82-96.

Loizos. P. (1994) "A broken mirror: masculine sexuality in Greek echnography". chapter in Dislocating Masculinity (eds) A. Cornwall \& N. Lindisfarne, London: Routledge. p66-81.

Luxton. M. (1993). "Dreams and Dilemmas: Feminist Musings on "The Man Question". chapter in Men and Masculinitues: A Critical Anthology. p347-374.

Marcia-Lees et al (1989) "The postmodernist turn in anthropology: cautions from a ferninist perspective" Signs: A lournal of Women in Culture and Society 15. p7-33.

Marcus, G. (1992) "Commentary 'More (critically) reflexive than thou': the current identity politics of representation", Environment and Plannine D: Society and Space. Vol. 10, p489-493.

Marnotc, M. (1976) "Hindu transactions: diversity without dualism", chapter in Iransaction and Meaning. (ed) B. Kapferer. Philadelphia: ISHI Publications.

Massey. D. (1984) Spatial Divisions of Labour: Social Structures and the Geography of Production. Basingstoke: Macmillan.

Massey. D. (1991) "Flexible Sexism". Environment and Planning: D: Sociecy and Space Vol. 9, p31.57.

Massey. D. (1993a) "Questions of Locality". Geognphy 78(2). p1 42-149.

Massey. D. (1993b) "Power-Geometry and a progressive sense of place", chapter in Mappine che Futures: bal cultures global change (eds) J. Bird. B. Curtis. T. Putnam. G. Robertson \& L. Tickner. London: Routledge, p59-69.

McDowell, L. (1988) "Coming in from the Dark", chapter in Eeminist Retearch in Geoseraphy (ed) J.Eyles. Oxford: Blackwell.

McDowell, L. (199/a) "The Bath and the Baby Water: Diversit); Deconstruction and Feminist Theory in Geography", Geolorum Vol. 22 no. 2, p123-133.

McDowell. L. (199/b) "Life without father and Ford: The new zender order of postfordism", Innsuctions of the lastitute of Britush Geogrnohers NS.16, p400-419. 
McDowell. I.. (1992a) "Multiple Voices: Speaking from Inside and Outside 'The Project'". Antugode 241. p56.72.

McDowell, L. (1992b) "Doing gender: ferninism, feminisis and research methods in human geography". Iransactions of she Instutue of Brisush Geographers NS-17. p399.416.

McDowell. L. (1993a) "Space, place and gender relations: Part I. Feminist empuricism and the geography of social relations". Propress in Human Geopraphy 17.2. p157-179.

McDowell. L. (19936) "Space, place ind gender relations: Part II. Identity, difference, feminist geometries and geographies". Progress in Human Geography 17.2. p305.318.

McDowell, L. (1994) "Missing Subjects: Gender, Power and Sexwality in Merchant Banking". Economic Geography. p229-251.

McDowell. L. (1995) "Body Work: heterosexual gender performances in city workplaces", chapter in Mapping Desire: geopraphies of sexualities (eds) D. Bell \& G. Valentine, London: Routledge.

McElhinny. B. (1994) "An economy of effect: Objectivity, masculinity and the gendering of police work". chapter in Dislocating Masculinity (eds) A. Cornwall \& N. Lindisfarne. London: Routledge. p159-171.

McNee, R. (1984) "If you are squeamish". Eass Lakes Geographer 19, p16-27.

Millar, P. (1994) "If Men are the problem, what's the solution?", The Sunday Imes September 18, p3.7.

Minh-ha, T. (1989) Women-Native-Qther Bloomington IN: Indiana University Press.

Minh-ha, T. (1991) When the Moon Waxes Red: Representation, Gender and Cultural Poliuss. New York: Routledge.

Momsen, J. (1994) "Response to Peter Gould: 'Sharing A Tradition - Geographies from the Enlightenment"'. The Camadian Geographer Vol. 38, no. 3, p202-204.

Moore, S. (1988) "Getting a Bit of the Other - the Pimps of Postmodernism", chapter in Male Qrder: Unwrappine Masculinity(eds) Rowena Chapman \& Jonathan Rutherford, London: Lawrence \& Wishart. p165-192.

Morgan, D. (1992) Discovering Men. London: New York.

Mouffe. C. (1992) "Feminism. Citizenship and Radical Democratic Politics", chapter in Feminists Theorize the Political, (eds) J. Butler \& J. Scott, New York: Routledge, p369-384.

Nast, H. (1994) "Women in the Field: Critical Feminist Methodologies and Theoretical Perspectives". Professional Geogrnpher 46(1). p54.66.

Nelson. C. (1987) "Men. Feminism: The Materiality of Discourse", chapter in Men_ln Ferminism. (eds) A. Jardine \& P. Smith. New York: Methuen, p153-172.

Olsson. G. (1994) "Job and the case of the herbarium". Environment and Plannine D: Soccesy and Space Vol. 12. p221.225.

Owens, C. (1987) "Outlaws: Gay Men in Feminism", chapter in Men In Feminism. (eds) A. Jardine 2. Smith, New York: Methuen.

Parmar. P. (1990) "Black Feminism: the Politics of Articulation", chapeer in Ldentuby: Cemmunity. Culture. Difference. (ed) J. Rutherford, London: Lawrence \& Wishart. 
Parr. ). (1990) The Gender of Breadwinners: Women. Men and Change in I wo Industrial Towns. 1880. 1950 Toronto: University of Toronto Press.

Peake. L (1994) " 'Proper Words in Proper Places...' Or. Of Young Turks and Old Turkeys". The Candinn Geogenoher Vol. 38, no. 3. p204-206.

Peet, R. (1992) "Some Critical Questions for Anti-Essentialism". Antipode 24:2, pl I 3-1 30

Pile, S. (1993) "Human Agency and human geography revisited: a crituque of 'new models' of the self", Irnszctions of the Institution of British Geognphers NS-18. p122-139.

Pile, S. (1994) "Masculinism, the use of dualistic epistemologies and third spaces". Antipode 26:3, p255-277.

Pleck. J. (1993) "Are 'Family-Supportive' Employer Policies Relevant to Men?". chapter in Men Work. and Eamily (ed) J. Hood. London: Sage Publications. p217.237.

"Points of View". Geognohisal Marazine July 1990. p62.

"Points of View". Geosenphical Magarine August 1990. p62-63.

Porter. D. (ed) (1992) Berween Men and Feminism. London: Routledge.

Pratt, G. (1992) "Progress Report: Feminist Geography". Urban Geogrzohy 13,4, p385-391.

Pratt, G. (1993) "Reflections on Poststructuralism and Femınist Empirics. Theory and Practice". Antipode 25:1.p51-63

Pratt. G. \& S. Hanson (1994) "Geography and the Construction of Difference", Gender. Phace and Culture Vol. I no. I, p5-29.

Probyn. E. (1993) Sexine the Sell. London: Routledge.

Parazanoglu. C. (1989) Feminism and the Contradictions of Oppression London: Routledge.

Ramazanoglu, C. (1992) "What can you do with a Man?: Feminism and the Critical Appraisal of Masculinity". Women's Studies International Forum Vol. 15 no. 3. p339-350.

Ramazanoglu, C. (1993) Up against foucault: explorations of some rensions berween foucaule and Itminism. London: Routledge.

Remharz, S. (1992) Eeminiss Methods in Social Resenrch, New York: Oxford University.

Revill, G. (1993) "Reading Rosehill: Community, identity and inner-city Derby", chapter in Phaceand the Bolitice of Hdentity. (eds) M. Keith \& S. Pile, London: Routledge, pl 17.140.

Richer, S. (forthcoming) "Reaching the Men: Inclusion and Exclusion in Feminist Teaching".

Robinson, F. D. Sadler (1985) "Routine Action, reproduction of social relations, and the place market: Consett after closure", Enviconmens and Plannine D: Sosiety and Spacs Vol. 3, p1 09-120.

Roiphe, K. (1993) Sex. Fear and Feminism, Boston: Lietle, Brown and Company.

Rose, G. (1993) Eeminism \& Grosraphy. Minneapolis: University of Minnesoca Press.

Rose, G. (1994) "Engendering and degendering", Progress in Human Grogrnohy Vol. 18 no. 4. p507.515. 
Ross. A. (1987) “No Question of Silence", chapter in Men In Feminism. (eds) A. Jardine \& P. Smith. New York: Methuen. p85.92.

Ross. K. (1988) The Emergence of Socint Space: Rimbaud and the Paus Commune. Munneapolis: University of Minnesota Press.

Rubin, G. (1975) "Comment: Prostitution in Nevada". Annals of the American Association of Gepenphers 65. pl13.115.

Rutherford, J. (1988) "Who's That Man?". chapter in Male Order: Unwrappine Masculinity (eds) R. Chapman \& J. Rutherford, London: Lawrence \& Wishart.

Rutherford. J. (ed) (1990) Identiry: Community, Culture, Difference. London: Lawrence \& Wishart.

Rutherford. J. (1992) Men's Silences: Predicaments in masculinity London: Routledge.

Ruthven, K. K. (1990) Feminist Literany Studies Cambridge: Cambridge University Press.

Said, E. (1985) Orientalism, New York: Vintage Books.

Savage, M. \& S. Duncan (1990) "Space. Scale and Locality: A Reply to Cooke and Warde". Antupode 22:1. p67.72.

Sayer. A. (1985) "The Difference that Space Makes". chapter in Social Relations and Spatial Structures. (ed) D. Gregory \& J. Urry. Basingstoke: Macmillan, p49-64.

Sayer, A. (1993) "Postmodernist Thought in Geography: A Realist View". Antipode 25:4, p 320-344.

Schoenberger. E. (1991) "The corporate interview as a research method in economic geography". The Professional Geoprapher 43, pl80-189.

Scoth James (1990) Domination and the Arts of Resistance: Hidden Transcripts. New Haven: Yale University Press.

Scott Joan (1990) "Deconstructing Equality-Versus-Difference: Or. the Uses of Poststructuralist Theory for Feminism". chapter in Conflicss In Feminism (eds) M. Hirsch \& E. Fox. New York: Routledge, p1 34149.

Scoth. ). (1992) "Experience", chapter in Eeminists Theorize the Political (eds) J. Butler \& J. Scote. New York: Routledge. p22-41.

Segal, L (1987) is the Future Female ! Iroubled Theughts on Contemporarx Feminism. London: Virago.

Segal, L. (1990) Slow Motion: Changine Masculinitues. Changing Men, London: Virago Press.

Segal, L. (1994) "Lets be straight with one another". New Statesmno \& Society, 16 September 1994, p1618.

Seidler. V. (ed) (1991) The Achilles Heel Reader. Men, Sexual Polisics \& Socialisin London: Routledge.

Seidman, S. (1993) "Identity and Polities in a 'Postmodern' Gay Cutture: Some Histoncal and Conceptual Notes", chapter in Eerr of a Oueer Planes: Queer Politics and Social Theory. (ed) M. Warner.

Minneapolis: University of Minnesota Press, p105.142 
Shire, C. (1994) "Men don't go to the moon: Language, space and masculinities in Zimbabwe", chapter in Dislocatine Masculinicy (eds) A. Cornwall \& N. Lindisfarne. London: Routledge. pl 47-158.

Showalter. E. (1987) "Critical Cross-Dressing Male Feminists and the Woman of the year", chapter in Men In Feminism. (eds) A Jardine \& P. Smith. New York: Mechuen, p1 16-132.

Stoan, L. (1991) "Beyond Dialogue". San Francisce Bay Guardian Literary Sypplement March 1991.

Smith, P. (1987) “Men In Feminism: Men and Feminist Theory”, chapter in Men In Feminism (eds) A. jardine \&. P. Smith. New York: Methuen. p33.46.

Sntrow, A. (1990) "A Gender Diary", chapter in Conflicts In Ferminism. (eds) M. Hirsch \& E. Fox, New York: Routledge. p9.40.

Soja. E. (1989) Postmodern Geographies: the reassertion of space in critucal secel theen, London: Verso.

Soja, E. \& B. Hooper (1993) "The Space that Difference Makes. Some notes on the geographical margins of the new cultural politics". chapter in Place and the Politics of Identiry (eds) M. Keith \& S. Pile. London: Routledge, p183-205.

Solanas. V. (1968) The Scym Manifeste. London: Black Widow.

Sornmers. C. (1994) Whe Stole Feminism: Women who berrayed scher women. New York: Simon 8 Schuster.

Sparke. M. (1994a) "Escaping the herbarium: a critique of Gunnar Olsson's 'Chiasm of thought-andaction"." Environment and Plannine D: Society and Space Vol. 12. p207-220.

Sparke. M. (1994b) "The return of the same in geography: a reply to Olsson". Environment and Planning D: Sociesy and Space Vol. 12, p226-228.

Sparke. M. (1994c) 'Writing on patriarchal missiles: the chauvinism of the 'Gulf War' and the limits of critique". Environment and Plannine A Vol. 26. p1061-1089.

Spivak. G. (1982) "The politics of Interpretation". Critical lnquing $9(1)$.

Spivak. G. (1988) "Can the Subaltern Speak!", chapter in Marx। land the Interpretation of Culture, (eds) C. Nelson \& L Grossberg. Urbana: University of Illinois.

Spivak, G. (1989), A Response to 'The Dilference Within: Femınism and Critıcal Theory' in E. Messe \& A. Parker (eds) The Difference Within: Feminism and Critical Theorx. Amsterdam: John Benjamins, p207. 220.

Staeheli, L. 2 V. Lawson (1994) "A Discussion of 'Women in the Field": The Politics of Feminist Fieldwork". Professional Geegrapher 46(1), p96-102.

Stoller, R. (1976) Sex and Gender. London: Hogarth Press.

Stoltenberg. J. (i 990) Refusine to be a man; Essnys on Sex and Justice. Middlesex: Penguin.

Stoltenberg. f. (1994) The Fnd of Mrnhood: A Book for Men of Conscience, Middlesex: Penguin.

Strathern. M. (1988) The Gender of the Gift: Problems with Women and Problems with Socievy in

Melanesia, Berkeley CA: University of Califomia Press. 
Strauss, S. (1982) Iraitors to the masculine cause: The Men's Campasn for Womenis Ruaths. Westport. Connecticut: Greenwood Press.

Symanski, R. (1974) "Prostitution in Nevada". Annals of the American Assoriarion of Geographers 64. p357.377.

Symanski, R. (1975) "Comment in reply". Annals of the American Association of Geopraphers 65, pl IS. 120.

Tannen. D. (1990) You just don't understand; women and men in conversation. New York: Ballantıne Books.

Tannen, D. (1994) Gender 2 Discourse. New York: Oxford University Press.

Thomas. D. (1993) Nor Guily - Men; The Case for the Defence London: Weidenfield \& Nicholson.

Valentine, G. (1993a) "(Hetero)sexing space: lesbian perceptions and experiences of everyday spaces". Environment and Planning. D: Society and Space Vol. II. p395.413.

Valentine, G. (1993b) "Negotiating and managing multuple sexual identities: lesbian tume-space strategies". Iransactions of the Instuture of British Geopraphers NS-18. p37-248.

Walby, S. (1990) Theorising Patriarchy, Oxford: Blackwell.

Walby, S. (1994) "Methodological and theoretical issues in comparative analysis of gender relations in Western Europe". Environment and Plannine A Vol. 26. p1339.1354.

Warner. M. (ed) (1993) Fear of a Queer Planet: Queer Politics and Social Theory. Minneapolis: University of Minnesoca Press.

Wilkinson, H. (1994) NeTurning Back: generations and the genderouake London: Demos.

Women and Geography Study Group/Institute of British Geographers (1984) Geography and Gender. London: Hutchison.

Women and Geography Study Group (1992) "Report: Feminists and Feminism in the Academy". Antipode 24:3, p218-237.

Wood. J. (1994) Gendered lives: Communication. Gender and Culture. California:Wadsworth. Young, I. (1994) "Gender as Seriality: Thinkıng about Women as a Social Collective". Sıpns Vol. I9 no. 3. p709-740. 

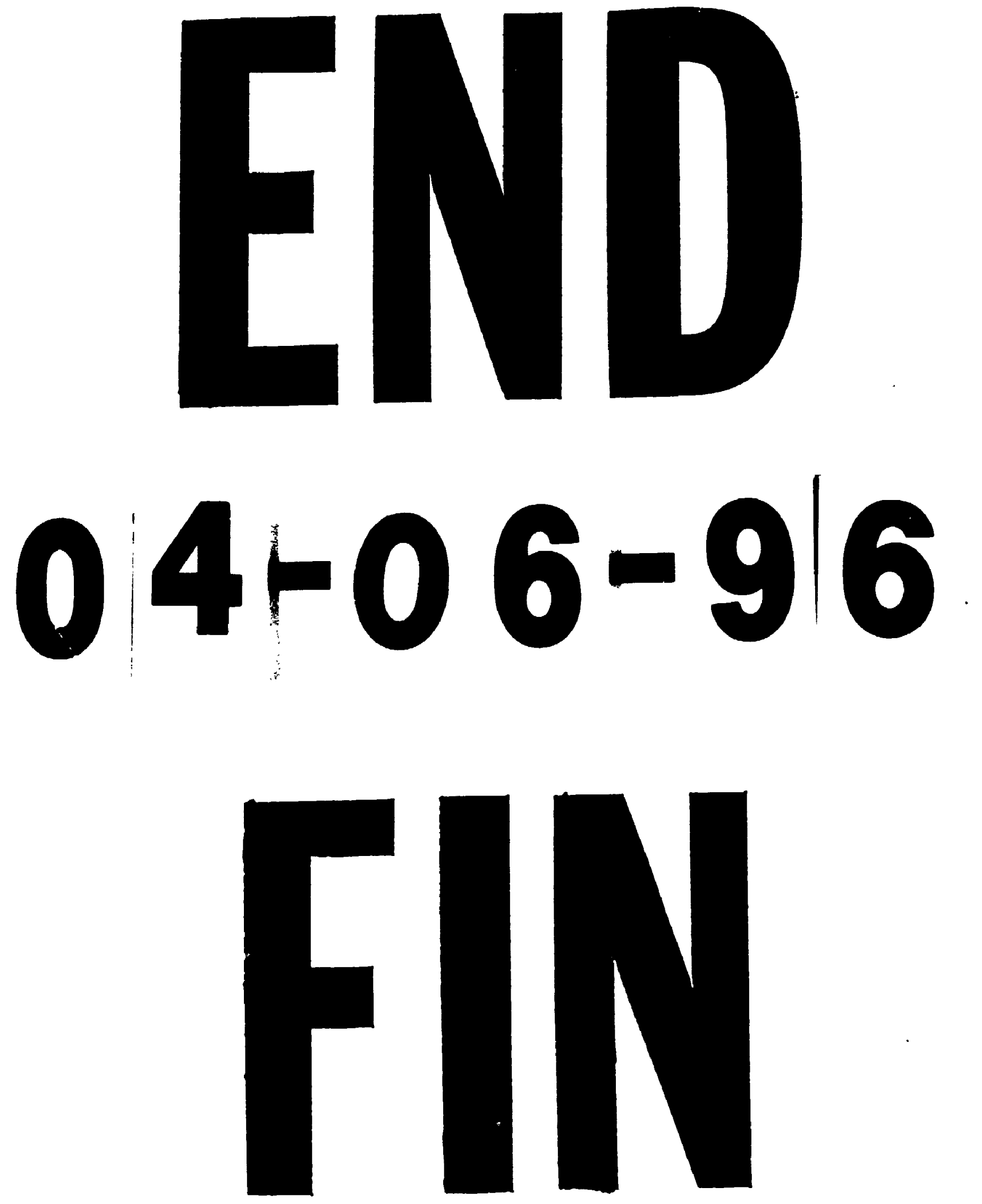